University of Louisville

ThinkIR: The University of Louisville's Institutional Repository

Electronic Theses and Dissertations

$5-2009$

\title{
Teachers valuation and implementation of formative assessment strategies in elementary science classrooms.
}

Pamela M. Jett

University of Louisville

Follow this and additional works at: https://ir.library.louisville.edu/etd

\section{Recommended Citation}

Jett, Pamela M., "Teachers valuation and implementation of formative assessment strategies in elementary science classrooms." (2009). Electronic Theses and Dissertations. Paper 684.

https://doi.org/10.18297/etd/684

This Doctoral Dissertation is brought to you for free and open access by ThinkIR: The University of Louisville's Institutional Repository. It has been accepted for inclusion in Electronic Theses and Dissertations by an authorized administrator of ThinkIR: The University of Louisville's Institutional Repository. This title appears here courtesy of the author, who has retained all other copyrights. For more information, please contact thinkir@louisville.edu. 
By

Pamela M. Jett

B.A., Spalding University, 1973

M.A., Spalding University, 1988

Ed.S., University of Louisville, 2001

\author{
A Dissertation \\ Submitted to the Faculty of the \\ Graduate School of the University of Louisville \\ in Partial Fulfillment of the Requirements \\ for the Degree of
}

Doctor of Philosophy

Department of Teaching and Learning

University of Louisville

Louisville, Kentucky

May 2009 


\section{TEACHERS VALUATION AND IMPLEMENTATION OF FORMATIVE}

ASSESSMENT STRATEGIES IN ELEMENTARY SCIENCE CLASSROOMS

By

Pamela M. Jett

B.A., Spalding University

M.A., Spalding University

Ed.S., University of Louisville

A Dissertation Approved on

March 27, 2009

by the following Dissertation Committee:

Dissertation Co-Chair

Dissertation Co-Chair 


\section{ACKNOWLEDGMENTS}

I am so very grateful to my dissertation committee co-chairs, Dr. Thomas Tretter and Dr. Sherri Brown, for their constant guidance and inspiring insight into the preparation of this dissertation. Both Dr. Tretter and Dr. Brown provided thoughtful analysis of my work, taught me how to use data in ways that made numerical and qualitative data come alive, and constantly challenged me to think and write in a more professional and academic manner. Their support and willingness to guide me through this process has made it a most enjoyable and rewarding adventure, and I sincerely thank them both.

To Dr. Karen Karp I am grateful for the opportunity given me to teach at the university; her encouragement and trust shown is most appreciated. To Dr. Diane Kyle, who also served as my program chair, I am thankful for her guidance and advice throughout this process to take advantage of many opportunities to expand my knowledge and experiences. To Dr. Sam Stringfield, who always took time to express unconditional support and encouragement for my pursuits, I am grateful for his thoughtful analysis of my work, his kind spirit and gentle manner.

And finally, to my husband Richard, who has encouraged me for so long to stretch beyond the limited parameters in which I cast myself, your constant love and unflagging support are very dear to me. 


\begin{abstract}
TEACHER IMPLEMENTATION AND VALUATION OF FORMATIVE ASSESSMENT STRATEGIES IN ELEMENTARY SCIENCE CLASSROOMS
\end{abstract}

Pamela M. Jett

May 9, 2009

Formative assessment is frequently used by educators, but when asked to define, responses tend to vary widely. In essence, formative assessment is when teachers and students engage in instructional conversations discussing content information and gathering data about present levels of understanding. This feedback exchanged between teachers and students about knowledge gained is a critical element that provides structure and support to move student learning forward. For teachers who effectively use formative assessment strategies, it is the responsive element of adjusting lesson plans, instruction and assessments to give students multiple avenues to develop deeper understanding and to address student learning needs. For students it is the clarification provided by the teacher to link what was known, to what is known to achieve desired learning.

In this study elementary teachers in one school district were surveyed by means of a questionnaire to ascertain their perspectives on value and implementation of formative assessment. Four teachers were selected for intensive observations of science lessons utilizing what each perceived to be formative assessment strategies. This study used a mixed methods approach to analyze data from three sources: a questionnaire, 
classroom observations and teacher interviews. Factor analysis and confirmatory structural equation modeling were used to determine the validity of the questionnaire about teacher's beliefs and use of formative assessment strategies; SEM also provided underlying structural relationships of formative assessment strategies. Teachers' value of formative assessment strategies strongly correlated with their reported use of same strategies. Regression analysis determined no significant correlation between years of experience and use of formative assessment.

Interview analysis of case studies indicated that those who had a more studentfocused or constructivist approach to science teaching, were more likely to effectively use a wider variety of formative assessment strategies in their instruction; conversely, teacher-focused instructors used fewer formative assessment strategies and did not exemplify those characteristics a constructivist philosophy.

A Teacher Profile has been proposed which categorizes teaching behaviors that are more consistent with who embodies the knowledge, beliefs and dispositions about effective formative assessment. This profile has suggested uses for university teacher educators, education administrators, professional development trainers, and professional learning communities. 


\section{TABLE OF CONTENTS}

\section{PAGE}

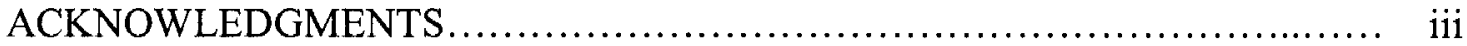

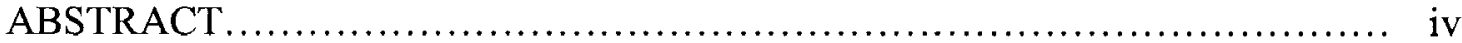

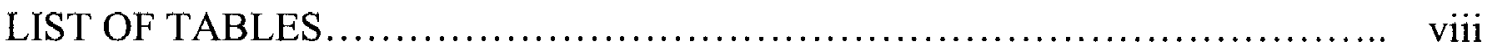

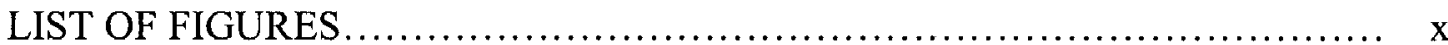

CHAPTER

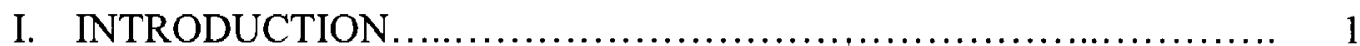

II. LITERATURE REVIEW .......................................... 10

III. METHODOLOGY …............................................. 65

Participants ..................................................... 66

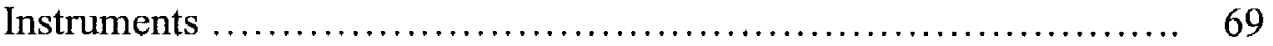

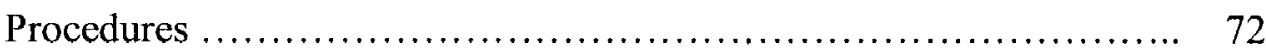

Analysis ............................................................ 75

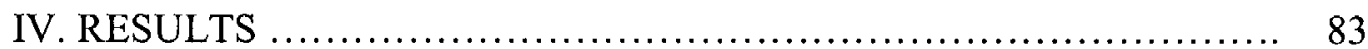

Data Processing and Screening .................................... 83

Quantitative Results ........................................... 91

Factor Analysis ............................................ 91

Correlations .................................................. 93

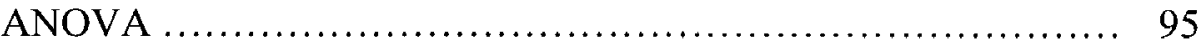

Structural Equation Modeling ................................ 101

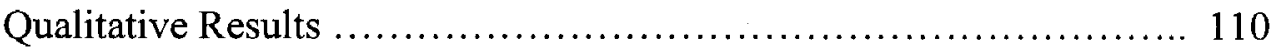


Formative Assessment Questionnaire ..................... 110

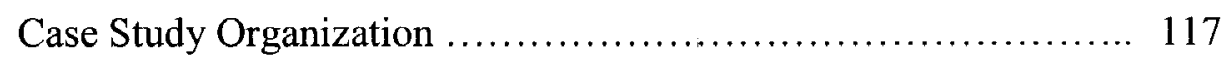

Case Study Results by Teachers $\ldots \ldots \ldots \ldots \ldots \ldots \ldots \ldots \ldots \ldots \ldots, 124$

V. DISCUSSION OF FOUR CASE STUDIES $\ldots \ldots \ldots \ldots \ldots \ldots \ldots \ldots \ldots . \ldots \ldots$

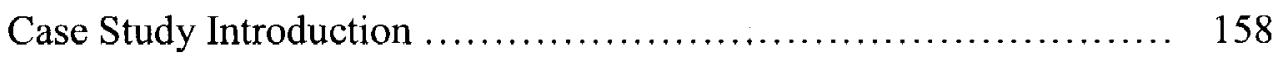

Teacher-Focused and Student-Focused Approaches to Instruction .... 159

Two Teacher-Focused Case Studies ............................ 162

Two Student-Focused Case Studies $\ldots \ldots \ldots \ldots \ldots \ldots \ldots \ldots \ldots \ldots \ldots, 178$

VI. DISCUSSION ............................................ 196

Teacher Value of Formative Assessment ....................... 197

Teacher Use of Formative Assessment ........................ 198

Professional Development and Formative Assessment ............. 205

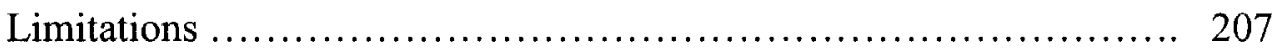

Conclusions and Recommendations ........................... 210

Creating a Teacher Profile ................................... 215

Implications for Further Research and Implementation ............ 220

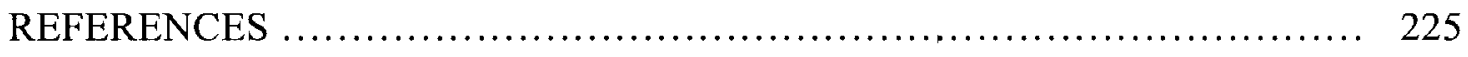

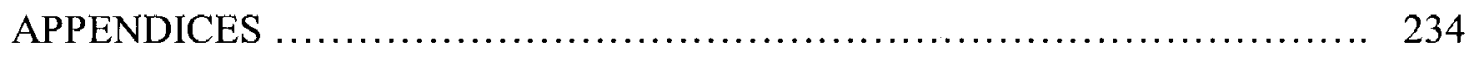

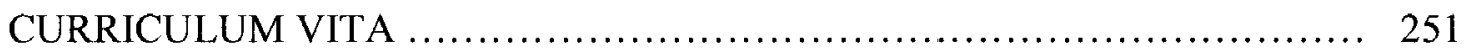




\section{LIST OF TABLES}

TABLE

PAGE

2.1 Comparison of Leahy et al. Criteria with Selected Other Relevant Studies..... 63

3.1 Demographics for All Students in the School District .................... 68

3.2 Observation Schedule for the Case Studies ............................. 71

3.3 Correspondence between Interview Questions and Questionnaire Items....... 81

4.1 Patterns of PD Training Experiences Related to Formative Assessment........ 88

4.2 Grade Level Categories................................................ 90

4.3 Data Distribution Characteristics...................................... 90

4.4 Factor Analysis of the Value and Use Scores............................ 92

4.5 Predicting Use Frequency of a Strategy from Perceived Value............... 95

4.6 Tukey HSD Results for Total Mean Value Scores by Grades Taught............ 96

4.7 Tukey HSD Results for Total Mean Use Scores for Grades Taught............ 97

4.8 Tukey HSD ANOVA Post-Hoc p-values Between PD Training Group Pairs... 98

4.9 Examination of the Four Sub-Constructs of the Questionnaire Across Levels

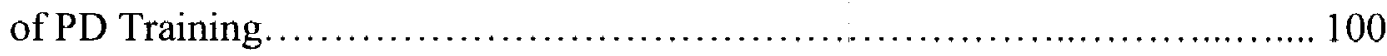

4.10 Model Modification Process for Value Scores on Formative Assessment...... 104

4.11 Model Modification Process for Use Scores on Formative Assessment.......... 107

4.12 Short-Response Statements from the Formative Assessment Questionnaire..... 111

4.13 Categorical Codes for Teacher Short Responses to Statements 3-6......... 112

4.14 Codes for Teacher Responses to "Formative assessment works well when"... 114 
4.15 Codes for Teacher Responses to "Formative assessment hinders my work"... 116

4.16 Interpreting Value and Use Scores for Case Studies........................ 118

4.17 Average Mean Scores for Case Studies on Questionnaire

Sub-Constructs..................................................... 119

4.18 Five Criteria of Formative Assessment with Detailed Criteria....................121

4.19 Interview Items with Explanations........................................ 123

5.1 Case Study Teachers' View about Their Teaching.............................161

5.2 Jordan's Reported Value and Use of Formative Assessment Strategies......... 166

5.3 Jordan's Detailed Use of Formative Assessment Strategies..................... 167

5.4 Tina's Reported Value and Use of Formative Assessment Strategies...........174

5.5 Tina's Detailed Use of Formative Assessment Strategies...................... 175

5.6 Leigh's Reported Value and Use of Formative As\$essment Strategies.......... 183

5.7 Leigh's Detailed Use of Formative Assessment Strategies................... 184

5.8 Virginia's Reported Value and Use of Formative Assessment Strategies.........191

5.9 Virginia's Detailed Use of Formative Assessment Strategies.................. 192

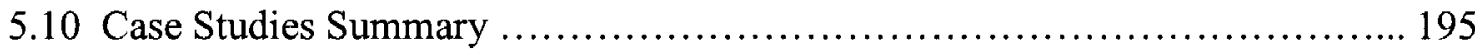




\section{LIST OF FIGURES}

$\begin{array}{ll}\text { FIGURE } & \text { PAGE }\end{array}$

4.1 Correlation of value scores and use scores ............................... 94

4.2 Structural equation model for the latent construct for value ................. 102

4.3 Structural equation model for the latent construct for use ..................... 109

5.1 Sequential representation of the four elements of Bruner's theory ............ 159

5.2 A visual representation of the five instructional styles .................... 160

5.3 A photo of an "All About" book ..................................... 181

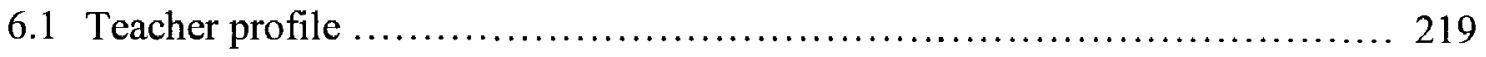




\section{CHAPTER I}

\section{INTRODUCTION}

Teachers typically use a wide variety of instructional and assessment strategies as they implement a lesson. These strategies likely include formative assessments along with other instructional strategies for the purpose of determining what students have learned and the degree of proficiency of that learning. Instructional strategies may be classified as formative assessment if they provide the teacher with some knowledge of what students know and are able to do. Therefore, if an assessment does provide that critical information to the teacher or to the students, then it can be considered formative (Black \& Wiliam, 1998a; Atkin, Black \& Coffey, 2001). Due to the fact that the term formative assessment has been widely and frequently used in recent research and popular professional literature, teachers may hold varying definitions of what they believe formative assessment strategies are or are not.

It is unclear what teachers understand about formative assessment and whether they implement such practices within their instructional repertoire. Even though formative assessment has been included in university teacher preparations programs, it has not been the predominant method of assessment that classroom teachers typically use. Instead, summative assessments in the form of tests, projects and performances have been the predominant methods employed to evaluate student learning (Shepard, 2000; Stiggins, 2002). Because teachers rely heavily on summative assessments to 
judge student acquisition of knowledge, it is reasonable to question teacher knowledge and confidence when it comes to the implementation of formative assessment as a reliable instructional and assessment process to assess student knowledge, and this presents a cause for concern. Teachers may not understand the potential of formative assessment as an instructional strategy having a positive impact on student learning. An additional concern is whether teachers who are expected to implement formative assessment strategies have had the necessary professional development training to build knowledge and confidence with these strategies. This study investigated formative assessment issues including teachers' knowledge, values, beliefs and usage during classroom instruction.

\section{Background}

With the publication of Assessment and Classroom Learning (Black \& Wiliam, 1998a), a meta-analysis of formative assessment, and with the subsequent article, Inside the Black Box: Raising Standards Through Classroom Assessment (Black \& Wiliam, 1998b), Black and Wiliam sparked renewed interests and investigations into formative assessment because of its demonstrated impact on student achievement. They reported an effect size of between 0.4 and 0.7 standard deviation units when teachers regularly incorporated formative assessment strategies, particularly noting how these strategies were helpful for students who had been labeled as low-achieving (Black \& Wiliam, 1998a). An effect size of this magnitude indicated that student achievement scores could rise substantially on a given achievement test when formative assessments were regularly used by the classroom teacher. Achievement of this sort attracted the attention 
of school boards, state assessment coordinators, and national assessment agencies in addition to educational researchers.

Black and Wiliam (1998a) broadly defined formative assessment to include all activities that teachers and students undertake to acquire information that can be used diagnostically to alter teaching and learning activities. Under this expansive definition, formative assessment would encompass such things as teachers' observation of students at work, classroom discussions, evaluation of student assignments, review of homework, and analysis of test scores. The distinctive feature of formative assessment is when these activities and the data sources resulting from student-teacher interactions are used to adapt teaching tactics for the specific purposes of meeting identified student learning needs; providing activities to support struggling students and providing opportunities for deeper learning to occur. When these types of activities occur, assessment is considered formative.

Prior to the publication of Assessment and Classroom Learning (Black \& Wiliam, 1998a), studies had been conducted evaluating formative assessment, but the focus had been primarily on the feedback element, that is, the type and mode of evaluative responses teachers provided students. Ramaprasad (1983) sought to develop a simple definition for feedback and suggested that it was a way to alter the gap in performance between what had been currently assessed and the desired outcome for that performance. Sadler (1989) had concerns about the use of feedback during instruction and the environment that would support a feedback loop which he described as "a teacher who knows which skills are to be learned, and who can recognize and describe a 
fine performance, demonstrate a fine performance and indicate how a poor performance can be improved"' (p. 120).

Having clear indicators of mastery learning to describe a proficient performance would be an ideal situation for teachers to communicate to their students prior to a learning event. However, doubts exist about teachers' assessment skills. Stiggins (2002) claimed that U.S. teachers are "a national faculty unschooled in the principles of sound assessment" (p. 762). This brings into question the classroom teachers' ability to design reliable assessments to determine whether students have gained the knowledge planned for and presented within a given lesson. With formative assessment, the teacher would have benchmarks to indicate how well a student was progressing and would feed back to the student the skills and knowledge that had been demonstrated and what tasks still needed to be accomplished to successfully reached indicated benchmarks.

Assessment behavior of this kind had not been consistently observed by Black (2000) who noted that teachers' classroom assessment practices were weak and in one study noted that in particular science teachers' tests contained superficial and rotememorization questions. Particularly with those kinds of tests, the primary purpose was to see what facts students could recall and not necessarily to reveal deep learning. Harlen and James (1997) have suggested that in an attempt to simulate standardized tests (a summative assessment), classroom teachers created assessments that mimicked the standardized test yet labeled them as formative in an effort to prepare students for future high-stakes testing. Commenting on this paradox between formative and summative assessments, Black (2000) lamented that tests in general mislead and oppress teachers who are trying to implement formative assessment strategies and 
"wither for lack of support and are actually inhibited by the pressures of summative testing" (p.340-1).

Teachers are conflicted regarding when to use formative assessment and when to use summative assessments, and presumably have been left in a quandary. There are pressures to prepare students for high-stakes accountability tests while simultaneously evaluating student knowledge to meet curriculum standards. Formative assessment and standardized testing are not compatible; the former being an instructional strategy utilized while the learning is occurring, and the latter being a measure of student acquisition of performance standards especially when compared with peers (Bell \& Cowie, 2001). To compound this problem, Pellegrino (2002) reported doubts that reliable information was contained in the results of standardized tests due to the disconnect between state standards for learning, instructional practices and philosophies, and the narrowness of the tested content. In a report from the National Research Council, the authors suggested that "it [was] time to rethink the basic assumptions underlying how we assess students and how we use assessment data to enhance teaching and learning"" (Donovan, Bransford \& Pellegrino, 2000, p. 3). Additionally, it was reported that the information gained from summative measurements provided broad sweeping generalizations about student knowledge, were not reported in a timely manner, and could not provide teachers with diagnostic information to implement immediately in the classroom or to strengthen student learning.

Some have advocated a shift in focus away from a focus on summative assessment toward an emphasis on formative assessment. For teachers to gather 
evidence about what students have actually learned during a unit of study they require information from a variety of sources; these sources may include small tests and quizzes given along the course of several lessons. As a teacher evaluates the results from formative assessments, acquisition of knowledge should become clearer. Because classroom teachers encounter students who are gifted and talented, students who are unmotivated, students who are not confident in their abilities, and students who just want to complete the task and move on, all in the same class at the same time, a variety of instructional strategies need to be employed to determine student learning and understanding. Planning lessons that use formative assessment strategies, providing students with personalized reasons for learning, designing supports and challenges to meet diverse student needs, are demanding tasks teachers face daily. It would seem reasonable to assume that this does not occur in every classroom, every day, in every school. While it may be the ultimate goal of good teaching, it is still a Herculean task for a teacher to be confident of what each student has learned and whether implementation of formative assessments would actually achieving the desired learning outcomes.

One way to bolster teacher confidence with formative assessment was suggested by Hunt and Pellegrino (2002) noting that "formative assessment should be seamlessly integrated within instruction" (p. 76). Leahy, Lyon, Thompson and Wiliam (2005) proposed using formative assessment to support instruction by having it become a natural element of daily classroom instruction; they proposed criteria to frame the development of daily formative assessments activities. This framework addressed (1) clarifying learning goals, (2) strengthening questioning and classroom discussion skills 
including wait time, (3) providing frequent feedback to students, and (4) incorporating elements of active student learning along with self-assessment to strengthen students' ownership of their own learning.

\section{Professional Significance}

A desired goal of this research was to determine what elementary classroom teachers knew about formative assessment by examining beliefs and usage, and how beliefs about formative assessment are implemented during classroom instruction. For students to achieve the effect size results reported by Black and Wiliam (1998a), professional development training may be needed to assess and enhance teachers' knowledge, understanding, and use of formative assessment strategies. The literature on effective professional development is clear about effective approaches-professional development needs to directly address the expertise of the teachers, relate to teachers' questions and concerns, and reflect how effective learning occurs which tends to be accomplished through collaborative teams efforts (McTighe \& Emberger, 2006; Wiliam, 2006b). Models for effective professional development on formative assessment proposed by Black and Wiliam (1998b) included intensive workshops to introduce the concept with follow-up meetings where discussions were specifically focused on designing assessments, using strategies in the classrooms, and analyzing the results of student work. However, Wiliam (2006b) readily admitted that adequately training all teachers in formative assessment would take an extraordinary amount of time and resources. Therefore, with this study, once a determination has been made about what teachers know or don't know about formative assessment and how 
implementation occurred or didn't, it became more clear what additional professional development training teachers need.

\section{Delimitations and Assumptions}

Assessment is a naturally occurring teaching activity; however, it is usually cast as a negative, uncomfortable, but necessary teaching task (Shepard, 2000). This researcher's perspective about formative assessment is that it is a useful data source; one that will generate valuable information to increase teacher knowledge about student learning. Operating from a frarnework of formative assessment as an instructional tool rather than an end-product of learning may influence coding of instances of formative assessment that are noted during classroom observations that may be different from the teacher's perspective.

Although there is no evidence to suggest that the researcher's position within the district from which data were collected influenced the data in any way, the researcher's standing is an important contextual piece of information to share. The researcher's position was an administrator in the school district where this study took place. This administrative role was not hidden from the respondents who completed the questionnaire, or the teachers who volunteered to participate in the case studies.

\section{The Problem Statement}

Formative assessment has been shown to be a most effective instructional strategy when purposefully utilized by teachers and results in significant and observable growth in student learning (Black \& Wiliam, 1998a). Researchers have collaborated with teachers to increase understanding and utilization of formative assessment strategies by engaging students through instructional conversations (Bell, 2000; van 
Zee, Iwasyk, Kurose, Simpson \& Wild, 2001). These collaborations were conducted with a limited number of teachers in a longitudinal design that took up to two years to accomplish the desired outcome. Under this training model, it would likely take many years to train teachers to become more proficient with implementing formative assessments into instructional repertoires.

The purpose of this study was to investigate how teachers' stated values and use of formative assessment strategies are implemented during classroom instruction. The current literature on formative assessment has indicated five specific constructs are critical when responding to student learning needs. These included: (a) clarifying learning intentions; (b) engineering classroom discussions; (c) providing feedback to students; (d) activating students as owners of their work; and (e) having students selfand peer-assess (Leahy et al., 2005). Therefore, this investigation attempted to determine teachers' knowledge about formative assessment by examining how their beliefs translate into actions with regard to these specific criteria for formative assessment. In an attempt to understand what teachers know about formative assessment, their values and beliefs about formative assessment strategies and their responses to student learning needs became imperative measures. Another outcome of this study was the investigation of the types of professional development training teachers have participated in and the influence of that training on their usage of formative assessment strategies during instruction. 


\section{CHAPTER II}

\section{LITERATURE REVIEW}

When teachers present concepts to students, there can be as many interpretations of that information as there are students sitting in the classroom. For example, a notion as simple as, "the earth revolves around the sun," may conjure up mental images in each student's mind about what those words mean. If a verbal statement was the sole method of presentation to the students, different connotations and even misunderstandings can occur if a word's meaning was unknown to a student. In the previous example, the word "revolve" may invoke student misunderstandings (Osborne \& Freyberg, 1985). As this particular lesson proceeds, the teacher may provide a planetary illustration (i.e., EarthSun model or other visual aid). Then, the likelihood that more students will grasp idea that planet Earth moves around a stationary object, the Sun, greatly increases. Likewise, the gap between what may have been misunderstood and the scientifically correct conception diminishes.

If the teacher asked students to physically enact this planetary motion (i.e., one student remains still while another student walks around that student), the possibility that more students have strengthened their understanding of this physical phenomenon should increase. To continue assessing students' understanding of "the earth revolves around the sun," students could draw a picture, label it, and explain it to another student. The teacher then listens, encourages, corrects, explains, or praises the students' responses by examining their products, interacting and responding to students' 
questions and giving specific feedback to correct and move learning forward. At the conclusion of this series of concept building about the earth revolving around the sun, students should have developed a solid idea of this phenomenon; likewise, the teacher should know with increased certainty which students have comprehended, and which students may need additional assistance.

The above example illustrates formative assessment being used during instruction. A concept was presented and multiple opportunities and multiple instructional strategies were provided for students to grasp a particular concept. The teacher interacted with each student in an assessment modality and gave feedback to confirm understanding of "the earth revolves around the sun." If the assessment for learning "shapes that student's learning" (Wiliam, 2006b, p. 284) and information gained from the students is used to alter the outcome of what they can accomplish, then it is formative assessment. This form of assessment is an "essential component" (Bell and Cowie, 1999) of teaching due to the responsive element by the teacher. It was formative because students were developing a greater understanding of a concept; some may have known the information previously, others may have had a partial or unclear understanding; perhaps a few had never been given the opportunity to develop this mental schema (Donovan, Bransford \& Pellegrino, 2000). Upon completion of this instructional sequence, the teacher would have developed a clearer and more accurate understanding of what each student knew or did not know about this scientific concept. At various points within the instructional sequence, the teacher could have proceeded with increased confidence knowing that each student had obtained the desired learning objective. This instruction-assessment interaction helps the teacher to present content by 
continually soliciting feedback from students and assessing student learning to accomplish the intended outcome of the learning event.

\section{Defining Formative Assessment}

This instruction-assessment interaction is what Wiggins and McTighe (1998) commonly referred to as, "backward design." Their recommendation that all learning events begin with the proficiencies for declared knowledge should be clearly stated at the beginning of the planning process. The test, lab exercise or performance event is designed prior to instruction with the assessment criteria clearly established defining the skills needed to attain a proficient level of understanding.

Like backward design, formative assessment is a similar concept in that it is assessment that occurs while a student is learning (Bell, 2000). Complementing the backward design notion, benchmarks have been established along a learning progression to determine whether students are on track. Using the earth science example described earlier, the teacher would pose a question to which students would respond; then, the teacher would evaluate students' knowledge based upon those responses and provide feedback to guide learning. To some this might seem to be what teachers normally do in a science classroom.

Because of this seemingly simplistic nature, the usefulness of formative assessment had been relegated to a minor status in the repertoire of instructional strategies. Black (2000) commented about a commissioned study in England during the late-1980's saying "with hindsight it can be seen that the group did not know enough ... about both the benefits and the radical changes entailed ... and the learning advantage of enhanced formative assessment [as] a robust effect" (In Millar, Leach and Osborne, 
p. 335). This perceived oversight by the commission propelled Black and Wiliam (1998a) to comprehensively design a meta-analysis of formative assessment studies. They concluded that there were dramatic, positive effects on student achievement when feedback was used to improve student performance and declared that formative assessment was the "feature at the heart of effective teaching" (Black \& Wiliam, 1998b, p. 140).

When a teacher evaluates student responses, uses those responses in an evaluative manner, provides students with specific feedback about the quality of their responses and implements specific strategies for improving the learning, it completes the cycle defined as formative assessment. What Black and Wiliam (1998a) uncovered in their meta-analysis was the element of bi-directional feedback being the most critical component of the formative assessment cycle. Feedback enhances the interaction between teacher and student, and involves the student in a more active role in the learning process due to the specific feedback from the teacher, and the adjustments made to instruction.

It was Natriello's (1987) work that had a significant impact on Black and Wiliam (1998a) due primarily to his analysis of the effects of feedback on student performance. Natriello's instructional model was viewed from the perspective of evaluation. An eight-step planning process began by "establishing the purpose for evaluating students" (p.157) which set the criteria for student learning. The model continued in a cyclical manner by outlining the steps of the task with identified criteria, establishing standards for student performance, sampling the performance to determine 
progress, providing feedback, and monitoring the outcomes of the evaluation process to design the next task.

Feedback was also the term referenced in a business model to compare current performance and a desired outcome. What differentiates feedback from a normal response was "when the information received in reference to the gap is used to alter the gap" (Ramaprasad, 1983, p. 5). When a classroom teacher uses the information received from students' responses, questions or performances on an assignment, the feedback given to the students can then alter the gap between what students know and do not know.

Sadler's (1989) research also greatly influenced the Black and Wiliam study with regard to the use of feedback. Feedback was defined as occurring in a supportive environment and incorporating a "feedback loop" in which the teacher is aware of "the quality appropriate to the task, and [is] able to judge the student's work in relation to that concept" and subsequently the student "comes to hold a concept of quality roughly similar to that held by the teacher" (p. 121). Formative assessment was originally defined by Black and Wiliam (1998a) as "all those activities undertaken by teachers, and/or by their students, which provide information to be used as feedback to modify the teaching and learning activities in which they are engaged" (p. 7).

As Black and Wiliam (1998b) continued to communicate the results of their meta-analysis, they refined their definition of formative assessment as the following: "Feedback to any pupil should be about the particular qualities of his or her work, with advice on what he or she can do to improve, and should avoid comparisons with other pupils" [italics in original] (p. 143). Hence, formative assessment was not an assessment 
in the strictest sense of the word because it was not a final evaluation of student work. Rather it was an instructional process used by teachers to engage students in learning. Formative assessment is when teachers provide students with guidance in the form of specific feedback, and evidence from student work is used to adapt and modify the teaching and learning processes to meet revealed student needs (Bell \& Cowie, 2001; Black et al., 2004; Black \& Wiliam, 1998a, 1998b; Pellegrino, 2002; Stiggins, 2002; Stiggins \& Chappuis, 2006). An on-going evaluation process employs a diagnostic purpose where the teacher clearly understands the student misunderstandings and guides the students through feedback; the students clearly understand where gaps in the learning occur and can focus attention on remediating those gaps. This exchange of information between teachers and students about learning becomes an instructional conversation rather than a final evaluation about what a student knows at a given point in time (Bell, 2000; van Zee et al., 2001).

Exchange of information between teacher and student was investigated by Taras (2003) by integrating Sadler's (1989), feedback loop Torrance's (1993), feedback and feedforward exchange and Vygotsky's (1978) social construction of learning. Taras observed undergraduate students who were involved in a cyclical process of feedback between an evaluator and an evaluatee where emphasis was placed upon the missing information needed to close a learning gap. The gap occurred between what was demonstrated as learning and the desired end product. Even these college-aged students needed a feedback framework to understand where they were headed in the learning process before they could demonstrate competency. Taras' research placed an emphasis upon self-assessment where the student became a partner in the evaluation process and 
made contributions toward their own understanding along a clearly defined learning continuum.

As research into formative assessment has been conducted with students ranging from elementary to university age, with the majority of the studies taking place in middle and high schools, the definition has evolved to describe the relationship between the learner and the learning that is taking place (Aschbacher \& Alonzo, 2006; Bell \& Cowie, 2001; Chin, 2006; Cowie \& Bell, 1999; Dawson, 2005; Duschl \& Gitomer, 1997; Morrison \& Lederman, 2003; Ruiz-Primo, Shavelson, Li \& Schultz, 2001; RuizPrimo \& Furtak, 2006; Sato \& Atkin, 2007; White \& Frederiksen, 1998). Assessment for learning is the term now commonly used to describe the "process of seeking and interpreting evidence for use by learners and their teachers to decide where the learners are in their learning, where they need to go and how best to get there" (Assessment Reform Group, 2002, p. 2).

Why Formative Assessment?

Knowing where students are with their present ideas about a topic, recognizing the point reached in their metacognitive development, and then taking steps to move learners forward, constitutes formative assessment (Harlen, 2003). Formative assessment does not necessarily lend itself to a series of steps taken to lead a student toward mastery learning. Formative assessments are intentional responses to the interactions that occur in the classroom between the teacher and learners. As the literature was reviewed, some learning theories were considered to examine how theory meshed with the more practical tenets of formative assessment to provide a learner the best environmental conditions to lead toward mastering learning. 
Psychology Perspective for Formative Assessment

Approaching instruction from an educational psychology perspective, Bruner (1966) distinguished his theory of instruction as prescriptive rather than descriptive due to the fact that "it is concerned with how what one wishes to teach can best be learned, with improving rather than describing learning" (p.40). This instructional theory aligned with formative assessment as it proposed four elements to position a learner to have the frame of mind to learn and achieve new skills and knowledge. The first of the four elements of Bruner's theory addressed predisposing the learner to learning by creating an environment that was conducive to learning. Second was structuring of knowledge to be grasped by the learner while taking advantage of known abilities of the learner. Next was careful attention to the sequencing of the learning episodes utilizing questioning and pacing that suited the learner. The fourth element was the implementation of rewards and punishments to move the learner from extrinsic toward intrinsic motives to achieve more complex learning. This last issue of rewards and punishment emphasized that a "punishment" is a correction addressed by the teacher to the student to move the learner along a line of progression toward a greater and more satisfying learning experience, that is, feedback.

Using the four elements of Bruner's theory of instruction as a framework, research has been conducted to support these basic elements that are congruent with formative assessment. Looking at goals and classroom structure, Ames' (1992) research supported the first element of Bruner's theory finding that a carefully structured learning environment was necessary to encourage learners to believe they could accomplish and persist by spending additional time on-task. Most importantly was the 
occurrence of challenging work that would test and stretch students' cognitive ability to problem-solve.

Students need to have well-defined learning experiences within their reach but scaffolded to extend new learning that are linked to existing knowledge. When teachers carefully construct or structure knowledge (i.e., Bruner's second element) with the intention of deepening understanding, they link ideas together for the student. Cognitive learning theory supported the creation of links for students to help them make sense of new content. Because learning was an active process, students depended upon the methods teachers used when structuring knowledge (Harlen \& James, 1997; Shepard, 2000). The term "assisted performance" suggested by Tharp and Gallimore (1988) addressed this kind of teacher-constructed environment where connections are provided to assist students to associate existing knowledge with newly presented ideas. From a developmental perspective and with reference to Vygotsky's zone of proximal development (1978), teachers designed a task to gain and maintain focus in a socially supported environment to help students build capacity when accessing resources and tackling problems. The teacher's key role was one that was supportive through posing of questions and clarifying or solidifying new knowledge in response to students' inquiries. The teacher led and guided students to connect observations with basic understandings of a concept and to progress toward more sophisticated levels of knowledge (Harlen, 2003).

Because students enter the classroom with varying levels of knowledge about their world (Osborne \& Freyberg, 1985), a desired lesson plan goal would be to move each student from an informal toward a more formal understanding of a concept. Within 
a formative assessment framework, the presentation of content from simple, beginning ideas toward more abstract ones utilizes and extends the sequencing concept (i.e., the third element of Bruner's theory of instruction). When teachers actively engaged students by providing opportunities for them to reveal their thinking, and build upon more formal understanding of the subject matter, formative assessment feedback served as the conduit for extending and building confidence when learning new material (Donovan, Bransford \& Pellegrino, 2000).

The quality of the student work and the evaluation of it needed to focus on the effort and not on the intelligence or confidence of the student performing the task was a conclusion drawn by the work of Dweck (2007). Receiving feedback was the critical element associated for a student to continue to make progress. For a student to demonstrate understanding and show improvement, the student needed to grasp a concept of roughly similar quality to that held by the teacher (Sadler, 1989) and the quality of the feedback, or "rewards and punishment" in Bruner's terminology, needed to be used to alter the gap (Ramaprasad, 1983). Both the teacher and the student gained from this interaction; the teacher accurately assessed progress, and the student found the way forward (Harlen \& James, 1997). The issue of autonomy has been shown to be a relevant motivating factor for students especially when given a choice of how to proceed through a task where gaining a sense of control over their own learning occurred (Ames, 1992).

Much of the learning theory associated with formative assessment also aligned with Bandura's (1977) social cognitive theory, especially that of self-efficacy. Selfefficacy permitted a student to persist with a task affecting motivation, perseverance 
and belief that the effort expended will result in positive outcomes. It became contextualized when the teaching was responsive to the environment in which the learning occurred; an interactive partnership between the teacher and students was created where meaning was constructed during the course of study (Bell, 2000).

\section{Socio-Cultural Perspective for Formative Assessment}

An assessment ultimately has one purpose and that is to enable one to make quality judgments about the knowledge that has been gained - "it is a process of gathering information for the purpose of making judgments about a current state of affairs" (Pellegrino, 2002, p. 48). From a teaching perspective it is a measure of the effectiveness of lesson planning where one could reflectively ask whether the student had demonstrated adequate acquisition of skills; Bell (2000) called this "planned formative assessment." From the students' perspective it was a way to self-assess and receive feedback to understand where one was with learning and next steps needed to achieve the stated learning goal. From a program evaluation perspective, assessment occurred when groups of teachers worked collaboratively in a professional learning community to analyze the effectiveness of assessment practices and determined student progress with the intended curriculum.

A 2000 National Research Council report (Donovan, Bransford \& Pellegrino, 2000) suggested there was an immediate need to examine how assessments at the classroom level, as well as large-scale assessments, are structured to reveal data about what students know. New ways of looking at testing as it applied to teaching and learning needed examination at a foundational level and serious questions needed to be asked about how student knowledge was measured. 
An assessment issue reviewed by Harlen and James (1997) focused on the dualistic role teachers play when conducting formative and summative assessments within the classroom and the possible confusion which could arise. Formative assessment has the goal of increased, deep learning; summative assessment is used for grading, placement, promotion and accountability purposes (NRC, 2001); this was where the confusion occurred.

In How People Learn, Donovan, Bransford and Pellegrino (2000) developed a broad overview of classroom learning environments with the stated commitment to design assessments to help students learn. They explored notions concerning how students arrive in classrooms with existing knowledge, and how they must be provided with opportunities to formalize their understanding and to strengthen their metacognitive skills. The social framework for evaluation of student learning is a wellengineered integration between the learner, the knowledge (i.e., the curriculum), and the assessment mechanisms. To align this with formative assessment, the teacher needed to rely upon certain critical factors. The first was to acknowledge the wealth of information students brought with them. Recalling Bruner's theory of instruction, this references pre-disposing students to learning by ascertaining first what is already known about the subject matter. Well-organized curriculum with intentional connections between one concept and the next must be made explicit.

The next element of this learning environment was regular, on-going assessment which exposed what was and was not known; where the teacher could make instructional adjustments for the student to determine the pathway to obtain the intended goal. The final element of this socially constructed environment reached beyond the 
walls of an individual classroom where the learning had broader relevance and value beyond the textbook.

When students ask the very legitimate question, "Why do I need to know this?" teachers must be ready with a realistic response. Authentic learning and real world connections need to be made for students; ones that cause students to understand the big ideas of the curriculum and to be able to make connections to their own lives. Kennedy proclaimed, "Citizens in the $21^{\text {st }}$ century will not be judged by their ability to bubble in answers on test forms, their success both personally and professionally will depend on their capacity ... to think for a living” (as cited in Hiebert \& Calfee, 1989).

\section{Supporting Research for Formative Assessment}

\section{The Research Background}

When Black and Wiliam (1998a) began their meta-analysis of formative assessment, their objective was to diminish the singular perspective of assessment as an instrument of testing and instead shift the focus toward instruction. If formative assessment could be thought of as an instructional practice rather than an assessment practice, the goals of formative assessment (e.g., increased student understanding through teacher feedback and student self-evaluation) could more easily be attained. Their impetus to challenge classroom instructional practices was due to observations made that pointed to specific non-productive practices. They were concerned that evaluation practices too often focused on memorization of isolated facts about the subject under study and that little was done with the results of tests. Furthermore, test results were not shared and apparent reflection of these results had little impact on future instruction. They found that teachers placed an over-emphasis on grading and 
giving students marks for their efforts, and how an ill-advised competitive factor of comparing one student to another was impairing individual student achievement. Shepard (2000) has reported how teachers embrace more traditional views when it came to testing in that assessment needed to be an "official event, separate from instruction" (p. 5).

Early in the 1990's when researchers were beginning to examine learning from an integrative perspective, Graue (1993) described an instructional assessment framework where she proposed "to meld teaching and assessment so that they are simultaneous and dialogic ... both teacher and students become learners" (p. 285). This integration of assessment and instruction, especially from a constructivist perspective, was posed as a part of the educational process and not a stand-alone event. She added, "Assessment and instruction are often conceived as curiously separate in both time and purpose" (p. 291). In an earlier reflection on assessment practices, Hiebert and Calfee (1989) proposed "embedded evaluation in on-going instructional procedures" (p. 53).

Bloom (1984) reported research findings comparing a direct instruction environment with a mastery learning environment and concluded that the defining difference lay with the utilization of assessment for learning; it was present in the mastery learning situation and absent in the direct instruction situation. The mastery learning students achieved one to two standard deviations higher than the control group. Bloom based this conclusion upon an earlier investigation where he reported "the use of 'formative evaluation' to provide feedback and correctives at each stage in the learning process" was a more valid use of assessment tools that teachers had at their disposal. He 
continued by stating that "we see much more effective use of formative evaluation if it is separated from the grading process and used primarily as an aid to teaching" (Bloom, 1969, p.48). Assessment as an instructional process and grading as a deterrent to student progress are ideas that have been considered, but have not had the supporting empirical data to thoroughly convince educators that these practices had an effect on learning, until studies such as those conducted by Black and Wiliam were published.

Recalling "backward design" where assessment planning is entrenched in the instructional process, Wiggins (1992) asked whether a test should be enticing and an authentic indicator of knowledge gained. In defining an authentic assessment, he delineated eight criteria which ranged from creating a task worth mastering with clear scoring criteria, to real problem solving, to ultimately sharing results with all affected parties. He claimed that "Typical tests, even demanding ones, tend to over-assess student knowledge and under-assess student know-how with knowledge" (p. 27).

Similar to Wiggins' use of the term "authentic assessment," Graue (1993) referred to "embedded assessment" in response to critics of testing. She wrote, "These critiques of assessment practices share a commitment to gathering information that is multidimensional and that illuminates the learning process rather than taking snapshots of performance at a single point in time" (p. 300).

The background research on integrated assessment and instruction by Graue (1993), mastery learning and formative evaluation by Bloom (1969/1984), authentic assessment by Wiggins (1992), assisted performance by Tharp and Gallimore (1988), and backward design by Wiggins and McTighe (1998) concluded with similar findings regarding the measure of student achievement. They proposed that to accurately 
measure what a student knows (a) some protocol other than simply presenting a lesson must be occur, (b) learning activities must engage the learner, and (c) tests needed to measure each student's gain in new skills and knowledge. Therefore, when Black and Wiliam (1998a) presented their research findings, educators readily endorsed their conclusions about formative assessment due to the comprehensive manner in which they had collected diverse research studies and had methodically pieced them together into a cohesive framework.

Colleagues of Black and Wiliam began in earnest to design and conduct studies that utilized key elements of the formative assessment meta-analysis demonstrating how classroom teachers could impact student achievement. Black et al. (2004) posed the question, "Is there evidence about how to improve formative assessment?" (p.10). It was relatively clear from the Black and Wiliam (1998a) study that formative assessment did raise achievement, and there was again strong evidence that a need for teachers to make improvements in their instructional practices existed, however, the portion of the research that was less clear was in the implementation strategies. In Working Inside the Black Box: Assessment for Learning in the Classroom" (Black et al., 2004) a team of researchers identified three main issues with regard to current teacher practices centering around assessment methods, grading practices, and the nature of the feedback. They perceived that much work still needed to be done to communicate their conclusions about formative assessment and to train teachers to implement the instructional practices that would result in the achievement their research had indicated.

Concurrent meta-analysis research by Marzano, Pickering and Pollock (2001) examined many studies of the teaching-learning cycle and indicated there were nine 
instructional practices that increased student achievement. Marzano's meta-analysis combined results of studies to determine an average effect size, much like that of Black and Wiliam (1998a). Compelling data, with an effect size that ranged from 0.59 to 1.61 standard deviations, indicated that with the implementation of particular strategies and methods dramatic improvement in student performance would result. These strategies are:

1) Identifying similarities and differences

2) Summarizing and note taking

3) Reinforcing effort and providing recognition

4) Homework and practice

5) Nonlinguistic representations

6) Cooperative learning

7) Setting objectives and providing feedback

8) Generating an testing hypotheses

9) Cues, questions, and advance organizers

Similarly, Marzano reported that "setting objectives and providing feedback" had an average effect size of 0.61 standard deviations which was well within the range Black and Wiliam had disclosed.

Clearly, the research that has been conducted in the past two decades has supported specific changes that needed to occur during classroom instruction. These changes would include placement of students in advantageous positions to understand what they were learning, why they were learning it, and how to apply that knowledge in a real world scenario. 


\section{Formative Assessment Concerns}

Time and pressure. Implementing formative assessments takes time. Time is needed for teachers to plan and develop questions, to engage students in thinking that allows them to guess, hypothesize, predict, to ask their own questions and wonder aloud. Hunt and Pellegrino (2002) claimed that, "There is no point in formative assessment by a teacher if the teacher cannot identify, analyze, and respond to the problems of individual students" (p. 75) Extended time is required for students to work with ideas and materials to discover important, relevant concepts that may be applicable in multiple situations. From an outsider's perspective, watching a group of students "play" with an idea might be viewed as "loose instruction" when the teacher presented students with the essential components for discovery. This student-centered approach to instruction positions the teacher in a less explicit role as observer, questioner, and guide for those who may stray from the objective on their way to the discovery. Formative assessment requires a teacher to be very attentive to the many interactions that occur in the classroom, to examine each student's work, to listen to each student's comments, and to provide specific feedback to any who may lose focus. Teachers greatly value time they have with their students during class meetings; thus time-consuming elements of formative assessment may be seen as unnecessary and direct instruction, a more teacher-centered approach, may be preferred.

Progressing through a series of lessons in order to cover the content is a pressure teacher's face daily. Teachers often comment how they feel pressured to "cover the content" and "just can't seem to fit it all in." Wiggins and McTighe (1998) suggested teachers should prepare for anticipated difficult concepts and potential 
misunderstanding when preparing lessons by designing questions, learning activities and formative assessments to uncover the objectives and goals of those lessons. They proposed the practice of uncovering the content, and encouraging teachers to ask themselves, "To what extent does the content require uncoverage?" (p. 23). This style of planning can result in class time being devoted toward more collaborative work with the content.

Summative assessment practices. The key element of formative assessment is feedback to students about their individual performances. Natriello (1987) remarked that "a good deal of evaluative information is never communicated to performers" ( $p$. 160). Hiebert and Calfee (1989) concurred and bemoaned the fact that teachergenerated data gathered from student work were a rich source of information about student learning but these data were often lost when progress reports were sent to parents. The only remaining data were a few numbers resulting from tests that inadequately measured student knowledge. When the work was boiled down to a simple number, the students have been "left in the dark" about the strengths and weaknesses of their efforts, ways to improve it, and next steps to gain and strengthen their own learning. Bell (2000) remarked about how the continued practice of equating "continuous summative assessment, in which marks or grades are collected over a period of time and collated into an overall grade at the end of the teaching segment" ( $\mathrm{p}$. 49) was still a common practice and often passed off as formative assessment. Black and Wiliam (1998b) observed that there was a "poverty of practice ... beset with problems and shortcomings" (p. 141) with regard to classroom teachers' assessment practices. In a commentary, Wiliam (2006b) suggested that some 
"assessments being used were summative assessment pressed into service for formative purposes" (p. 288) which leads one to understand the confusion that still exists with regard to assessment purposes, formats and functions. Suggestions for future research should focus on teachers' formative assessment practices because they are "very weak and ought to be developed" (Black, 2000, p. 339).

Continuing their work into the effectiveness of formative assessment, Black et al. (2004) identified three problems with assessments and raising standards of achievement. These are described as (a) teacher assessment methods that were not particularly effective in promoting good learning, (b) teacher grading practices tending to emphasize competition among students rather than improving individual student performance, and (c) feedback that students received was more often than not negative, especially that given to lower-achieving students.

Other reasons arise as to formative assessment has not being a consistent classroom. Darling-Hammond (2006) found that teacher candidates, who were about to become certified teachers, lacked assessment skills when it came to developing lesson plans and linking learning goals and objectives with assessment strategies necessary to determine whether all students had gained skills and content knowledge. Hiebert and Calfee (1989) had noted a similar concern with regard to assessment having written that "many teachers lack confidence in their ability to assessment student progress" (p. 53). They encouraged university teacher education programs to re-examine their teacher preparation with regard to assessment practices. Harlen (2003) reported an undervaluing of inquiry learning, especially in science classrooms, along with the time it took for 
students to self-assess, as two reasons why formative assessment had not been widely implemented.

With the advent of No Child Left Behind legislation (Stiggins, 2005) and the increased pressure to test students' reading and mathematics skills, large-scale assessments have become more frequent and intrusive in our nation's classrooms. This kind of testing has several limitations largely because the measurements (a) provide results that are of little or no use to the classroom teacher; (b) are limited in the scope of the content measured; (c) do not inform classroom teachers about strategies to improve student learning; (d) give only a "snapshot" view of student knowledge and progress; and (e) have raised questions about fairness and equity for the masses of students (Pellegrino, 2001). Good and Brophy (2003) agreed that high stakes tests are often "poorly prepared, inadequately scored, and serve primarily to rank schools as successful or failing without doing anything to promote the learning of individual students" (p. 31). But teachers continue to reproduce these types of measurements in their own classrooms as part of their pre-testing and post-testing routines (Shepard, 2000); possibly due to pressures placed upon them by principals, district administrators and others who encourage the use of assessments that mimic standardized test formats.

From the Black and Wiliam (1998b) assessment for learning study, three issues emerged. The first was that most teachers' tests emphasize rote memorization; the results are not shared with colleagues; and quantity is emphasized over quality. These issues addressed the negative and largely irrelevant information that traditional testing, and subsequently grading practices, provide students. Because of this, the second issue of the impact of grading has been categorized as useless feedback since it does not 
necessarily improve student learning and may even have a negative effect especially for those students labeled as low-achieving (Butler, 1988). A third issue has a more management perspective due to teachers' attempts to imitate large-scale measurements; thus they replicated the problems generally associated with those tests. Predicting student success on classroom tests may seem simple, but largely a useless process if it was missing the formative assessment component of useful feedback that students need to progress in their learning (Black \&Wiliam, 1998b).

A Framework for Formative Assessment Integration of Instruction and Assessment

Despite issues with the time it takes to incorporate formative assessment practices, the pressure faced to address content, and under-developed assessment practices, significant research findings from studies conducted in England, New Zealand, and the United States have found formative assessment to be essential for students' intellectual growth. Black and Wiliam (1998b) stated, "It is clear that instruction and formative assessment are indivisible" and that "opportunities for the pupils to communicate their evolving understanding are built into the planning" (p. 143). It has been essential for teachers to provide students with feedback to help them monitor progress toward the lesson goal, and therefore provide the appropriate opportunities to help one another obtain that goal (Harlen, 2003). Pellegrino (2002) agreed that formative assessment was an integral part of instruction where students acquired information about the quality of their work, what can be done to improve work, and how understanding of lesson goals and expected levels of the performance are necessary for intellectually growth. 


\section{Refining Instructional Strategies}

Formative assessment has been described as occurring at the intersection of teaching and learning; where teaching, learning, and assessment are integrated within the instruction delivery method utilized (Bell \& Cowie, 2001; Gipps, 1994). This integrative perspective was investigated in a two-year study with teachers, first in a summer workshop, and then through classroom observations, over the course of a school year (Leahy, Lyon, Thompson \& Wiliam, 2005). Though teachers used a variety of techniques (some useful and some not) when implementing formative assessment for learning, it was found that five broad strategies emerged that have been regarded "as non-negotiable in that they define the territory of assessment for learning" [italics added] (p. 19). These strategies were found to be consistent across grade levels and subject areas:

1) Clarifying and sharing learning intentions and criteria for success

2) Engineering effective classroom discussions, questions, and learning tasks

3) Providing feedback that moves learners forward

4) Activating students as the owners of their own learning

5) Activating students as instructional resources for one another These five criteria have been used to frame the research for this study. Each criterion will be discussed to address the research that has been conducted to support their inclusion in this framework. However, due to the fact that the intersection of teaching, learning and assessment are closely associated and the criteria are interrelated, each will be discussed separately, however, some overlap will unavoidably occur. 


\section{Assessment for Learning}

Clarifying and sharing learning objectives. An early lesson presented to preservice teacher candidates is the need to have clearly stated objectives with specific conditions for performance and criterion for evaluation of that performance (Orlich, Harder, Callahan, Trevisan, \& Brown, 2007). Much time is spent reading, discussing and writing lesson plan objectives (i.e., defining what teachers want students to know and be able to do). There are various methods employed in writing lesson plan objectives, but ultimately each objective should clearly state what knowledge, skills, and accountability measures students should have acquired by the end of the lesson. On the surface this seems like a relatively easy task for teachers to accomplish; however, as the research has indicated, it is not always a simple task for teachers to accomplish which can lead to confusing students about criteria for learning.

Good and Brophy $(1986 ; 2003)$ stated in their research results that students often did not understand the purpose of the work assigned to them and that teachers were more often concerned with what the students were doing and how they were doing it rather than linking their work to a stated objective. Concurrent research by Natriello (1987) discussed the ambiguous tasks used for assessment purposes and how student work seemed unrelated to the overall evaluation process. There was characteristic vagueness between stated objectives identified in lesson plans and the questions posed on the summative exam. Shavelson, Ruiz-Primo and Wiley (2005) commented that lesson plan objectives were often "tacit," i.e., hidden from the students and in some incidences, hidden from the instructor, and remarked that, "If we could make all our 
goals explicit to our students and ourselves, we might expect much more of their learning and our teaching" (p. 413).

To uncover these goals and enhance student acquisition of stated objectives, students must be able to engage in some form of self-assessment (Black \& Wiliam, 1998a, 1998b; Bell 2000; Butler \& Winne, 1995; Cassidy, 2007; Dawson, 2005; McDonald \& Boud, 2003; Munns \& Woodward, 2006; Sadler, 1989). To do so, students must understand what the teachers' objectives were and the focus for their learning. Students "can assess themselves only when they have a sufficiently clear picture of the targets that their learning is meant to attain" (Black \& Wiliam, 1998b, p. 143). Much about these concerns is still valid because teachers still incorporate nonspecific evaluation criteria, such as participation points, effort, and conduct grades when constructing student assessment in their evaluation process. Shavelson, Ruiz-Primo and Wiley (2005) posed that if teachers could create more explicit goals for their teaching, then expectations for learning could be greater.

Engineering classroom discussions. Raider-Roth (2005b) addressed the concept of trust as the binding element in classroom relationships. In observing teacher-student interactions where trust was a primary factor, she stated that the "teacher trusted the students' intentions to be constructive and creative, and the students trusted the teacher to be interested in, supportive of, and provider of the requisite material for their explorations" (p. 32). She detailed how teachers needed to listen to children voices and help them understand the relational world of the classroom and how those relationships "directly affect their capacity to build knowledge that is trustworthy" (Raider-Roth, 2005a, p. 587). 
Establishing a trusting environment for instructional conversation is essential to the effectiveness of formative assessment, since the conversation that occurs between teacher and student becomes the guiding path for one to achieve success with the work. Bell (2000) termed the phrase "interactive formative assessment" as the occasion when a teacher responded to student feedback in the form of a class discussion or a questionanswer period when the teacher recognized the need to alter the lesson when that conversation revealed misconceptions.

Mortimer and Scott (2000) examined the "flow of discourse" and "patterns of classroom talk" between teacher and student from a socio-cultural perspective. Supporting an interactive relationship between teacher and student, they commented that "Learning science involves internalizing and developing competence in using the social language of science" (p. 128). Their analysis of classroom talk provided direction for examining how discourse assisted students in developing meaningful understanding of complex science concepts when the teacher provided a balance between presenting concepts and exploring ideas. The teacher's role was to guide and direct the conversation and to initiate, respond and provide feedback (Edwards \& Mercer, 1987); critical elements to the successful implementation of a model for questioning and responding.

When encouraging students to formulate questions about conversation topics, van Zee et al. (2001) found that when a teacher was attentive to student questions, the feedback information could be altered in direct response to what the questioner had indicated was known and unknown "by creating comfortable discourse environments" (p. 159). Wilen (2004) noted how a social studies classroom discussion consisting of 
higher-order questions by the teacher and students gave both opportunities for "applying knowledge and stimulating critical thinking to enhance understanding about an issue, problem, or other content" (p. 35). Graue (1993) commented that math instruction was more than a unidirectional form of communication; where the skillful teacher encouraged students to reveal their understanding and used the discourse to "make decisions about what students need on a moment-to-moment basis" (p. 293).

In defining informal formative assessment, Ruiz-Primo and Furtak (2006) used a familiar "assessment conversation" framework developed by Duschl and Gitomer (1997) where classroom conversation followed an initiation-response-evaluation (IRE) pattern. They elaborated on this concept by adding the element of "usage" when the teacher does follow the IRE pattern, but then used the student response to develop a question or other follow-up response. They reported that the most successful occurrence of this formative assessment strategy was when the teacher responded to the student's contribution, used that contribution to respond, and additionally use the student's comments during class discussion. They termed this pattern of discourse as instructional responsiveness.

Providing feedback. Feedback is the distinctive element of formative assessment and has been referenced often throughout this literature review. In addition to the earlier discussion on the topic of feedback within the construct of formative assessment, this section of text has been restricted to the works of Black and Wiliam. In their 1998 metaanalysis, it was stated that, "feedback to any pupil should be about the particular qualities of his or her work, with advice on what he or she can do to improve, and should avoid comparisons with other pupils" (Black \& Wiliam, 1998b, p. 143). 
Feedback can be viewed as the opportunity for teacher and student interaction that results in a reorientation of the student toward the desired performance goal.

As Black and Wiliam have continued their work with teachers and have commented upon the resulting successes when teachers have realized the effectiveness of using feedback, the definition of feedback has continued to be refined. In two separate articles, Wiliam redefined this term as "feedback that engages students and moves them forward is feedback that causes students to think" (Wiliam, 2006b, p. 18), and, "if it shapes that student's learning....and the information is actually used to alter what would have happened in the absence of the information" (Wiliam, 2006a, p. 284). Wiliam further elaborated with reference to feedback as a "moment of contingency-a point in the instructional sequence where the instruction can change direction in light of evidence about the students' achievement" (2006a, p. 285).

Student self-assessment. The fourth formative assessment strategy from the Leahy et al. (2005) framework was "activating students as owners of their own learning," or self-assessment. A question many teachers wanted an answer to involved how to motivate students to want to tackle the task at hand and extend their own learning. Ryan and Deci (1990) developed a cognitive evaluation theory framed in terms of social and environmental factors when considering student motivation. A focal point in the development of their theory involved the human need for competence and autonomy specifically when feedback was given in a socially contextualized environment. These two human characteristics were satisfied and intrinsic motivation was positively enhanced when students were given opportunities for self-assessment. 
Related to self-assessment is a cognitively-based concept termed metacognition. This concept consists of two basic processes which occur simultaneously: an individual monitoring their progress as learning occurs, and the individual making changes and adapting strategies if not performing within the construct of the task (Winn \& Snyder, 1998). This type of activity included self-reflection, self-responsibility and initiative, as well as goal setting and time management. In a study of metacognition and selfappraisal of work, it was found that students in upper elementary grades (especially relevant to this study) were able to provide rather sophisticated analysis of their work when interviewed directly by their teachers using a strategic questioning technique (van Kraayenoord \& Paris, 1997). These students also had a positive outlook about school and their relationships with their teachers reflective of Ryan and Deci's (1990) findings.

To encourage student self-assessment, an appropriate learning environment must be created by the classroom teacher to guide students to reveal their thinking since "ordinarily students don't do enough to provide the evaluator something to see" (Hiebert \& Calfee, 1989, p. 53). It was uncharacteristic for students to offer what they knew and understood in a typical classroom setting since often in a direct instruction environment these kinds of opportunities are not given. However, if an integrated approach to instruction and assessment were to occur, "students would also have a very different job" and "student participation in learning, premised on the idea of authenticity would include active engagement in generating information about that learning" (Graue, 1993, p. 296). As Chappuis and Stiggins (2002) summarized in an assessment for learning situation, "both teacher and student use classroom assessment information to modify teaching and learning activities" (p. 40). When a change of this 
sort occurred in the classroom, the contract between teacher and student was altered to reflect a formative assessment framework. Therefore, when students successfully selfassess, it is the cross-section of teacher feedback and student introspection resulting in new realizations about learning, as well as the result of trusting relationships between teacher and student that allow for such growth. Sato and Atkin (2007) found that when a rubric was developed with a self-assessment component it became an attractive and productive activity for both the teacher and student. The teacher realized how students reflected and conversed with one another about science content which had been an aspect absent in previous learning activities.

Activating students as resources for one another. In 1946 Edgar Dale developed the "Cone of Learning" in response to a need he perceived with students studying agriculture. His basic premise was that students needed to be actively involved in the work of agriculture and supplement that experience with reading about agriculture. Simply put, he determined that learning by doing was more conducive to learning by reading alone. In the Cone of Learning, Dale drafted a model which claimed that after two weeks people tended to remember about $10 \%$ of what was read, $20 \%$ of what was heard, and $30 \%$ of what was seen. His model progressed to claim that people remembered $90 \%$ of what was said and done.

The perceived truth of this cone of learning, which was later termed in educational literature as "active learning," was not based upon solid research with supporting empirical data (Lalley \& Miller, 2007). However, the use of active learning strategies, or experiential learning, has been well documented in the literature (Good \& Brophy, 1986; 2003). Teaching strategies such as differentiation of tasks, designing 
interesting and challenging work, peer tutoring, and designing engaging learning centers have been shown to increase student attention to task and motivation to persist (Ames, 1992; Bandura, 1977; Brophy, 1999; Ryan \& Deci, 2000).

The element of peer tutoring or peer assessment was viewed by Wiliam (2006b) as a "helpful stepping stone to self-assessment" (p. 19). The definition of selfassessment has been fairly consistent in the literature. It is one of those terms that is almost self-explanatory, but does carry some variation in interpretation by educational researchers. Lee and Gavine (2003) and Sadler and Good (2006) defined student selfassessment in terms of judgment, grading or ratings of student work. The former states, "it involves judgments of one's own attainment in relation to other children" (p.50); the later as "specific judgments of ratings made by pupils about their achievement, often in relation to teacher-designed categories" (p.2). Comparison drives most assessment strategies, i.e., comparing one child's attainment of knowledge or skills in relationship to another. This analytical approach to student self-assessment was echoed by Stiggins and Chappius (2005) as a judgment of progress made by an individual when compared to the group.

Whether approaching self-assessment from a comparative aspect or from a relational perspective, definitions of self-assessment ask children to examine their work in relation to themselves, their teachers, and their peers. When students reflect upon their work and begin to judge themselves as learners; their opinions are greatly influenced by what teachers have deemed valuable and their understanding of what is acceptable (Andrade \& Boulay, 2003; Black \& William, 1998a). Some students are more adept at recognizing their cognitive skills than others, but all can be taught to be 
more perceptive and self-aware (Joseph, 2006; Paris \& Paris, 2001). Teaching students to use effective questioning strategies can help to strengthen academic skills and understandings, and thus push students toward a more mature intellectual realization of their own cognitive strengths. Black and Wiliam (1998a) asserted that teacher feedback was more effective when given in a non-judgmental way with specific suggestions for improvement. Andrade and Boulay (2003) hypothesized in their study utilizing a selfassessment instrument that students can be an effective source of self-feedback when given the appropriate conditions and support. A key finding was that teachers needed to be persistent and intentional when training students to be self-reflective; simply handing students a rubric to judge the quality of their work lacked validity.

In a study by Sadler and Good (2006), middle school students were allowed to grade their own papers and self-subscribe ways to improve their work; this method indicated that significant learning had occurred. Later when given a similar but unannounced test, significant gains in achievement were found between the first and second testing of the same material (not necessarily the same test). In a subsequent assessment, these same students peer-assessed and no significant gain was noted in their learning. Stiggins and Chappius (2005) concluded "feedback lays a foundation for students to learn to self-assess and set goals. In this way, assessment for learning keeps students informed about where they are in relation to that agreed-upon definition of success" (p. 20).

\section{Questioning}

Posing planned questions to students is a skill and an art. Questioning can achieve many lesson plan objectives and can be most effective when the teacher has a 
clear understanding of goals and objectives and has communicated these to the students. Effective questions are those that are designed to lead students toward the essential learnings of the lesson, have been thoughtfully planned to determine student background knowledge and misconceptions, are scaffolded to structure the knowledge, stimulate thinking, diagnose student progress, and help students make connections. Questions give students an equal opportunity to respond but also to reciprocate by asking questions of their own to clarify their understanding. Asking and encouraging students to pose questions throughout a learning event was an essential method of communication and one that directly related to effective feedback (Black et al., 2004).

Purposeful questioning. Black and Wiliam (1998b) commented when conducting classroom observations that teachers predominantly asked more fact-based questions, at a rapid-fire pace, and students had little or no time to think about how to respond. It was noted at that point in the questioning sequence, the student either knew the answer or wasn't sure, but furthermore, was unwilling to take the risk to respond fearing a wrong answer.

Research into questions and cues by Marzano et al., (2001) reported an average effect sizes ranging from 0.26 to 1.21 standard deviations in their meta-analysis when used effectively. The power of questioning was summarized to include four criteria for questioning that would bring about the desired effects. These included questions that focused on important information as opposed to that which was unusual or interesting; higher level questions to generate deeper thinking by students; inclusion of wait time; and designing questions in advance of the learning event. This last criterion was one that communicated to students that the lesson has a purpose and that questioning was 
the methodology that led the way forward to help students make connections. Black and Harrison's (2001) results agreed with Marzano's findings and proposed that questioning had taken upon a new importance with a teacher study group. The teachers in this group designed questions in advance of the lesson and realizing the importance and relevance for their students' progress. They commented that "many teachers do not plan and conduct classroom dialogue in ways that might help students to learn" (p. 11). In a later study with in-service teachers, Black et al. (2004) noted that "carefully crafted questioning can open up the subject and allow students to make connections by introducing new pieces of evidence and argument" (p. 17). This redesigned lesson planning tactic helped teachers give students feedback.

Ruiz-Primo and Furtak (2006) found that when teachers asked specific questions, the teacher used student response to pose a follow-up question; the students' understanding of the content of the conversation increased dramatically. When the teachers in their study listened carefully to what the students were or were not saying, and then crafted another question, effectiveness of their instruction increased.

On the receiving end of the teacher's question are the students who must respond, but also must be encouraged to pose their own questions. van Zee et al., (2006) found that students in a science class asked questions under certain circumstances such as, when they were invited by the teacher, when they were familiar with the content, when they perceived a safe and comfortable environment, and when they worked together with their peers. They concluded that there were three ways of speaking that teachers valued most: "guided discussions, student-generated inquiry discussions, and peer collaborations" (p. 159). 
Contrary to the findings of van Zee et al. (2006) was the study conducted by Morrison and Lederman (2003) into the beliefs and practices of experienced science teachers and their use of questions to diagnose and understand student preconceptions of science concepts. Although each of the four teachers in this study indicated they used questioning to uncover preconceptions, in practice only one of the four actually did by using a probing-type questioning. This teacher was also the most experienced with 34 years of service. The fact that each teacher perceived their line of question as probing to understand student background knowledge, may lead one to believe that teacher's beliefs and practices are not necessarily aligned as the Morrison and Lederman study indicated.

Wait Time. In the summer of 1991 I attended a special lecture given by Mary Budd Rowe on the Stanford University campus. She stood at a lecture podium casually dressed and, warning her audience, lit a firecracker, sat it on the edge of the podium, and waited, as we all did, while the wick burned and then exploded. This demonstration certainly got the attention she desired. Her intended message, however, was that whenever we posed a question to students, we had to wait; we had to allow students to think before they could respond, just as we had waited and anticipated what was about to happen with her demonstration.

Though this was rather dramatic, this demonstration was based upon research she had conducted about wait time where she found that in general teachers waited less than one second after asking a question before asking a student to respond (Rowe, 1974). In addition, many teachers she observed prior to wait time training, tended to give the answer themselves, call on another student, rephrase the question, or give clues 
and hints about the correct response. Rowe's hypothesis was that if students were given time to think after hearing a question, then they may be able to formulate a more thoughtful response. When teachers were trained to wait three to five seconds after posing a question, the quality of the students' responses increased dramatically. Students were able to give more thorough answers with higher quality attributes when compared to the responses given without wait time.

Applying this practice of wait time to teacher questioning practices and the conversational instruction that occurred in classrooms, Black and Harrison (2001) trained a group of teachers to utilize wait time. These teachers noticed the same dramatic difference in the kinds of responses students were able to give before they had implemented wait time. These awkward spans of time (three to five seconds) that occurred while waiting were difficult for some teachers to handle, just as Rowe (1974) had found with her study participants. These teachers realized that their routine of rapidfire questioning was appropriate in some incidents, but not when requiring students to provide thoughtful answers. As a result, teachers realized their routine(s) had to change to more effectively implement this element of formative assessment. Assessing student knowledge was more effective when using wait time because of the quality of the answer provided by the students.

\section{Feedback and Grading}

It is difficult to discuss feedback without also mentioning grading and grading practices. Even though feedback and grading have been discussed separately in the research they are often discussed in tandem. Feedback alone has received much attention and has been described as being multi-dimensional (Natriello, 1987), used to 
establish "guild knowledge about student work" (Sadler, 1989), resulted in positive and negative effects on student learning (Ames, 1992), and affected student learning based upon the environmental circumstances in which the feedback was received (Hattie \& Timperley, 2007). To give feedback to a student is to make an evaluative statement about the quality of the work. Research has encouraged educators to focus feedback on the task to gain the greatest impact for improvement (Brophy, 1981) and to avoid feedback relative to personal qualities.

Early studies by Bloom (1969) cautioned about the use of grades and keeping them separate from formative "evaluation" saying that formative assessment was much more effective when used primarily as an instructional tool rather than an assessment tool. Sadler (1989) agreed thát, “A grade therefore may actually be counterproductive for formative purposes" (p.121). This idea of giving a grade as a counterproductive activity was confirmed in research conducted by Butler (1988). Findings indicated that (a) a grade alone did not give the student an idea of what had been done well, (b) a comment (feedback) with a grade resulted in the comment being ignored and focus remained on the numerical value, and (c) a comment (feedback) alone was the more effective and relevant method to focus student's attention on the task because it provided ways to improve the work. Black et al. (2004) commented that "a numerical score or a grade does not tell students how to improve their work, so an opportunity to enhance their learning is lost" (p. 13).

Natriello (1987) reported on the effects of feedback to students with and without grades and cited a classic study by E. B. Page. Page (1958) found that when teachers made comments on students' papers "these apparently have a measurable and potent 
effect upon student effort, or attention, or attitude or whatever it is which causes learning to improve..." (p. 180-181). An additional comment by Natriello as to the affective value of feedback seemed to indicate that even though the effects of feedback "appear to be powerful" (p. 169), he cautioned that the consequences of feedback need to be carefully considered.

Clymer and Wiliam (2006) have supported Natriello's claim and stated that the collection of student grades must have instructional significance to inform the teacher about the next step(s) needed in the instructional sequence. Their work extended to how science teachers grade student work and found that grading systems need to be a dynamic and flexible system and have a greater effect to integrate "assessment for learning ... into assessment of learning systems" (p. 36). When using a standards-based grading system, the student work was viewed as a work in progress and through feedback and communication with the student, learning improved considerably when the student was able to show mastery after several opportunities to demonstrate additional learning were given and revisions allowed.

Kluger and DeNisi (1996) found the power of feedback was greatly influenced by the source and direction of the feedback relative to the task undertaken. In their meta-analysis, it was found that two of every five studies investigated, providing feedback had an undesirably negative effect on performance especially when the feedback focused on the person and not on learning task. Dweck's work (1999) focused on the use of praise as a form of feedback. Her findings were similar to Kluger and DeNisi and stated that praise can have a momentarily positive effect on students' 
attitude but it does not help their learning unless the feedback explicitly stated what the student had done well and what needed to be done to improve the performance.

Indeed, feedback can be viewed as having both positive and negative consequences depending on the source and focus of the feedback. Ames (1992) studied the factors that affect student motivation reporting that the way in which students are graded was "one of the most salient classroom factors that can affect student motivation" (p. 263), and that detrimental effects on student motivation are negatively affected by social comparisons to themselves and others. Ames (1992) concluded with "Enhancing motivation means enhancing children's valuing of effort and a commitment to effort-based strategies through the design of mastery-oriented classroom structures" (p. 271). Therefore, feedback and grading need to be focused on the mastery of the content under study and used to motivate students to persist with the task at hand (Bandura, Barbaranelli, Caprara, \& Pastorelli, 2001; Brophy, 2001).

One element necessary for students to persist with a task recalls Bruner's (1966) supposition that a student must be pre-disposed to the learning task by attending to their readiness to learn. In a study conducted with kindergarten children where particular attention was paid to designing developmentally appropriate tasks, Bergan, Sladeczek and Schwarz (1991) concluded that cognitive growth was achieved when the learning environment matched the development level of each child, and furthermore that formative assessment was a key element in giving and receiving feedback during instruction.

To assist teachers in distinguishing types of feedback Tunstall and Gipps (1996) developed a typology to determine the effectiveness of feedback in relation to student 
learning. They defined formative assessment as "that process of appraising, judging or evaluating students' work or performance and using this to shape and improve their competence" (p. 389). Feedback was re-defined and fell into two categories, either evaluative or descriptive. Evaluative feedback has a positive or negative quality usually associated with approving or disapproving of the way the work was done; the descriptive feedback had achievement or improvement as its focus and comments were related to task attainment and ways to improve the work.

Cowie and Bell (1999) working with science teachers in New Zealand distinguished between planned and interactive formative assessment they observed teachers using. Planned formative assessment had a distinct purpose to gain information from the whole class, was used to generate questions, to confirm the teachers' knowledge, and to filter out irrelevant information. Interactive feedback was embedded in teaching activities, was described as thinking and action in progress, and relied upon a more constructivist view of instruction.

\section{Formative Assessment in the Science Classroom}

Elementary science classrooms are busy places with much interaction between teachers and students and should provide a rich source of information regarding teachers' beliefs and practices with formative assessment. Because students bring many ideas and conceptual models of the way science works in the real world with them into the classroom, teachers will have to be attuned to the many preconceptions and even some misunderstandings that are present in children's minds as a science lesson begins (Morrison \& Lederman, 2003). "Students ideas are strongly influenced by their egocentric or human-centered view of the world" (Osborne \& Freyberg, 1985, p. 11) 
and have convincing reasons and explanations for why the world works the way they perceive it to be. This is just one problem that teachers may knowingly or unknowingly face as they begin to teach a science lesson. Discovering what and why students think the way they do needs to be uncovered prior to the introduction of new science concepts and formative assessment, with multiple feedback opportunities, can serve as an array of instructional strategies for teachers to implement, guide and assist students to adjust their scientific thinking (Hattie \& Timperley, 2007). Because elementary science classrooms offer a rich potential and benefit for formative assessment strategies, this particular study has focused on formative assessment in that particular context.

Wiliam (2006a) commented that in the science classrooms "teachers can often itemize the knowledge that they want students to acquire. This makes it relatively straightforward to move from monitoring ... to diagnosis ... to action" (p. 286). When Black and Wiliam (1998b) first published their formative assessment meta-analysis, they claimed there were essential elements of "recognition of the desired goal, evidence about present position, [and] understanding of a way to close the gap between the two" (p. 143, italics in original). Subsequently three essential questions were raised about whether learning was taking place, whether there was information not being learned, and if so, what actions needed to be taken to address those concepts not learned.

These same three basic questions tend to re-appear as other researchers have investigated formative assessment relative to instruction within the science classroom. Bell and Cowie (2001) worked with science teachers in New Zealand's "Learning in Science Project" asking teachers to determine if their formative assessment usage was "on-going, dynamic and progressive" (p. 544). Chappuis and Stiggins (2002) asked 
students to reflect where they are trying to go, where they are now, and how to best close the gap. Hattie and Timperley (2007) continued to ask similar questions relative to feedback by posing, how am I going, where to next, and where am I going?

Fortunately, answers are emerging to respond to these basic, but important questions. Aschbacher and Alonzo (2006) explored how students' science notebooks might serve as a formative assessment tool for teachers to determine how well students understood a science concept. Findings indicated that these science notebooks had potential for revealing student understanding; however, the primary drawback was the time it took to read and assess each notebook. Though when teachers did carefully assess what students had drawn and had written (the example was an electrical circuit), they were able to provide students with specific feedback and used that information to shape future instruction.

White and Frederiksen (1998) investigated how teaching students a metacognitively-based approach to learning science could strengthen students' inquiry skills. This specific methodology was incorporated into the instructional program for younger and lower-achieving students. They concluded that when an inquiry-oriented, model-based constructivist approach to science education was used, these students were able to use a self-reflection process to assess their progress and actually achieve at a higher level than previously demonstrated. Their findings stressed that students need to understand the criteria for success in order to produce high-quality work.

To teach students to become more self-reflective, opportunities for discussion of science concepts need to occur. As has been noted, students can have alternative explanations for scientific phenomenon and when the teacher anticipated these 
misconceptions and brought them up for discussion students could test their assumptions and engage in critical thought. These opportunities do need to be "engineered" to give students time to extend their understanding of a concept, to discuss it in small groups, to ask questions and "to provide feedback that challenges them by introducing new pieces of evidence as argument that supports the scientific model" (Black et al., 2004, p.17).

Questioning in science classrooms received close analysis by Chin (2006) to determine whether teachers use of questioning engaged students in thinking and constructing knowledge. "Teacher questioning that elicits information about students' understanding and provokes classroom dialogue is an important instrument for formative assessment" (p. 1341) because of the types of feedback that teachers gave that promoted continued thought. It has been found that the quality of the teacher's question had a direct influence on the quality of the student response to extend their thinking and draw out ideas. Similar findings supported by Black and Harrison (2001) remarked about ways questions were used to "promote classroom dialogue [and] ways of responding to such dialogue ..." (p. 55). Chin (2006) concluded her study with, "As orchestrators of classroom discourse in shaping students' learning, teachers need to position themselves as enablers of talk for thinking" (p. 1343).

To become skilled at questioning, specific coursework for pre-service teachers and professional development for in-service teachers is needed. Aram and Bradshaw (2001) worked specifically with elementary science teachers on developing skills at asking questions, listening to student responses, interacting with the students and guiding them toward more valid and meaningful ways of understanding scientific 
concepts. They relied upon a Science Interview Protocol developed by Osborne and Freyberg (1985). This instrument gave the pre-service teachers a model to lead them and the students through a question-answer period during a science lessons. In a separate study Enochs and Riggs (1990) developed an instrument to measure the selfefficacy of pre-service elementary science teachers. This instrument exposed the uncertainties and misgivings related to teaching science and helped these university professors respond to and more adequately train teacher candidates in methods to overcome perceived shortcomings with science instruction.

For in-service teachers to use or acquire more highly-developed questioning skills, concerns rest more with support from administration and district-level personnel to support use of this constructivist instructional approach. Dass (2001) found that teachers who were trained in the Collier Chautauqua Programme sought support not just from administration but from colleagues, and requested professional development to increase teachers' capacity to improve science education programs.

To strengthen science education, to give students alternate ways to demonstrate learning and to provide teachers with formative assessment strategies to bolster their instructional repertoire, research has indicated there are approaches other than traditional paper-pencil tests to assess student learning. Students' science notebooks entries can provide much detailed information that may not have been considered valid for assessment purposes. Teaching students how to self-assess and allowing students to give feedback to the teacher can be an empowering activity. Strengthening teacher's questioning and instructional conversation skills can have the added benefit that in turn strengthens science knowledge. 


\section{Professional Development}

To adequately incorporate one of these aforementioned approaches to improving science instruction with formative assessment strategies will require professional development training. Fullan (1991) remarked that "Nothing has promised so much and has been so frustratingly wasteful as the thousands of workshops and conferences that led to no significant change in practice when teachers returned to their classrooms" (p. 315). Many hours of professional development have had the best of intentions but timing, presentation, materials and follow-up have been less than fruitful to adequately improve teacher skills. With regard to formative assessment, Wiliam (2006b) stated, "In other words, the task of improving formative assessment is substantially, if not mainly, about teacher professional development” (p. 287).

\section{In-Service Programs}

Commenting on ways to improve the professional skills of science teaching through targeted training programs, Wenglinsky and Silverstein (2006) examined the results of National Assessment of Educational Progress (NAEP) science scores and teacher survey responses. In many cases where students had scored well on the NAEP, the teachers indicated their preferred professional development training methodology. To increase their scientific skills and knowledge, they desired increased training in laboratory skills, hands-on learning, the use of instructional technology and ways to use formative assessment to assess student knowledge.

These types of professional development trainings take time to develop and need to involve the teacher in active, collective participation in order to build and strengthen skills. The same holds true to deepen teachers' knowledge of science and provide a 
broader repertoire of formative assessment strategies to respond to students. Wiliam (2006a) remarked that "to realize the promise of teacher learning ... take into account the nature of teacher expertise and how teachers learn" (p. 19) by focusing on circumstances as they relate to the local conditions of the school district and student clientele in which the teachers work. Recommendations included allowing time to process the desired changes; one-day events and wholesale changes were the least desirable. Being flexible and allowing teachers to make changes and refine them within their classrooms were choice teachers felt empowered with by making the changes themselves. Having a clearly defined framework and having an accountability system in place that relied more on assessment by peers within a teacher learning community gave teachers flexible options and immediate feedback. Bell and Cowie (2001) concurred that formative assessment is not something teachers are likely to learn to do in a short session during an in-service course. It was a professional skill that developed with increasing professional experience, awareness and reflection that seemed to be the most effective.

In "How People Learn," Donovan, Bransford and Pellegrino (2000) presented research-based criteria about learning in general, but related it specifically to adult learning with regard to professional development with the intent to increase professional skills and knowledge. These criteria had four components:

(1) learner-centered, where specific inquiries were made about the needs of the teachers;

(2) knowledge-centered, for each teacher to understand why, when, and how the information presented would be useful for them and their students; 
(3) assessment-centered, with respect to practicing the new skill in one's own classroom and thus receiving feedback on its effectiveness, and (4) community-centered, by approaching new learnings relative to the larger community in which it would be implemented.

"They [professional development programs] neglect to develop the capacity in the teacher to judge successful transfer of the technique to the classroom or its effects on student achievement" (p. 24). The intent to avoid isolated implementation of new learnings and instead strengthen teacher learnings through continued contact and support through a community-centered approach was a desired outcome. Harlen (2003) also provided support for a collaborative PD model stating that teachers' lack of awareness of the benefits of formative assessment were due more often to isolation rather than a lack of training, or an unwillingness to learn.

\section{Professional Learning Communities}

Collaborative learning environments are not only helpful for teachers but also for students. A growing trend in schools is the creation of professional learning communities (PLC). Richard DuFour and the Solution Tree Institute ${ }^{\mathrm{TM}}$ (DuFour, R., DuFour, R., Eaker, R, \& Karhanek, G., 2004) have developed a professional learning community framework which challenges schools to directly tackle the tough task of specifying strategies for assisting students who struggle with content or process skills. "Failure is not an option" is advocated. Other beliefs are tied directly to having a strong curriculum framework in place with a backward design approach to assessment as well as planned options for students to go beyond the minimum requirements of the adopted curriculum. Schools that implement professional learning communities have given 
teachers an immediate and meaningful cohort of colleagues with which to plan lessons, to communicate about aligned curriculum and to design common assessments for the purpose of more accurately measuring student progress with the curriculum.

McTighe and Emberger (2006) found that with respect to common assessments, that when teachers were able to design these in a collaborative setting there were several benefits. Not only were the teachers planning for commonly-instructed content, they were also giving one another feedback about the effectiveness of their instructional strategies. Teachers in PLCs were having focused discussions about how well students were doing with the content when they compared the results of their common assessments. The active engagement of teachers examining student work allowed them to diagnostically assess the learning and give feedback to the student to improve their performance. This is a critical aspect of the assessment for learning process where the learning was still in a formative stage and when feedback was critical to student growth (Bell \& Cowie, 2001; Black et al., 2004; Chappuis \& Stiggins, 2002; Clymer \& Wiliam, 2006; Stiggins, 2002).

Just as students needed feedback to increase their learning, teachers required the same from colleagues, but more importantly, from administrators and school district personnel. Preferring to use the terminology of "teacher learning community" Wiliam (2006b) gave a note of caution regarding how to implement these professional cohorts stating that, "The creation of teacher learning communities focused on formative assessment appear to show the greatest potential for improving teaching practice and student achievement" (p. 287) and added that, "it may be that it is just too hard for 
teachers to use information at the end of a sequence of learning to adapt instruction, due to the pressure from curriculum pacing guides or sequencing charts" (p. 288).

Not leaving this effort without a note of hope, Wiliam (2006a) proposed a model for teacher learning communities to include initial teacher workshops, monthly meetings, peer observations and training for lead teachers. The model incorporated both the process (how teachers learn) and the content (what teachers need to learn) to effect teacher change. When a deliberate change of this sort is instituted within a school district it "must be based on more than superficial knowledge of a strategy or innovation ... and accept that it takes time to make an idea or practice one's own" (Sato \& Atkin, 2007, p.79).

\section{How Teachers Utilize Formative Assessment Strategies}

Formative assessment is a familiar, though perhaps not a readily identifiable practice in daily classroom life. Teachers interact with students, make on-the-spot judgments and provide support and encouragement. Formative assessment creates a venue to formalize methods of making those judgments and providing effective feedback in response to student progress. Harlen (2003) outlined five benefits of an intentional formative assessment approach specifically for an inquiry-based science approach to teaching. These benefits range from students being able to actively construct meaning and making connection to situations beyond the classroom, to students not only understanding what they are learning but also demonstrating a commitment to the learning. 


\section{Honoring Teachers' Methods}

It is important to note that there is no one right way to teach (Orlich et al., 2007), "there are no recipes to follow in a uniform way" (Black et al., 2004, p. 20) but honoring individual teachers' paths to finding ways to formatively assess student learning is essential. A teacher's belief system should have a direct impact on the effectiveness of formative assessment and potential student learning. Bell (2000) found that science teachers were often doing formative assessment but were unaware of exactly what they were doing; however, with increased awareness it was shown that they were better able to reflect on their practices and purposefully incorporate more formative-like strategies.

\section{Re-creating the Learning Environment}

Increasing awareness and defining formative-like assessment strategies for teachers has been the hallmark of studies led by Black and Wiliam and others who have continued their work with formative assessment (Black, 2000; Black, 2005; Black \& Harrison, 2001; Black et al., 2004; Black \& Wiliam, 2003; Clymer \& Wiliam, 2006; Harlen, 2003; James, 2002; James, Black, McCormick, Pedder, Wiliam, 2002; Leahy et al., 2005; Wiliam, 2006a; 2006b). Common findings from these studies indicate that teachers must become more "effective engineers" of the learning environment by (a) planning activities to allow students to express their thinking; (b) providing feedback to guide learning; (c) designing interactive and collaborative activities for students to exchange ideas; and (d) ensuring that students are active partners and participants when constructing meaning of complex science ideas. 
To effectively determine whether students are actively involved in their learning including the self-assessment component, Chappuis and Stiggins (2002) have endorsed and expanded upon what a classroom with effective formative assessment looks like. They described a learning environment where students could determine the "attributes of good performance" - reminiscent of Sadler's (1989) "fine performance" - and used rubrics to evaluate and guide their work, and demonstrate understanding through the ability to communicate with others.

\section{Developing Lesson Plans}

When a teacher plans a science lesson, several things should have occurred to address both the cognitive and affective domains in a constructivist approach to teaching and learning. First, attention should be paid to how the new information is related to past lessons, in other words a contextual relationship; the teacher has planned for ways to predict and respond to preconceptions and misunderstandings about the science concept, and has designed appropriate learning activities to address these. Secondly, attention needs to be paid to how students' past responses have generated clues about how they handle new information; for example, the teacher may have incorporated multiple intelligences to address various learning styles. Finally, the lesson design should include assessment devices both of a formative and summative nature to thoroughly determine student understanding of the new material along with frequent feedback.

Because these elements of a well-designed science lesson are not unique, but nevertheless important, an observation instrument created by Morrell, Flick and Wainwright (2004) for use with pre-service teachers at the University of Portland, 
Oregon State University and Pacific University, stated a rationale for its development as "if prospective teachers have firsthand experience in learning mathematics and science through strategies that are reform oriented" (p. 199) then they would have a strong model to carry into the development of their own pedagogy when beginning to teach. This observation instrument (OCEPT-Teacher Observation Protocol; Flick, Morrell, Wainwright, 2004) was characterized by its constructivist-based approach to teaching and learning. The components included giving students multiple problem-solving opportunities with open-ended questioning to deepen their understanding, encouraging students to express their understanding, and deliberately designing collaborative group work with real-world connections. These attributes are congruent with the science instructional practices recommended by the National Research Council's (Atkin, Black \& Coffey, 2001) "Classroom Assessment and the National Science Education Standards." These included hands-on instruction, inquiry teaching and learning, teaching process skills along with the content, practicing discovery learning, and making real-life applications.

Related to these same themes, Reynolds, Martin and Groulx (1995) explored "patterns of understanding" when studying veteran science teachers. These patterns were identified as the way a student's demeanor changed, and how students modified, changed, or altered a concept to indicate understanding. Specific student behaviors such as using shortcuts, explanations in their own words, and persistence with a task were also seen as indications of deeper learning. 


\section{Statement of the Problem and Research Questions}

The framework for much of this literature review was based on the criteria presented by Leahy et al., (2005) as they delineated five broad strategies that seemed to encompass most teaching situations in a formative assessment framework. The first criterion was clarifying and sharing learning intentions and criteria for success to ensure clear communication of goals with unambiguous directions given to students. The second criterion was engineering effective classroom discussion, questions, and learning tasks where instructional conversations included feedback between the teacher and the student. The next criterion was providing feedback that moves learners forward with clearly designed questioning strategies that allow for thinking and not just recall of facts while providing wait time to allow for expanded student thinking. Next was activating students as the owners of their own learning and finally, activating students as instructional resources for one another including self- and peer-assessments.

In subsequent studies, researchers have added to the existing knowledge base regarding the value of formative assessment. Table 2.1 details the relationship between the Leahy et al., (2005) criteria and relevant contributions made within this field of formative assessment. 
Table 2.1

Comparison of Leahy et al. Criteria with Selected Other Relevant Studies

Leahy, Lyons, Thompson \& Wiliam (2005)

Five Broad Strategies:

Studies Adding to Existing Knowledge

Assessment for Learning

about Formative Assessment

Clarifying and sharing learning intentions and criteria for success

Chappuis and Stiggins (2002)

Detailed a learning environment where students can determine the "attributes of a good performance" reminiscent of Sadler's (1989) "fine performance"

Engineering effective classroom discussions, questions and learning tasks

Black and Wiliam's (1998a)

Teachers plan activities to allow students to express their thinking and provide feedback to guide learning

Morrell, Flick and Wainwright (2004)

Giving students multiple problem-solving opportunities with open-ended questioning to deepen their understanding

NRC (2001)

Encourages inquiry teaching and learning with increased student teacher interaction

Providing feedback that moves learners

Black \& Wiliam (1998a)

forward

Design interactive and collaborative activities for students to exchange ideas and construct meaning of complex science ideas

Chappuis \& Stiggins (2002)

Demonstrate understanding through the ability to communicate with others

$\underline{\text { NRC (2001) }}$

Practice discovery learning to increase meaning

Reynolds, Martin \& Groulx (1995) When students modified, changed or altered a concept to indicate understanding and were able to explain in own words 
Activating students as owners of their own learning

Activating students as instructional resources for one another
Morrell, Flick \& Wainwright (2004) Encouraging students to express their understanding through questioning strategies

Reynolds, Martin \& Groulx (1995)

When students changed or altered an idea to demonstrate understanding and making real-life connections

Black \& Wiliam (1998a)

Ensure that students are active partners in learning

Chappuis \& Stiggins (2002)

Use rubrics to evaluate and guide work

Even though the field of formative assessment has received great attention in the decade since the Black and Wiliam (1998a) meta-analysis, and significant contributions have been noted throughout this literature review, there are still questions which arise. Popham (2009) recognized this uncertainty writing, "One deterrent to its [formative assessment] use is the considerable confusion among educators regarding what formative assessment actually is." This study proposes to add clarification to the kinds of formative assessment practices that occur within the elementary science classroom and describe what teachers are doing that is formative, that is, assessment for learning, rather than assessment of learning. The specific research questions that guided this study are:

1) What formative assessment strategies do teachers value?

2) What formative assessment strategies do teachers use?

3) How do teachers respond to student learning needs with formative assessment?

4) What effect does professional development have on value and use of formative assessment? 


\section{CHAPTER III}

\section{METHODOLOGY}

The data for this descriptive study entailed collecting both quantitative and qualitative information. Data sources included responses to the Formative Assessment Questionnaire (FAQ) with 30 Likert-type questions for both value and use of four categories of formative assessment strategies (Neesom, 2000). The teachers who responded could expand upon their use of these strategies by completing six shortresponse statements. Therefore, a rich source of data was obtained from many of the 274 teachers who completed the FAQ. The value each respondent placed upon the strategies, the use of those strategies, and a written explanation about how the strategies were implemented with students in the classroom provided multiple perspectives about formative assessment. Other important data sources were observations of science instruction and interviews with four teachers; artifacts from the science lessons were also provided.

Quantitative analysis of the FAQ utilized four statistical models which included correlations, ANOVA, Factor Analysis and Structural Equation Modeling to determine the effect of variables and their impact on formative assessment strategy value and usage. As teachers completed the FAQ, they were asked to provide information about grade(s) taught, length of teaching experience, and the kinds of professional 
development trainings relative to formative assessment. These data were quantified and used for the statistical models.

A mixed methodological approach has been employed for this descriptive study, combining quantitative data to sample across a large number of teachers, and complemented by qualitative data to enrich and enhance confidence in data interpretation (Tashakkori \& Teddlie, 1998). To achieve the goals of this study, it is important to know teacher beliefs and motivations in order to portray teacher practices while using formative assessment strategies during science instruction in elementary classrooms. Secondly, it is important to compare and contrast how teachers employ formative assessment strategies in response to student learning and to develop a profile of teachers using formative assessment.

\section{Participants \\ School District Context}

This study took place in a school district where formative assessment had become one of the foci of the district's improvement initiative. This focus was situated within the framework of Professional Learning Communities (PLC) as advocated by Richard DuFour and the Solution Tree Institute ${ }^{\mathrm{TM}}$ (DuFour et al., 2004). In preparation for this district-wide focus on professional learning communities, some administrators and some lead teachers attended summer conferences hosted by the Solution Tree Institute and shared gained information with colleagues as the 2007-2008 school year began.

One component of the PLC framework challenges schools to directly address the rigorous task of developing specific strategies for assisting students who struggle 
with content or process skills. This belief system advocated by the PLC framework was congruent with that of the school district's mission, policies and professional development intentions. Each school had been asked by the superintendent to implement PLCs to provide teachers an immediate and meaningful cohort of colleagues with which to plan lessons, to communicate about aligned curriculum and to design common formative assessments for the purpose of more accurately measuring how students progressed with the curriculum.

Implementation of the PLC framework and the associated emphasis on formative assessment (FA) occurred over a relatively short period of time. District-level administrators held a one-day FA summer workshop and two first semester, after-school briefings for lead teachers and additional personnel (district-training). The school-based administrators and lead teachers guided teachers through the implementation period via faculty meetings, grade-level and department meetings, and formal classroom observations. Within this FA implementation period, classroom teachers learned about and were simultaneously asked to implement the professional learning community philosophy with the primary training from the school administrators and lead teachers (school-based training).

When a deliberate change of this magnitude is instituted within a school district it "must be based on more than superficial knowledge of a strategy or innovation ... and accept that it takes time to make an idea or practice one's own" (Sato \& Atkin, 2007, p.79). The use of formative assessment strategies was one key element district teachers had been encouraged to utilize in their classrooms to assist students with mastering content. 
This school district has nine elementary schools with 5521 students (K-5) out of a total population of 11,911 students (K-12) during the 2007-2008 school year. Table

3.1 presents demographic data for all students in this district.

Table 3.1

Demographics for All Students in the School District

\begin{tabular}{ll}
\hline Description & Percentage of students \\
\hline Students receiving Free Lunch & $13 \%(1564$ students $)$ \\
Students receiving Reduced Lunch & $3.7 \%$ (445 students $)$ \\
Total Exceptional Children Population & $14.8 \%$ (1767 children ages $3-21$ \\
yrs.) & \\
English Language Learners & $2 \%$ of the total population \\
& $(60 \%$ are in elementary schools $)$ \\
Ethnicity & $3 \%$ African-American \\
& $3 \%$ Hispanic \\
& $1.2 \%$ Pacific Islander \\
& $2 \%$ Other includes Native \\
& Americans
\end{tabular}

Note. Data are for the entire school district.

\section{Elementary Teachers}

Focusing on elementary teachers' use of formative assessment with their students has had limited examination. This study took place in elementary science classrooms looking at the implementation of formative assessment utilized during science instruction.

An individual FAQ was distributed to every consenting elementary teacher $(n=274)$ regardless of grade level or specialty area during a regularly scheduled faculty meeting at each of the nine elementary schools in the district. For more intensive study, 
four teachers were purposively selected from a pool of 18 volunteers for both classroom observations and one-on-one interviews. These teachers were chosen by the researcher's dissertation co-chair based upon data generated by responses on the FAQ. The selection criteria were based on purposively selecting case study participants representing a wide range of aggregate FAQ responses. The researcher did not know FAQ results for these four teachers during the classroom observations and personal interviews or data analysis.

\section{Instruments}

\section{Formative Assessment Questionnaire (FAQ)}

A questionnaire was used to survey knowledge and beliefs the teachers held regarding the identification of formative assessment strategies that they used. The original "Formative Assessment" questionnaire was developed by the Qualifications and Curriculum Authority (QCA, 2000). This organization is the equivalent of a national education department whose mission includes, "a vital role in the development, delivery and reform of the education and training framework for England" (http://www.qca.org.uk/).

Most of the data from this questionnaire are Likert ratings asking respondents to rate the value of specific formative assessment strategies and to indicate frequency of usage of each strategy. The FAQ also contains six short-response statements regarding the advantages and disadvantages of formative assessment. This researcher added some demographic questions about the respondent to the original questionnaire (see Appendix A). 
This instrument was created and validated by the Learning How to Learn Project (L2L) which is funded by the Economic and Social Research Council, London. Researchers from the University of Cambridge, Kings College London, University of Reading, and the Open University have collaborated to investigate and develop a greater understanding about learning and how learning occurs in classrooms. The particular questionnaire used in this study was a modified version of the original one developed for studies conducted by Neesom (2000) and her research group. The original questionnaire has been used in several studies commissioned by the Assessment Reform Group (the research arm of the QCA) and its trustworthiness has been established after repeated uses. James, Black, McCormick, Pedder and Wiliam (2006), all associated with the L2L Project, reported using a logic model of three levels (classroom, school and "network", i.e., school district) to acquire reliability data. The first level, classroom, was where this study's attention was focused and the conditions under which formative assessment occurred. Multiple regression analysis was used by James et al., (2006) to explore the relationships between the values and usage of formative assessment. Analysis of the qualitative data utilized constant comparative analysis to establish validity. Permission to use this questionnaire was obtained from Professor James at the Institute of Education, University of London (personal communication, January 8, 2008).

A design feature of this questionnaire was to determine how teachers (a) involve students in their own learning; (b) utilize student work as models during instruction; (c) employ various kinds of feedback; and (d) incorporate student self-assessment strategies (Neesom, 2000). These four elements are directly related to the "non-negotiables" 
criteria established by Leahy, Lyon, Thompson and Wiliam's (2005) study of classroom formative assessment; they define desirable instruction in an assessment for learning context.

\section{Observations}

The number or length of classroom observations was not specified, thus the teachers allowed the researcher to visit their classrooms to observe their science lesson instruction based upon their unique schedules. Each teacher was contacted once names were disclosed by the researcher's dissertation co-chair. Agreement was reached between each teacher and the researcher as to dates and times for observations and a schedule was devised. Classroom observations of these teachers occurred at their convenience and preference. Table 3.2 details the observation schedule.

Table 3.2

Observation Schedule for the Case Studies

\begin{tabular}{lcll}
\hline Teacher & $\begin{array}{l}\text { Number of } \\
\text { Observations }\end{array}$ & $\begin{array}{l}\text { Length of Each } \\
\text { Observations }\end{array}$ & $\begin{array}{l}\text { Span of Time for } \\
\text { All Observation }\end{array}$ \\
\hline Jordan & 2 & 60 minutes & 4 school days \\
Tina & 3 & 55 minutes & 7 school days \\
Virginia & 4 & 75 minutes & 4 school days \\
Leigh & 5 & 40 minutes & 8 school days \\
\hline
\end{tabular}

Note. All teacher names used in this study are pseudonyms.

The researcher did make a request for written lesson plans to analyze congruency and divergence from what had been planned to what actually was observed during the science lesson; any lesson plan format was accepted. During the 
observations, the researcher scripted the events and noted interactions that occurred in the classroom between teacher and students and made anecdotal notes. These raw data served as the basis for subsequent analysis of the observations. Foci for the observations and scripted notes were determined by the analysis plan for this data source; see "Analyses" section below for descriptions of the aspects of the classroom instruction that were of particular interest for this study.

\section{Interviews}

In addition to observations, the four teachers were each interviewed once. The interview protocol, a Teacher Belief Instrument (TBI) was developed by Luft and Roehrig (2007) and asked basic questions about instruction. Answers to the seven questions defined a teacher as having a teacher-focused, transitional or student-focused

approach to science instruction (see Appendix B). This interview protocol was selected because of the intrinsic connection between rich, thorough use of formative assessment strategies and a strong student-focused approach to science instruction.

Procedures

The $F A Q$

After a brief introduction regarding the purpose of the questionnaire, the FAQ was distributed to each consenting K-5 elementary teacher in the school district $(n=274)$ regardless of grade level or specialty area during a regularly scheduled faculty meeting. Teachers completed and returned the questionnaire during the faculty meeting. All teachers were given the opportunity to indicate willingness to participate further in this study as one of the case study participants. All were informed that their consent would involve both classroom observations and an interview. From the affirmative responses 
received, teachers were stratified by grade level and aggregate totals of FAQ responses; the goal was to purposively select teachers that would represent a broad range of both grade levels and responses to the FAQ.

The questionnaire measured teachers' background knowledge regarding formative assessment. Black et al. (2004) suggested a first step to incorporate formative assessment strategies was to reflect and consider what is currently being done and then evaluate its effectiveness. The responses to the Likert items and short-response statements was an important compilation of data to determine a baseline for teachers' perceptions regarding formative assessment strategies.

\section{Observations}

The teachers provided convenient times and dates for classroom observations of science lessons. The researcher provided no contingencies, prompts or expectations to the teacher to indicate that any particular strategy, content, or learning activity was more or less appropriate; the only stipulation was that the lesson addressed science content. The teacher controlled the variables regarding time, date and specific content of the lesson. However, due to the fact that the questionnaire and interview questions addressed formative assessment, it was presumed that the teacher would recognize that formative assessment was one of the main objectives of the observation. Prior to the observation, the teacher provided a lesson plan in a format of their choice.

During the observation, hand-scripted notes were taken about how the lesson was conducted. The researcher attempted to remain unobtrusive by sitting in a corner of the room to avoid interrupting the normal flow of instruction. Scripted notes focused on the progression of the lesson with particular attention directed toward the five elements 
of formative assessment as defined by Leahy, et al., (2005). Scripted notes also included questions posed by the teacher and responses by the student, whole group assessment strategies (e.g., quiz, exit slip), one-on-one instructional conversations or other instructional strategies. Any worksheets or handouts distributed to the students were collected as an artifact of the lesson.

\section{Post-Observation Interview}

Immediately following each observation, the researcher asked the teacher lesson-specific questions for clarification regarding any uncertainties about what the teacher or students had done during the lesson. These teachers were asked whether each would like to review the scripted notes (none made this request) and whether follow-up questions would be favorably received via email should the researcher have additional

questions or concerns. In each case, the teacher was amenable to these suggestions.

\section{Interviews}

The teachers were contacted and arrangements were made via email for a oneon-one, structured interview at the teacher's convenience. To reduce any potential anxiety about the interview and to place the teachers at ease, the seven interview questions were sent to the teacher in advance of the interview date (see Appendix B). The interview occurred in the teacher's classroom (a familiar setting) and all responses were audio-taped. The Teacher Belief Instrument (Luft \& Roehrig, 2007) was used as the interview protocol. After conducting the interviews, the recorded responses were transcribed verbatim. The interview results served as a data source to triangulate the questionnaire responses with the observational data for purposes of adding depth to all data sources. 
One goal for the interviews was to develop a richer understanding of the teachers' values, beliefs and knowledge about how students learn and their use of formative assessment strategies to aid in that learning process. It also provided a window into the instructional pedagogy the teachers exemplified during their instruction and added clarity to the original survey responses. The interview was a critical element in the triangulation of the data sources for this study. Table 3.3 (at the end of this chapter) displays researcher-anticipated correspondence between interview questions and the four sub-constructs of the questionnaire. Participant responses suggested different and/or additional correlations which was dependent upon their unique responses during the interview.

Analysis

\section{Qualitative Analysis}

\section{The FAQ Short-Response Statements}

Due to the open-ended format of the six short-response statements, a wide variety of responses were submitted based upon respondents' individual experiences with formative assessment. During the initial reading of all responses for the six statements, the researcher utilized a grounded theory approach with an open coding approach to allow codes and categories to emerge freely resulting in a constant comparative method of data analysis from what the respondent had written to acquire a general sense of what was considered to be formative assessment strategies (Glaser \& Strauss, 1967). This process resulted in a very broad range of categories across the six statements and across the 274 respondents; some statements aligned directly within the Black and Wiliam framework, while others did not. 
In an attempt to determine trends within the data that were consistent with formative assessment definitions, the researcher undertook a second reading utilizing the criteria specified by the Likert items, that is, involving students, using quality models, providing feedback and self-assessing. In using this literature-guided approach, the analysis had more structure. While some themes arose from the statements that were not directly comparable to the criteria framed by the Likert items, some consistent themes did arise. The researcher discovered that this strategic approach was more appropriate for statements \#3-\#6, but not appropriate for statements \#1 and \#2.

Therefore, two coding schemes were adopted. An open coding system was used for statements \#1 and \#2 since these statements did not contain prompts to which the respondent was forced to respond within defined parameters. As a result three categories emerged from these written statements regarding how teachers used formative assessment within their instructional repertoire: (a) how formative assessment was used for lesson planning purposes, (b) how teachers provided feedback to their students, and (c) how teachers collected data from their students to understand current levels of understanding (see Tables 4.14 and 4.15).

By comparing written responses for questions \#3-\#6 to defined criteria of formative assessment, a more restricted approach to coding was utilized. Responses to those questions were categorized into one or more of the four areas that are consistent with the Black and Wiliam's (1998a) definition of formative assessment, i.e., involving students, modeling quality work, providing feedback, self-assessment (see Table 4.13).

The researcher collaborated with the dissertation co-chair and a consensus was reached that the information contained in statements \#3-\#6 was important, but not 
critical to answering the research questions. Instead, a deliberate focus was shifted to the teachers' responses for statements \#1 and \#2 since these more directly addressed what teachers knew about formative assessment and how they used it. The assumption was that since individuals had just responded to 30 items regarding value and use, their statements may have reflected some aspect of those items as they responded to statements \#3-\#6. This approach provided a more manageable data set for operationalizing a coding scheme (Miles \& Huberman, 1994).

After agreement about the definition for the codes, the dissertation co-chair and researcher independently coded the open-response data to determine interrater reliability. To achieve inter-rater results, a portion of the responses were coded together for training purposes; then a second portion of the responses were coded independently ( $28 \%$ of the sample). Interrater reliability between the researcher and co-chair resulted in $82 \%$ agreement for statement $\# 1$ and $85 \%$ for statement $\# 2$. Any differences of opinion were discussed to achieve consensus.

\section{Observation Data Analysis}

The foundation of formative assessment is situated in a constructivist philosophy. The formative assessment questionnaire supported involving students in their work, modeling quality work, giving feedback and utilizing student selfassessment; the tenets of this questionnaire aligned with the social construction of knowledge. The observation data collection form was aligned with the Leahy, et al. (2005) framework. For each of the five non-negotiable criteria previously listed, the researcher identified specific instructional strategies to operationally define each criterion. Those criteria are detailed in Table 4.18 in Chapter IV. The placement of 
these defined criteria is located in Chapter IV as opposed to this chapter to position the data within a logical sequence.

However, for the purpose of analysis, some detail is provided here. The observation data were collected using a form created by the researcher. Reflecting on the circumstances in which the actions occurred, the scripted notes were read and coded utilizing the criteria establish by Leahy et al. (2005) and other relevant criteria denoted in the literature review. The actions of the teacher, and often the students, were situated into one of the five non-negotiable categories (see Appendix C - Formative Assessment Observation Form; also see Table 4.18).

\section{Interview Data Analysis}

Each interview was analyzed based upon responses the teachers made to each of the seven interview questions on the TBI. The researcher coded the response to each question by using a concept map of sample responses; the sample responses were provided by the instrument authors (Luft \& Roehrig, 2007). After placing segments of each response onto the concept map, statements were holistically evaluated to determine whether the entire response provided evidence of a more teacher-focused or a more student-Focused position or a combination of any of the five categories (traditional, instructional, transitional, responsive/early constructivist and reform-based/experienced constructivist). Once all responses were coded, a pattern emerged indicating an overall positioning of the teacher within the teacher belief continuum as to approaches to science teaching.

To provide a measure of confidence with regard to this coding system, the dissertation co-chair, a science education professor, also used the concept maps to code 
all interview responses for each case study. After discussing the coding scheme, consensus was reached as to the determination of whether the teacher was more teacherfocused or student-focused in their approach to science education. An actual percentage was not calculated.

\section{Quantitative Analysis}

In addition to the short-response statements from the FAQ, each respondent provided demographic data (e.g., current grade level, years teaching experience, and formative assessment professional development training). Additionally, teachers made judgments (in a 5-point Likert scale format) regarding the perceived value and frequency of use of 30 specific formative assessment strategies; the questionnaire effectively contained 60 Likert items because of the two independent judgments made about value and use for each formative assessment sub-construct.

Factor Analysis and Structural Equation Modeling.

A factor analysis of the two sets of 30 Likert questionnaire items was conducted to confirm instrument validity across the four reported use and value constructs conceptualized as collectively measuring a teacher's formative assessment perception and use. For those items which load satisfactorily on their respective construct, a structural equation model was designed to explore the relative weightings of each item for each construct, as well as the relative weighting of each of the four constructs on the overall latent variable of formative assessment. These analyses provided some insight into teachers' perceptions of which aspects of formative assessment were of the most value and which are used more frequently. 
An ANOVA was used to determine the variance within and across grade levels for the formative assessment score totals. This was explored for each of the four constructs designed into the questionnaire: involving students, modeling quality work, providing feedback, and opportunities for student self-assessment. Each of these constructs was further analyzed for the use and value scores to determine whether differentiation existed among grade levels regarding these aspects of formative assessment.

Teachers' responses to the open-ended statements on the questionnaire addressing the nature of professional development (PD) training received were used to generate an ordinal code (low, medium, high) quantifying the relative amounts of PD associated with formative assessment. This categorical variable was used to define groups of teachers based upon the kinds of PD with regard to the topic of formative assessment, and scores of these groups on formative assessment use and value were compared using an ANOVA.

\section{Correlations}

In addition to comparing responses within and across groups, two correlations were explored. The first investigated whether teachers' years of experience correlates with the total formative assessment score on the questionnaire; the second investigated whether the use and value category built into the questionnaire for each of the 30 Likert items correlated with each other.

These various quantitative results were combined with qualitative results obtained from classroom observations, teacher interviews, and written responses to 
open-ended prompts. These qualitative analyses provided an additional avenue and insight for interpreting results emerging from the quantitative analysis.

\section{Correspondence between Interview Question and FAQ Items}

The interview protocol (TBI) captured teacher's beliefs regarding instruction. Luft and Roehrig (2007), developers of the instrument, stated that "it is important to make beliefs "visible"' (p. 41). For data triangulation purposes, qualitative data generated by individual interview questions were posited to correspond to questionnaire sections as indicated in Table 3.3. The correspondence was determined by an identification of which questionnaire constructs were implied by each question; this identification was undertaken by a team consisting of the researcher and two university professors of science education. The four constructs of the questionnaire were coded as indicated: involving students in their learning (QI), modeling quality work (QM), giving feedback (QF), and providing students with self-assessment opportunities (QS). 
Table 3.3

Correspondence between Interview Questions and Questionnaire Items

Interview Questions

Constructs (Luft \& Roehrig, 2007)

Questionnaire

(Neesom, 2000)

How do you maximize student learning in your classroom? QI, QF, QS

How do you describe your role as teacher?

QI, QF

How do you know when your students understand?

QI, QF, QM, QS

In the school setting, how do you decide what to teach and what not to teach?

$\mathrm{QF}, \mathrm{QM}$

How do you decide when to move onto a new topic in

QF, QM, QS

your class?

How do your students learn science best?

QI, QF, QM

How do you know when learning is occurring in your

QI, QM, QS

classroom?

Note. QI - Questionnaire/Involving students in their learning. QM - Questionnaire/Modeling quality work. QF - Questionnaire/Giving feedback. QS - Questionnaire/Student self-assessment

Luft and Roehrig (2007) identified a range of possible responses to the interview questions which were categorized as "teacher-focused" or "student-focused" across a spectrum of five instructional perspectives: traditional, instructive, transitional, early constructivist and experienced constructivist. There is a decidedly constructivist interpretation lens applied to this interview instrument, which is compatible with formative assessment. For this study instruction that is teacher-focused or studentfocused has been taken into consideration for each of the case studies. 


\section{CHAPTER IV}

\section{RESULTS}

The results of this study are presented in three sections. The first is data screening and processing where the questionnaire was re-coded, and outliers and missing data were addressed. Data processing provided an analytical framework to examine professional development training and grade level categorization. The data shape was detailed.

The second section presents quantitative results. These results were obtained using factor analysis, correlations, ANOVA and structural equation modeling. The third section of this chapter reports on a detailed analysis of qualitative data which examined teacher responses to the questionnaire short-response statements along with case study data (classroom observations and interviews) that were extensively collected for each of the four teachers.

\section{Data Screening and Processing}

\section{Data Screening}

Prior to conducting analyses, the raw data were screened and processed. Data screening identified outliers or other problematic entries such as cases with extensive missing data or other characteristics that may unduly impact results. Data processing included the generation of categorization codes for teacher characteristic variables of 
professional development opportunities and grade levels taught. These categorical codes then permitted analyses of groups.

To maintain maximum confidence in results, the goal was to retain as much of the questionnaire data as possible. Initial data screening identified two respondents who appeared to have reversed the Likert codes on the teacher questionnaire. A second readily apparent aberration was another two respondents who omitted answering many of the items. Even though a number of respondents omitted a few items, these two respondents had significant omissions. The data screening process described below ultimately resulted in discarding 4 of the 274 questionnaires. The sections below detail the process of identifying these four problematic cases.

\section{Outliers}

Screening the data for outliers revealed two respondents whose overall rankings of formative assessment strategies substantially varied from the remaining respondents. Two respondents had mean value scores of 4.2 and 4.8 (on a 5-point scale), and the next nearest score among the remaining 272 respondents was 2.4 . Reviewing the specific rankings of these two respondents while simultaneously reviewing the questionnaire suggested that these two appeared to have reversed the 5-point Likert codes specified on the questionnaire. Although the questionnaire had been structured to position the least positive responses ("no value" and "never") at the extreme right of the scale (indicated by high numbers), it is quite feasible that these respondents instinctively inadvertently coded the more positive responses ("very valuable" and "most lessons") by circling the right side (high numbers) of the scale (see Appendix A). This supposition is strongly supported by the data because these two response patterns were distinctively different 
from the other 272 respondents. Eliminating these two outliers eliminated the disproportionately large influence these two outliers would potentially have on subsequent data analysis. For example, the correlation coefficient between value and use scores with these two outliers included was .485; without it was .552. This removal of only 2 cases would not substantially impact the power of the analysis because of the remaining large sample size. This reduced the total number of respondents for data analysis to 272 .

\section{Re-coding the Questionnaire Data}

Screening for the outliers mentioned above raised a concern about intuitive interpretations of the questionnaire rankings. The original developers of the questionnaire structured the Likert scales to range from $\mathrm{A}$ to $\mathrm{E}$ for value and 1 to 5 for use of each formative assessment strategy. The A responses were coded as 1, B as 2, C as 3 , etc., when originally entering response data. In both cases, the lower value represented the most value or most use; conversely, the higher value represented the least value or least use. Due to its counter-intuitive nature, an initial data processing step included re-coding the scale so that "1" equaled the least value/use and " 5 " equaled the most value/use. This recoding-for purposes of reporting results in this study-facilitated subsequent interpretations of the results since high scores would now represent a particular formative assessment strategy that was indeed highly valued or frequently used. Data reported throughout this study are all based upon this recoding. Missing Data

In addition to outliers, the data were screened for individual respondents who were missing large percentages of data on the questionnaires. Of the 60 rankings 
requested on the questionnaire (30 strategies with a separate value and a use ranking each), only 2 of the remaining 272 respondents failed to respond to substantially more than half the items. Of the 60 rankings, these two respondents were missing 28 and 32 ; a frequency count reveal the next nearest respondent with missing data had 14 missing rankings. Because this high percentage of missing data from two respondents may be indicative of a potential validity threat from responses that may not have been thoughtfully considered, the data from these two individuals were eliminated from further analyses, resulting in a total sample of 270.

Approximately $70 \%$ of the remaining 270 respondents had indicated rankings for all 60 items; the remainder had at least one missing ranking, but $25 \%$ of the total sample was only missing 4 or fewer, leaving only approximately $5 \%$ of the sample missing more than a handful of responses. To eliminate the difficulty of comparing raw score totals that would vary because of these missing data, mean scores for each of the four sub-constructs of the questionnaire as well as for total scores were used for later analyses. The total number of respondents to be considered for further analysis stands at 270.

\section{Data Processing}

\section{Professional Development Categories}

One potentially important mediating variable was the type and extent of professional development (PD) teachers had participated in as part of the professional learning communities focus on the topic of formative assessment. On the questionnaire, there were originally five PD classifications (see Appendix A) where the respondents could select as many as applied. The scope of the PD training respondents could 
indicate included: national or regional conferences, district training PD, school or teambased PD, and individual pursuits such as taking classes or reading professional books. These choices presented a hierarchy of scope from large scale to more local scale. Because respondents could indicate as many PD options as appropriate, this generated a code that was a concatenation of the various choices selected. The data showed that there was a strong pattern of those who had been involved in PD in largerscale venues such as national conferences or district leadership PD and those who had been involved in additional PD in other venues (see Table 4.1). This pattern provided a substantial justification for adequately representing an individual's PD experiences exclusively by the top level code, because the top-level code generally represented an aggregation of many of the codes below them. This resulted in teachers' self-reported PD experiences being classified into one of four non-overlapping categories. 
Table 4.1

Patterns of PD Training Experiences Related to Formative Assessment

\begin{tabular}{|c|c|c|c|c|c|c|c|}
\hline \multicolumn{2}{|c|}{$\begin{array}{l}1=\text { National } \\
\text { or Regional }\end{array}$} & \multicolumn{2}{|c|}{$2=$ District } & \multicolumn{2}{|c|}{$3=$ School-based } & \multicolumn{2}{|c|}{$\begin{array}{l}4 \text { or } 5=\text { Individual } \\
\text { Pursuit (class, book) }\end{array}$} \\
\hline Code & $n$ & Code & $n$ & Code & $n$ & Code & $n$ \\
\hline 12345 & 16 & 2345 & 42 & 345 & 9 & 45 & 5 \\
\hline 1345 & 3 & 245 & 4 & 35 & 13 & 4 & 1 \\
\hline 1234 & 2 & 235 & 8 & 34 & 11 & 5 & 9 \\
\hline 135 & 1 & 234 & 30 & 3 & 14 & & \\
\hline 125 & 1 & 25 & 2 & & & & \\
\hline 123 & 1 & 24 & 2 & & & & \\
\hline \multirow[t]{2}{*}{12} & 1 & 23 & 21 & & & & \\
\hline & & 2 & 7 & & & & \\
\hline \multicolumn{2}{|c|}{$\begin{array}{l}84 \% \text { had } 4 \\
\text { or more codes }\end{array}$} & \multicolumn{2}{|c|}{$\begin{array}{l}72 \% \text { had } 3 \\
\text { or more codes }\end{array}$} & \multicolumn{2}{|c|}{$\begin{array}{l}70 \% \text { had } 2 \\
\text { or more codes }\end{array}$} & & \\
\hline
\end{tabular}

Note. Each numerical code consists of a concatenation of the five available codes (since each respondent could choose as many as was appropriate). Columns are organized by the largest scale (smallest code number) that is present in the concatenation. Based on this table, all respondents in a particular column were grouped into a PD code based on the largest scale setting of their PD experiences.

\section{Grade Level Categories}

Another teacher characteristic variable was the grade(s) levels that respondents reported teaching. Consideration had been made about creating schemes such as, $\mathrm{K}-1$, 2-3, $4-5$ or $\mathrm{K}-2,3-5$; however, because there was extensive overlap of grades, creating non-overlapping discrete groups was impractical. A decision was made to create three groups in order to have the possibility of greater sensitivity to group differences in the 
analysis. The three groups (early, middle and late) captured the majority of the grade groups taught across the nine elementary schools.

The "early" group included Kindergarten, $1^{\text {st }}$ and $2^{\text {nd }}$ grades. Second graders were included in this group only when combined with a first-grade group. Specifically, 23 teachers reported teaching a combined $1^{\text {st }} / 2^{\text {nd }}$ grade class. The "middle" group included $2^{\text {nd }}, 3^{\text {rd }}$ and some $4^{\text {th }}$ grade students. Like the "early" group, only those fourthgrade students who were combined with third-graders were included; 22 teachers reported teaching a combined $3^{\text {rd }} / 4^{\text {th }}$ class. Lastly, the "late" group included $4^{\text {th }}$ and $5^{\text {th }}$ grade students. Categorizing the higher grade when combined with a lower grade was consistent across all three grade categories (early, middle and late). The logic for categorizing in this manner was the consideration of classroom dynamics that are often established to help all students succeed. These dynamics and supports for the younger students would likely remain to meet the needs of the younger students in the class in terms of formative assessment. Thus, the older students in these mixed age classrooms were likely to have experienced formative assessment similar to that experienced by the younger students.

Table 4.2 summarizes the resulting four grade level categories: all grades (K-5), early elementary, middle elementary and late elementary. Teachers who reported teaching all (or nearly all) grade levels K-5 were mostly specialized area teachers who taught Art, PE/Health, Special Education, and Music; some were special educations classes. 
Table 4.2

Grade Level Categories

\begin{tabular}{ll}
\hline Categories & Description \\
\hline All Grades & Includes teaching kindergarten through $5^{\text {th }}$ grade \\
Early Elementary & Includes teaching grades $\mathrm{K}, 1, \mathrm{~K}-2, \mathrm{~K}-1-2$, or $1-2$ \\
Middle Elementary & Includes teaching grades $2,2-3,3$, or $3-4$ \\
Late Elementary & Includes teaching grades $4,4-5$, or 5 \\
\hline
\end{tabular}

\section{Data Shape}

Because many data analytic techniques are grounded in analyses that seek to explain and partition variance in the data, the amount of variance in the input data is an important factor to consider. Another important factor is the distribution of the data; many techniques assume the data are normally distributed, which is an aspect of the data that should be reviewed. Table 4.3 summarizes critical features of the data distribution.

Table 4.3

Data Distribution Characteristics $(n=270)$

\begin{tabular}{lccccc}
\hline & Range & Mean (SD) & Variance & Skewness & Kurtosis \\
\hline Mean value score & $3.63-5.0$ & $4.46(0.31)$ & 0.095 & -0.270 & 0.459 \\
Mean use score & $2.0-5.0$ & $3.83(0.49)$ & 0.242 & -0.310 & 0.556 \\
\hline
\end{tabular}

Note. The questionnaire data are based on a 5-point Likert scale.

The skewness and kurtosis in Table 4.3 show that the distributions of both the value and the use scores closely approximate a normal distribution. The range, standard deviation, and variance all suggest that the variance of these data is somewhat 
restricted, particularly for the value score. This restricted variance suggests the data may lack sensitivity to potentially important differences. Although subsequent analyses that incorporate variance can provide useful and interpretable results, the restricted variance suggests a cautionary note be applied to those outcomes.

Quantitative Results

\section{Factor Structure of Questionnaire}

Factor analysis was used to determine whether the four sub-constructs of the formative assessment questionnaire (involving students, modeling quality work, giving feedback and self-assessment) were evident for this sample. Results indicated that these individual, separate sub-constructs were indistinguishable, that is, not well delineated by the data; the instrument functioned strongly to measure one construct, and subconstructs were not well-defined separately from the overall construct of formative assessment (see Table 4.4). 
These results indicate that formative assessment as an instructional strategy may not be easily separated into these four sub-constructs, that is, questionnaire respondents who tend to value one formative assessment sub-construct also tend to value the three other sub-constructs. Likewise, people who tend to use one formative assessment subconstruct tend to use the others.

\section{Correlations}

Years of Teaching Experience Correlated with "Value" and "Use" Scores

To explore the potential relationship between teaching experience and formative assessment strategies, the correlation between years of teaching experience and value or use of formative assessment strategies was calculated. Not every teacher reported years of experience (mean $=10.35$ years, $S D=8.68$ ), which resulted in 247 data points included in this correlation computation. The correlation of years of teaching and the total mean value score for these teachers indicated there was an insignificant correlation (Pearson $\mathrm{r}=-.074 ; \mathrm{p}<.250$ ). The same result of an insignificant correlation held true for years experience and use of formative assessment strategies (Pearson $r=-.006 ; p<$ $.899)$.

Correlation Between Total Mean "Value" Score and Total Mean "Use" Score.

Working from an assumption that a teacher's valuing of a particular formative assessment strategy may be a predictor of its actual use in a classroom setting, the relationship between these two scores was investigated. Correlating a respondent's total mean value score with their total mean use score (see Figure 4.1) resulted in a significant correlation (Pearson $r=.555 ; \mathrm{p}<.001$ ), showing that approximately $31 \%$ of the variance in the use score was explained by the value score. 


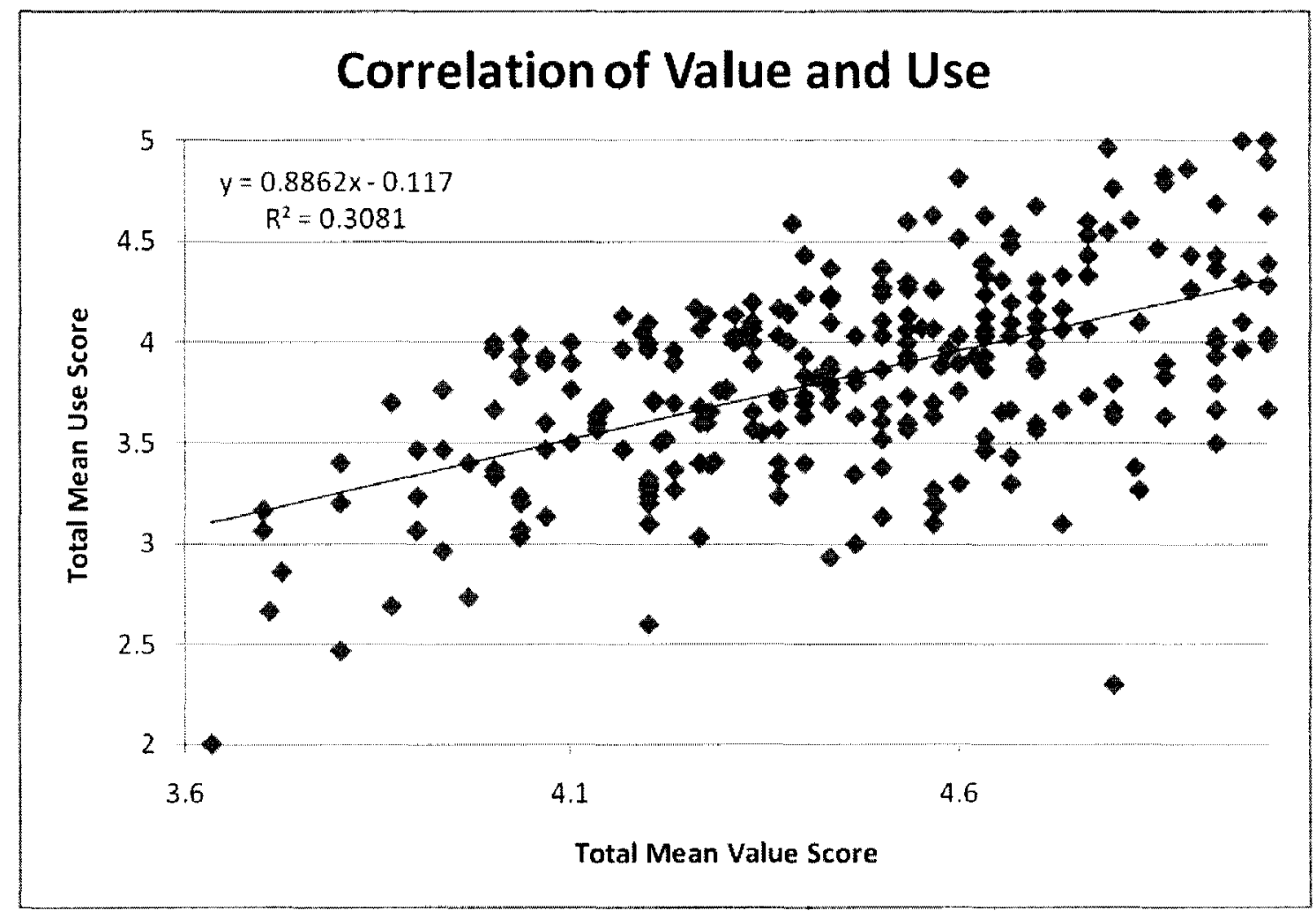

Figure 4.1. A graphic representation of the correlation between the total mean use scores and the total mean value scores.

Because the labels attached to the questionnaire Likert scale for value and use are different for these two aspects of formative assessment strategies, the range of responses across all respondents varied across this dimension. Value scores ranged from 5.0 (very valuable) to 3.63 (between valuable and no strong view), whereas use scores ranged from 5.0 (most lessons) to 2.0 (quarterly). The regression equation in Figure 4.1 provided the opportunity to calibrate a particular value ranking with a corresponding use ranking (see Table 4.5). Because the computations of frequency of use in Table 4.5 fell between the identified fixed points on the original Likert scale on the questionnaire, the researcher suggested text (in parentheses) that is interpolated between the defined 
Likert scale points. This positive correlation suggests that teachers' value of formative assessment does serve as an indicator of their likely use of those strategies.

Table 4.5

Predicting Use Frequency of a Strategy from Perceived Value

\begin{tabular}{ll}
\hline Value & Use Predicted from Value \\
\hline $5=$ very valuable & 4.3 most lessons \\
$4=$ valuable & 3.4 most days \\
$3=$ no strong view & 2.5 a few times per month \\
\hline
\end{tabular}

\section{ANOVA - Differences Across Teacher Characteristics}

Value and Use Scores Across Grade Levels

An investigation into which of the four grade-level groups of teachers may be using more formative assessment strategies than others was undertaken using a one-way ANOVA. Results indicated there was a significant difference between groups for total mean value score $([\mathrm{F}(3,245)=3.004, p=.031]$ and between groups for total mean use score $[F(3,245)=3.747, p=.012]$. Because these $p$-values indicated significant difference, a Tukey Highly Significant Difference (HSD) post hoc test was computed to identify the source of those differences.

Table 4.6 compares the four grade level groups and their reported value of formative assessment strategies. Two overlapping homogeneous subsets indicated there was a difference for those teachers who taught late elementary grades $(4,4-5$ or 5$)$ and those teachers who taught all grades (K-5). The late elementary teachers valued formative assessment strategies more strongly than the teachers who teach across the K5 spectrum. 
Table 4.6

Tukey HSD Results for Total Mean Value Scores by Grades Taught

\begin{tabular}{|c|c|c|c|}
\hline & \multicolumn{3}{|c|}{ Tukey HSD Subset for alpha $=0.05$} \\
\hline Grade Levels & $\mathrm{N}$ & $\begin{array}{l}\text { Value Mean Scores } \\
\text { Subset1 }\end{array}$ & $\begin{array}{l}\text { Value Mean Scores } \\
\text { Subset } 2\end{array}$ \\
\hline late elementary & 54 & 4.5471 & \\
\hline middle elementary & 66 & 4.4735 & 4.4735 \\
\hline early elementary & 80 & 4.4255 & 4.4255 \\
\hline all grades & 45 & & 4.3784 \\
\hline $\begin{array}{l}\text { Significance } \\
\text { for each subset }\end{array}$ & & .320 & .129 \\
\hline
\end{tabular}

Table 4.7 reports similar results for use of formative assessment strategies across grade level groups. The Tukey HSD post-hoc test resulted in two overlapping homogeneous subsets and revealed that the all elementary group of teachers reported lower use of formative assessment strategies than those who taught the late elementary students. This range of means is narrow (3.9096-3.6317); however, the all elementary group of teachers have reported lower value and now, lower use of formative assessment strategies than the late elementary group. 
Table 4.7

Tukey HSD Results for Total Mean Use Scores for Grades Taught

\begin{tabular}{|c|c|c|c|}
\hline \multirow[b]{2}{*}{ Grade Level } & \multicolumn{3}{|c|}{ Tukey HSD Subset for alpha $=0.05$} \\
\hline & $\mathrm{N}$ & $\begin{array}{l}\text { Score Means } \\
\text { Subset } 1\end{array}$ & $\begin{array}{c}\text { Use Score Means } \\
\text { Subset } 2\end{array}$ \\
\hline late elementary & 54 & & 3.9096 \\
\hline middle elementary & 66 & & 3.9034 \\
\hline early elementary & 80 & 3.8090 & 3.8090 \\
\hline all grades & 45 & 3.6317 & \\
\hline $\begin{array}{l}\text { Significance } \\
\text { for each subset }\end{array}$ & & .178 & .656 \\
\hline
\end{tabular}

Because the all elementary group was different from the other grade groups, an examination of short responses on the questionnaire was investigated. Analysis of the all elementary teachers' responses did not reveal any evidence that was different from the other respondents about the practice of using formative assessment. Their responses typically mirrored those of the other grade level groups.

Value and Use Scores Across Professional Development Training

The relationship between professional development training and teacher responses on the questionnaire with regard to their value and use of formative assessment strategies was investigated. The ANOVA indicated there was a significant difference between subsets at the $\alpha=0.05$ confidence level between the district-trained group and those who had received school-based training from colleagues. The total mean value score $[\mathrm{F}(3)=4.308, p=.006]$ and the total mean use score $[\mathrm{F}(3)=4.548$, 
$p<.004]$ revealed a difference among these four PD groups. A Tukey HSD post-hoc test was conducted to identify which groups accounted for the differences. Table 4.8 summarizes the p-values between each PD group pair for the post-hoc tests.

Table 4.8

Tukey HSD ANOVA Post-Hoc p-values between PD Training Group Pairs

\begin{tabular}{|c|c|c|c|c|}
\hline PD Training Groups & 1 & 2 & 3 & 4 \\
\hline & \multicolumn{4}{|c|}{ Value } \\
\hline National or regional & -- & .931 & .289 & .982 \\
\hline District trained & --- & --- & $.002 * *$ & .788 \\
\hline $\begin{array}{l}\text { School-based } \\
\text { trained }\end{array}$ & --- & --- & --- & .736 \\
\hline \multirow{2}{*}{$\begin{array}{l}\text { No formal } \\
\text { training }\end{array}$} & --- & --- & --- & --- \\
\hline & \multicolumn{4}{|c|}{ Use } \\
\hline National or regional & --- & .999 & .124 & .904 \\
\hline District trained & --- & --- & $.002 * *$ & .785 \\
\hline School-based & --- & --- & --- & .730 \\
\hline $\begin{array}{l}\text { No formal } \\
\text { training }\end{array}$ & --- & -- & --- & --- \\
\hline
\end{tabular}

Table 4.8 results showed that the differences in questionnaire responses based on PD experiences were due to differences between those teachers who experienced district training (higher value and higher use scores compared to school-based PD groups) and those who experienced school-based training (lower value and lower use scores compared to district-trained PD group). The other types of PD experiences 
(national/regional or individually pursued) did not show questionnaire response patterns any different from other PD training groups. Two possible interpretations emerge from this result. Either the district-trained group of teachers were selected because of their leadership role in using and communicating the value of formative assessment strategies (a selection bias for receiving district PD training); or the consequence of district PD training led to higher value and use of formative assessment strategies (differential impact of PD).

\section{Exploring the Four Sub-Constructs of the Questionnaire}

Because of the identified difference between the district PD group and the school-based PD group (the two groups that showed significant differences in the results above), a final ANOVA for all PD groups was used to determine where the difference may lie with regard to responses on the formative assessment questionnaire, i.e., an attempt to uncover what had distinguished these groups from one another. Even though the factor analysis had previously indicated no clear delineation across the four sub-constructs of formative assessment strategies built into the questionnaire, it seemed plausible that the differences may be revealed for these PD groups with additional analysis.

Using an ANOVA test, differences across the four PD groups (see Table 4.8) on each of the four sub-constructs, was investigated both for value and use scores resulting in a total of eight ANOVA tests (four sub-constructs for each of value and use). The ANOVA tests were followed by a Tukey HSD post hoc, specifying that in five of the

eight tests where significance was indicated, all were between the district PD group and the school-based PD group as had been previously determined, but more clarity was 
added with this investigation into the four sub-constructs. Table 4.9 highlights only those which indicated a level of significance at $\alpha=0.05$.

Table 4.9

Examination of the Four Sub-Constructs of the Questionnaire Across Levels of PD

Training

\begin{tabular}{lllcll}
\hline Sub-Construct & $\begin{array}{l}\text { Sum of } \\
\text { Squares }\end{array}$ & $d f$ & Mean Square & F ratio & Sig. \\
\hline $\begin{array}{l}\text { Mean value score } \\
\text { for quality }\end{array}$ & 1.926 & 3 & .642 & 3.231 & .023 \\
$\begin{array}{l}\text { Mean value score } \\
\text { for feedback }\end{array}$ & 1.776 & 3 & .592 & 4.933 & .002 \\
$\begin{array}{l}\text { Mean use score } \\
\text { for quality }\end{array}$ & 5.032 & 3 & 1.677 & 3.738 & .012 \\
$\begin{array}{l}\text { Mean use score } \\
\text { for feedback }\end{array}$ & 1.853 & 3 & .618 & 2.946 & .034 \\
$\begin{array}{l}\text { Mean use score } \\
\text { for self-assessment }\end{array}$ & 5.614 & 3 & 1.871 & 3.640 & .014 \\
\hline
\end{tabular}

Note. All differences are based on the Tukey HSD post-hoc due exclusively to district/school PD group differences based upon training.

From this table it can be seen that responses about (a) valuing and using quality models to assist students with learning new material, (b) valuing and using feedback to check for understanding, and (c) using student self-assessment, are significant areas of difference between the district and school-based trained groups. Examination of the qualitative data added further explanation to these distinguishable differences and will be discussed later in Chapters V and VI. 


\section{Structural Equation Model (SEM)}

Structural Equation Modeling (SEM) was an approach used to explore the measurement model of the questionnaire items loading on four latent sub-constructs of formative assessment, and the structural relationships existing among these latent variables. See Figure 4.2 for the final structural equation model; the initial model was similar to Figure 4.2 except that no error covariances were included. The goal was to determine how well this measurement instrument (the questionnaire) and the underlying hypothesized structure of formative assessment fit the data for this sample.

Additionally, these data were used to modify this model in ways that could be theoretically supported.

Initially this researcher accepted the theoretical structure of the formative assessment questionnaire as designed by Neesom (2000) which is a modified version of an original model adopted by the Leaning to Learn Project (L2L) (see James, Black et al., 2006) . 


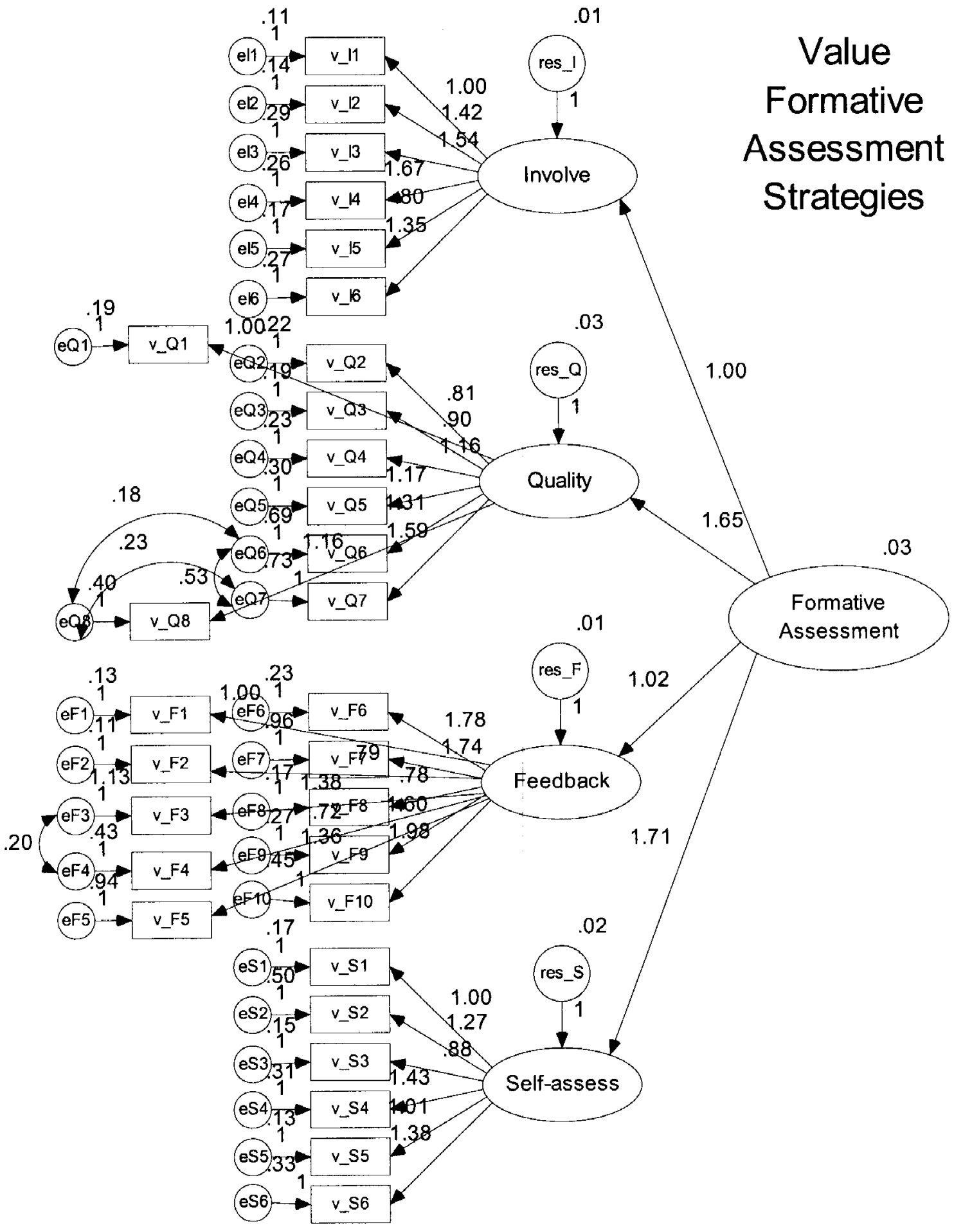

Figure 4.2. Structural Equation Model (final model) to illustrate the best fit for the latent construct of formative assessment for value. The path loadings for each subconstruct on the overall latent construct of 'formative assessment' are reported in the diagram. 
Several fit indices (RMSEA, GFI, CFI) were used to determine how well the initial model explained the data gathered from the teacher respondents. This suite of fit indices, rather than just one, provided a more robust indicator of model fit (Byrne, 2001; Kline, 2005). With some modifications to the original model a better-fitting model to these data were obtained. Following is a summary of the model fitting process undertaken with these data - the end result of this model modification process is the final model presented in Figure 4.2.

Model Modification for Value of Formative Assessment Strategies

The baseline model for the value scores produced three fit indices that were investigated. The RMSEA initially indicated a moderately good fit (.071), but the other indices (GFI and CFI) indicated some modifications to the model may result in a better fit; modification indices were used to identify potential modifications to the model that would result in a better fit to the data. Table 4.10 details the model modification steps taken to enhance the fit, which is reflected by a statistically significant reduction in the chi-square (CMIN). As the model fit improved, the GFI and CFI fit indices increased towards the value of 1 (ideally reaching 0.90 or better to indicate reasonably good fit) and RMSEA became smaller (ideally approaching 0.05 or smaller to indicate strong fit). 
Table 4.10

Model Modification Process for Value Scores on Formative Assessment Strategies

\begin{tabular}{|c|c|c|c|c|c|c|c|c|c|c|}
\hline \multirow{2}{*}{$\begin{array}{l}\text { Model } \\
\text { Description }\end{array}$} & \multirow[b]{2}{*}{$\mathrm{CMN}$} & \multirow[b]{2}{*}{$d f$} & \multirow[b]{2}{*}{$\Delta \chi^{2}$} & \multirow[b]{2}{*}{$\Delta d f$} & \multirow[b]{2}{*}{$\begin{array}{c}\text { Statistical } \\
\text { Significance }\end{array}$} & \multirow[b]{2}{*}{ GFI } & \multirow[b]{2}{*}{ CFI } & \multicolumn{3}{|c|}{ RMSEA } \\
\hline & & & & & & & & $\begin{array}{c}\text { Point } \\
\text { estimate }\end{array}$ & $\begin{array}{l}\mathrm{Lo}^{a} \\
90\end{array}$ & $\begin{array}{l}\mathrm{Hi}^{a} \\
90\end{array}$ \\
\hline $\begin{array}{l}\text { Model 1: } \\
\text { Baseline } \\
.076 \\
\text { model } \\
\text { (Fig. } 4.2 \text { with }\end{array}$ & out any & error & varian & (-- & -- & .794 & .740 & .071 & .065 & \\
\hline $\begin{array}{l}\text { Model 2: } \\
\text { Co-vary } \\
.066 \\
\text { Q6 \& Q7 }\end{array}$ & 786.7 & 400 & 151.2 & 1 & $\begin{array}{c}\text { Yes } \\
\mathrm{p}<0.001\end{array}$ & .840 & .813 & .060 & .054 & \\
\hline $\begin{array}{l}\text { Model 3: } \\
\text { Co-vary } \\
\text { Q6 \& Q8, } \\
\text { Q7 \& Q8 }\end{array}$ & 742.0 & 398 & 44.7 & 2 & $\begin{array}{c}\text { Yes } \\
\mathrm{p}<0.001\end{array}$ & .850 & .833 & .057 & .050 & .063 \\
\hline $\begin{array}{l}\text { Model 4: } \\
\text { Co-vary F3 } \\
\& \text { F4 }\end{array}$ & 719.9 & 397 & 22.1 & 1 & $\begin{array}{c}\text { Yes } \\
\mathrm{p}<0.001\end{array}$ & .852 & .844 & .055 & .049 & .061 \\
\hline
\end{tabular}

$\mathrm{Lo}^{a} 90$ and $\mathrm{Hi}^{a} 90$ are the $90 \%$ confidence interval for RMSEA

For each modification of the model, the researcher examined the questionnaire by re-reading the items and determining whether the modification could be reasonably justified. In each case, the wording of the item was thought to have led the respondent to produce similar response patterns. The selected model modifications seemed appropriate due to slight variations in wording of the item.

For example, items Q6 and Q7 began with similar wording and only differentiated between student performance and student progress. 
Q6: "Showing students a range of other students' work to make a judgment about performance."

Q7: "Showing students a range of other students' work to make a judgment about progress."

Similarly, item Q8 began with much of the same wording as Q6 and Q.

Q8: Showing students a range of other students' work to model or exemplify criteria."

A respondent may not have made the fine distinction the author of the statement intended (Neesom, 2000). From a careful re-examination of the instrument items, the researcher found that subsequent modification indices did not highlight additional modifications that could be supported.

After co-varying the three "modeling quality work" items (Q6, Q7 \& Q8) the chi-square improved significantly $(p<0.001)$ as indicated in Table 4.10. One final covariance was indicated by the modification index for feedback items F3 and F4. The final model with a GFI $=.852$, a $\mathrm{CFI}=.844$, and the $\mathrm{RMSEA}=.055$ all approached values indicating a moderately to very good fit for this model. The path loadings for each of the four sub-constructs of formative assessment were roughly similar to each other which suggest that all four sub-constructs were roughly equally weighted for the construct of value of formative assessment.

As with the modeling quality work items, the providing feedback items contained very similar expressions with regard to rewarding and recognizing student efforts to improve their work. Item F3, "giving rewards only when achievement is satisfactory for that student with specific comments referring to student's success" expressed similar sentiments as item F4, "expressing approval when achievement is satisfactory." In comparing these data sources (i.e., the covariance values and 
qualitative item statements) the researcher utilized a mixed methods approach to the data analysis.

Model Modification for Use of Formative Assessment Strategies

The baseline model for use of formative assessment strategies was the same as that for value of formative assessment strategies because the questionnaire was structured for respondents to indicate a value rating and a use rating for each item. See Figure 4.3 for the final structural equation model for use; the initial model was similar to Figure 4.3 except that no error covariances were included. As was done with the value model, this baseline model was modified based on modification indices to enhance the fit to the data for use of formative assessment strategies. Table 4.11 summarizes the steps taken for this model modification process. 
Table 4.11

Model Modification Process for Use Scores on Formative Assessment Strategies

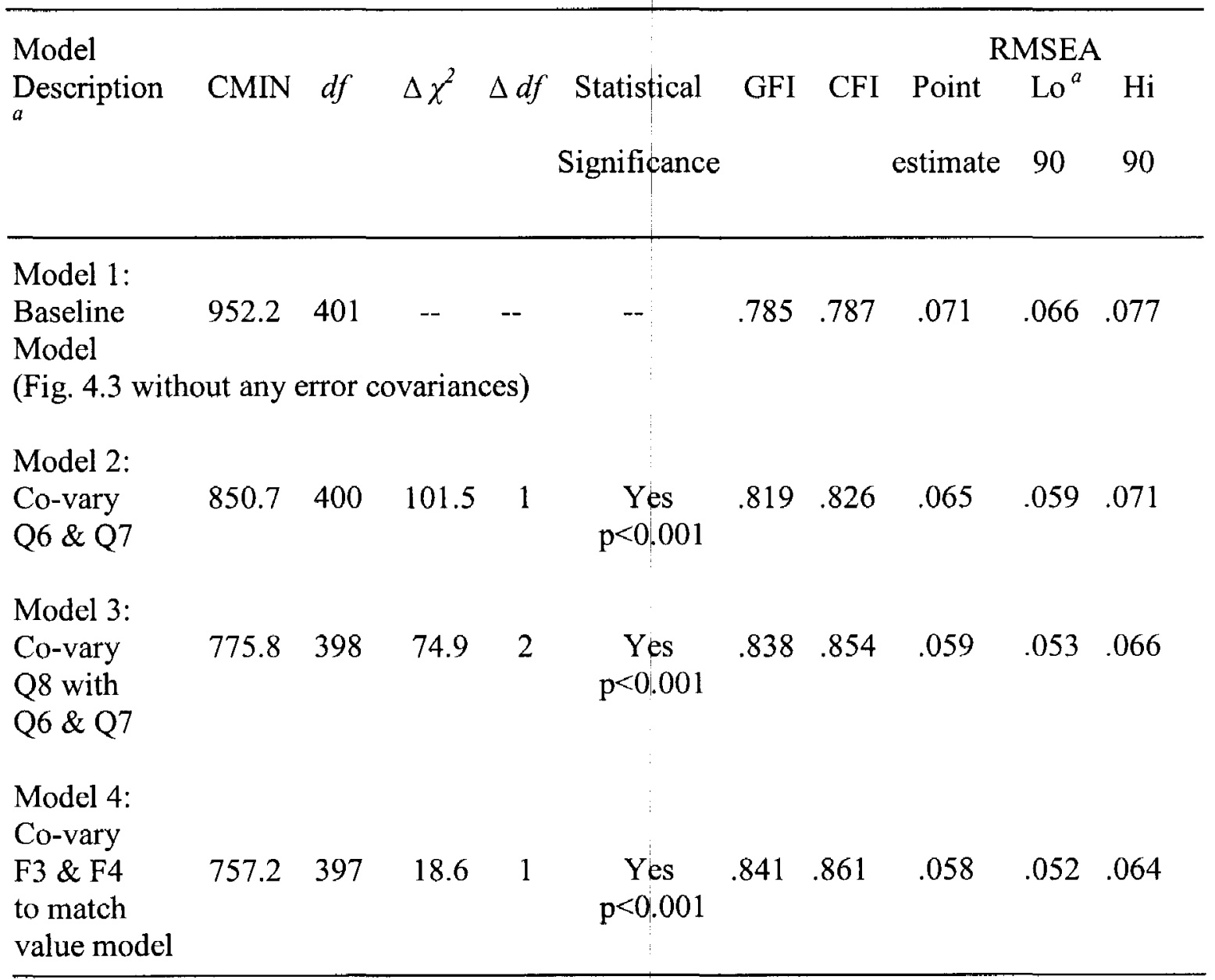

Although for this model the covariance of F3 and F4 was not as strongly indicated as it was for the value model, the decision was made to co-vary these to maintain model invariance across these two aspects (value and use) of formative assessment strategies. Modification indices for the use model did indicate that a statistically better fitting model may be obtained if S1 and S2 were co-varied. Although review of the items S1 and S2 suggested that it would be reasonable to expect them to co-vary, because this same model modification did not arise with the value model, the decision was made to not include this additional covariance for the use model in order 
to retain identical models for both value and use. The path loadings for each of the four sub-constructs of formative assessment were roughly similar to each other - less than a factor or 2 separating the weakest loading from the strongest - which suggests that all four sub-constructs were roughly equally weighted for the construct of use of formative assessment. 


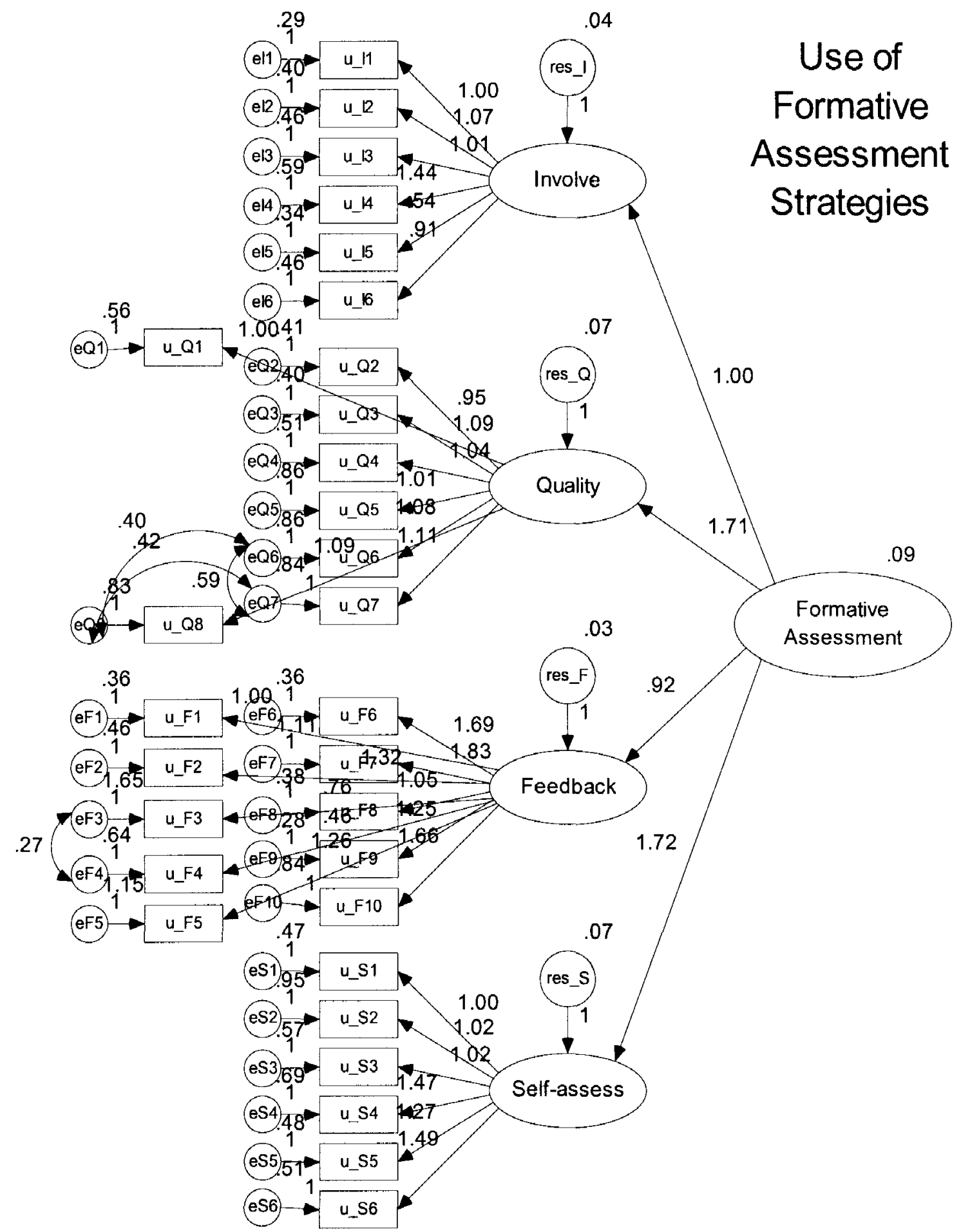

Figure 4.3. Structural Equation Model to illustrate the best fit for the latent construct of formative assessment for use. 
In conclusion, the SEM analysis provided support for the structure of formative assessment being thought of as four latent sub-constructs because the overall fit of the final model was strong. Based on the model modification process, several items on the questionnaire (Q6, Q7, Q8 and the pair F3, F4) were ultimately modeled as covarying; this same modification set independently appeared appropriate for both the value model and the use model.

\section{Qualitative Data}

Three data sources were utilized to acquire qualitative data. The first set of data came from the short-response statements on the questionnaire. The second were from teacher observations of the four teachers; and the third were obtained through interviews with the same four teachers. Each data set had its own unique characteristics and coding challenges to extract meaning, as applicable to the comprehensive construct of formative assessment.

\section{Formative Assessment Questionnaire}

The Formative Assessment Questionnaire (FAQ) provided qualitative data from the short-response statements detailed in Table 4.12. The first two statements were open-ended without the restrictions imposed by the other four statements which directly related to the four sub-constructs of the questionnaire. Upon initial screening of responses, categories emerged due in part to the guiding theme of these statements from the questionnaires; most teachers attempted to respond to each of the statements. As data were screened, certain patterns of responses were noted. These patterns of responses will be discussed later. 
Table 4.12

Short-Response Statements from the Formative Assessment Questionnaire

Statement Statement Themes

Number

I find formative assessment works well when ...

Formative assessment hinders my work when ...

I find it easiest to involve students in their learning when ...

I find it easiest to model quality work for students when ...

I find it easiest to give students feedback when ...

I find it easiest to give students opportunities to self-assess when ...

Analysis Structure for the Short Responses on the Questionnaire

Results from the four short-response statements on the questionnaire directly

related to the four sub-constructs (i.e., involving students, modeling quality work, providing feedback, and promoting student self-assessment) are discussed first.

Respondents wrote about their pedagogy, logistics, classroom management styles and philosophical frameworks as to how they personally dealt with teaching and learning at the practitioner level; these responses revealed a variety of tactics teachers utilized to manage students' learning. Table 4.13 provides categorical information resulting from examination of these responses. Initially codes were allowed to emerge from the data (an a priori approach), however, that method proved cumbersome due to the wide variety of responses. The second analysis adopted relied upon the structure of the questionnaire, i.e., grouping responses based upon the identified strategies found within the four sub-constructs. 
Table 4.13

Categorical Codes for Teacher Short Responses to Statements 3-6

Sub-Construct Categories

Coding Information

Involving students

Students are engaged and had ownership in their learning

Students are excited, interested or motivated about learning

Students understand lesson goals

Students are involved in hands-on activities, working in small groups, or one-on-one with the teacher

Modeling quality work

When the teacher had planned to present models

Teachers used good models to share with students

When teachers had a rubric or other assessment model to share with students

Teachers used technology to assist them in showing models to students

Giving feedback

Analyzing work in small group or one-on-one conferences Sensitive to meeting student learning in a timely manner Providing students with specific criteria for evaluating their work

Students self-assessing Used tests or homework criteria by which to judge student knowledge

Providing time for students to reflect on their work

Making goals clear to understand work

Providing models or samples for self-assessment

Making sure it was done in a timely manner

Some responses fell into more than one category. For example, one respondent completed the statement "I find it easiest to involve students in their learning when ... They can explain their knowledge and thinking." This statement revealed that students were engaged and understood the lesson learning goals (two codes within the involving students category).

The analysis and results for the remaining two short-response questionnaire statements are discussed in the next sections. 
Short Response: "Formative assessment works well when ..."

Black and Wiliam (1998a) had broadly defined formative assessment to include all activities that teachers and students undertake to acquire information that can be used diagnostically to alter teaching and learning activities. "Feedback to any pupil should be about the particular qualities of his or her work, with advice on what he or she can do to improve, and should avoid comparisons with other pupils" [italics in original] (Black \& Wiliam, 1998b, p. 143). Another important element of formative assessment is student self-assessment. To engage in self-assessment, students must understand the teachers' objectives and the direction for their learning. Students "can assess themselves only when they have a sufficiently clear picture of the targets that their learning is meant to attain" (Black \& Wiliam, 1998b, p.143). The responses teachers gave to the first statement were analyzed based upon the three criteria (planning, feedback and self-assessment) synthesized from Black and Wiliam's definition to operationalize how formative assessment practices may be enacted in a classroom setting:

Planning: The response included some reference to planning to determine students' understanding of lesson goals or objectives.

Feedback: The teacher had collected data about student learning to develop next steps in the lesson; there was an indication about giving feedback or making suggestions about how to improve; the teacher intended to address students' misconceptions. 
Self-Assessment: A self-assessment component was evident which indicated students were given the opportunity to reflect upon their work.

As responses were read and analyzed for meaning, subtleties emerged from the short responses. Along with the codes that were congruent with the Black and Wiliam (1998a) definition of formative assessment, two other themes emerged that did not fall under that framework. Table 4.14 contains a summary of statements, both within the Black and Wiliam framework and those that were not.

Table 4.14

Codes for Teacher Responses to "Formative assessment works well when ..."

Components Definition Number of Coded Teacher Responses

$(\mathrm{n}=214)$

Black and Wiliam (1998a) formative assessment qualities:

Planning:

Next steps

Next steps are ones that teachers take when planning lessons utilizing data they have gathered from student work.

Feedback:

Clears up misconceptions

Indicates the teacher used

information gathered from the student to re-teach some information.

Collect information The teacher has used some means to gather

to determine data about student learning.

current learning

Students know the goals

The response indicated that students are aware of the direction of the lesson or learning event. respond to student

Teachers indicated that by meeting with students in a small group or individually (one-on-one) an effort was made to re-direct student learning.

Self-Assess:

Students

The response indicated that students have some self-assess role in assessing their own work. 
Non-formative assessment qualities:

Confusing formative assessment with summative assessment

Class discussion
Some responses indicated that the teacher regarded formative assessment as a summative assessment. Responses indicated information obtained was final and not subject to change.

These responses did not specify how information obtained was used to change lesson plans or give feedback to students. Because formative assessment is generally meant to gain information about individual student progress, class discussion does not necessarily capitalize upon the individualized aspect of formative assessment.

Note. Interrater was established at $82 \%$.

A total of 214 tallies revealed what teachers had indicated about how formative assessment was utilized in their classrooms. Their responses revealed that feedback is the most frequent component of formative assessment (61\%). Using feedback or other information gained from students to be used for planning purposes was the second most referenced component $(18 \%)$. Utilizing student self-assessment was an infrequently mentioned component (4\%). Eighteen percent of the respondents indicated some confusion regarding the purpose of formative assessment by connecting it with summative assessments or indicating that discussion with students in a large setting was formatively assessing each student's knowledge.

Language appeared in teachers' responses denoting frequency of using formative assessment. Some short responses indicated it was "done daily," "as a quick check," "regularly," "always" or "as soon as possible." Frequency in and of itself is not a component of the formative assessment definition and therefore is reported here separately to give a sense of how teachers indicated they used it. Eighteen percent of the respondents used this type of terminology. 
Short Response: "Formative assessment hinders my work when ..."

A similar process to the analysis of the first statement was used for analyzing the second short-response statement, "Formative assessment hinders my work when ..." Since there were no established criteria to define what formative assessment is not, the researcher allowed the codes to emerge from the data. Five codes presented in Table 4.15 are shown with corresponding response percentages.

Table 4.15

Codes for Teacher Responses to "Formative assessment hinders my work ..."

Code Definition of Responses

Number of Coded

Teacher Responses $(\mathrm{n}=181)$

$\begin{array}{ll}\text { Thinks of formative } & \text { Expressed a concept about grading or } \\ \text { assessment as } & \text { indicated that student work was a final } \\ \text { summative } & \text { product of instruction }\end{array}$

Too many students Indicated that the number of students

Too much time

Indicated that formative assessment took too much time to implement or that it somehow limited instruction

FA is not integral to instruction

Does not hinder
Stated that formative assessment interrupted or interfered in some way with the natural flow of instruction

Revealed that formative assessment did not hinder or present any barriers to instruction

Note. Interrater agreement was established at $85 \%$.

Some responses contained information that permitted multiple codes across the matrix. A particular respondent wrote, "The content does not lend itself to formative assessment," which was coded as not being integral to the instruction process. Another 
response, "I don't have enough time to do these with all students!" was coded as too much time and too many students; the teacher seemed to express there were too many students, not enough time and formative assessment strategies hindered progress with instruction. The number of respondents who indicated that formative assessment was a hindrance totaled 156.

Twenty-five respondents indicated that there were no adverse effects from employing formative assessment strategies. Some example responses are, "Never. I think they are beneficial and guide my instruction," or "The learning and teaching is subjective. It's not always easy to assess growth and learning."

The responses to this statement provided a unique window into the thinking of the respondents. The data indicated that teachers may be confused about the boundaries between formative assessment and summative assessment; about a third of the respondents felt that formative assessment strategies took too much time. Fifteen percent of the respondents seemed to have a clearer understanding about the advantages of formative assessment and it did not interfere with their instruction.

\section{Case Study Organization}

Eighteen teachers volunteered for Phase II of this study which included being observed teaching science lessons and being interviewed. Four volunteers were purposefully selected by the dissertation co-chair regarding high value/use, moderate value/use and low value/use as well as attention to grade level distribution. The researcher had no prior knowledge of them or their responses on the FAQ. Only after all data had been collected and analyzed were their questionnaire responses revealed to the researcher. These four teachers, who were part of this more in-depth process, became the foci of four case studies presented below. 
In the following case studies, several items of information were revealed about each teacher. From the questionnaire, tallies of their value and use responses were reexamined and detailed analyses of their short-response statements are presented. Data from the observed science lessons and the teachers' responses to interview items were analyzed. The responses on the FAQ, scripting from the observations and transcription of interviews were triangulated by comparative analysis to reveal any patterns and trends, contradictions, and insight into each teacher's thinking and actions with regard to formative assessment.

Case Studies' Responses to Value and Use on the FAQ

One way to view the four case studies' responses on the FAQ was to consider them as a subset of the larger group with regard to their mean scores for value and use. Table 4.16 provides the interpretable ranges; Table 4.17 reports the responses for each case study.

Table 4.16

Interpreting Value and Use Scores for Case Studies

\begin{tabular}{lll} 
Mean Score Range & Value Meaning & Use Meaning \\
\hline $5.0-4.1$ & Very valuable & Most lessons \\
$4.0-3.1$ & Valuable & Most days \\
$3.0-2.1$ & No strong view & Weekly \\
$2.0-1.1$ & Of little value & Quarterly \\
$1.0-0$ & Of no value & Never \\
\hline
\end{tabular}


Table 4.17

Average Mean Scores for Case Studies on Questionnaire Sub-Constructs

\begin{tabular}{lllllll}
\hline & $\begin{array}{l}\text { Involve } \\
\text { Students }\end{array}$ & $\begin{array}{l}\text { Model } \\
\text { Quality } \\
\text { Work }\end{array}$ & $\begin{array}{l}\text { Provide } \\
\text { Feedback }\end{array}$ & $\begin{array}{l}\text { Self- } \\
\text { Assess }\end{array}$ & Mean & $\begin{array}{l}\text { Overall } \\
\text { Interpretation }\end{array}$ \\
\hline Virginia & 5.0 & 4.9 & 4.7 & 4.7 & 4.83 & Very valuable \\
Tina & 4.7 & 3.8 & 4.6 & 4.2 & 4.33 & Very valuable \\
Leigh & 5.0 & 4.5 & 4.7 & 5.0 & 4.8 & Very valuable \\
Jordan & 5.0 & 4.8 & 4.1 & 5.0 & 4.73 & Very valuable \\
& & & Use Mean Scores & & \\
Virginia & 4.7 & 4.1 & 3.5 & 3.2 & 3.86 & Most days \\
Tina & 3.5 & 1.9 & 4.2 & 2.8 & 3.1 & Most days \\
Leigh & 5.0 & 4.8 & 4.5 & 4.0 & 4.6 & Most lessons \\
Jordan & 2.6 & 3.0 & 3.5 & 3.6 & 3.2 & Most days \\
\hline
\end{tabular}

Note. All teacher names are pseudonyms.

Each teacher found formative assessment to be a very valuable strategy for assessing students' knowledge; their mean average score was 4.67 which was similar to the mean for the overall group of 270 teachers. Leigh reported using formative assessment strategies during most lessons (4.6), whereas the other three teachers reported using it less frequently, though Virginia's written short-responses indicated she may have used it more than the other teachers. 


\section{Teachers Observations}

Teacher observations occurred during the last two months of the school year when the teachers and students had well-established routines and had built solid relationships. The observations were hand-scripted noting (a) conversation between the teacher and students, and (b) activities and events occurring in the classroom.

The scripted notes were then analyzed using Leahy et al., (2005) criteria for formative assessment; the same criteria used to frame the literature review for this study. These five broad strategies are considered "as non-negotiable in that they define the territory of assessment for learning" (p. 20). The five criteria are:

1. Clarifying and sharing learning intentions and criteria for success.

2. Engineering effective classroom discussions, questions, and learning tasks.

3. Providing feedback that moves learners forward.

4. Activating students as the owners of their own learning.

5. Activating students as instructional resources for one another.

Specific qualities for each criterion are defined in Table 4.18. These criteria were derived from formative assessment research and the FAQ (Black \& Wiliam, 1998; Wiggins \& McTighe, 1998; Black \& Harrison, 2001; Chappuis \& Stiggins, 2002; Stiggins, 2002; Black et al., 2004; Black, 2005; Leahy, Lyon, Thompson \& Wiliam, 2005; Stiggins \& Chappuis, 2005; Clymer \& Wiliam, 2006; James, Black, McCormick, Pedder \& Wiliam, 2006). 
Table 4.18

Five Criteria of Formative Assessment with Detailed Criteria

\begin{tabular}{|c|c|c|c|c|}
\hline $\begin{array}{l}\text { Clarifying and } \\
\text { sharing learning } \\
\text { intentions } \\
\text { (CLI) }\end{array}$ & $\begin{array}{l}\text { Engineering } \\
\text { classroom } \\
\text { discussion } \\
\text { (ED) }\end{array}$ & $\begin{array}{l}\text { Providing } \\
\text { feedback } \\
(\mathrm{PF})\end{array}$ & $\begin{array}{l}\text { Activate student } \\
\text { as owner of their } \\
\text { learning } \\
\text { (ASO) }\end{array}$ & $\begin{array}{l}\text { Peer/Self- } \\
\text { assessment } \\
\text { (PSA) }\end{array}$ \\
\hline $\begin{array}{l}\text { State goals to } \\
\text { students }\end{array}$ & $\begin{array}{l}\text { Reflective } \\
\text { questions }\end{array}$ & $\begin{array}{l}\text { Quality of } \\
\text { student work }\end{array}$ & $\begin{array}{l}\text { Criteria in } \\
\text { student language }\end{array}$ & $\begin{array}{l}\text { Remarks to } \\
\text { others }\end{array}$ \\
\hline $\begin{array}{l}\text { Posted models or } \\
\text { grading } \\
\text { schema }\end{array}$ & $\begin{array}{l}\text { Stimulating } \\
\text { questions }\end{array}$ & $\begin{array}{l}\text { Comments on } \\
\text { how to improve }\end{array}$ & $\begin{array}{l}\text { Exemplars of } \\
\text { student work }\end{array}$ & $\begin{array}{l}\text { Use } \\
\text { criteria }\end{array}$ \\
\hline $\begin{array}{l}\text { What has been } \\
\text { done }\end{array}$ & $\begin{array}{l}\text { "Hot seat" } \\
\text { questions }\end{array}$ & $\begin{array}{l}\text { Addresses } \\
\text { misconceptions }\end{array}$ & $\begin{array}{l}\text { Students ask } \\
\text { questions }\end{array}$ & $\begin{array}{l}\text { Reflective } \\
\text { responses }\end{array}$ \\
\hline $\begin{array}{l}\text { Where are we } \\
\text { going }\end{array}$ & $\begin{array}{l}\text { No hands-up } \\
\text { questions }\end{array}$ & $\begin{array}{l}\text { Engages } \\
\text { students }\end{array}$ & $\begin{array}{l}\text { Establish lesson } \\
\text { pacing }\end{array}$ & $\begin{array}{l}\text { Students } \\
\text { review } \\
\text { own work }\end{array}$ \\
\hline $\begin{array}{l}\text { What is quality } \\
\text { work }\end{array}$ & Wait time & $\begin{array}{l}\text { Move students } \\
\text { forward }\end{array}$ & $\begin{array}{l}\text { Provide feedback } \\
\text { to teacher }\end{array}$ & $\begin{array}{l}\text { Students } \\
\text { review } \\
\text { work }\end{array}$ \\
\hline \multirow[t]{3}{*}{$\begin{array}{l}\text { Student-friendly } \\
\text { language }\end{array}$} & $\begin{array}{l}\text { Uses probing } \\
\text { questions }\end{array}$ & $\begin{array}{l}\text { Causes } \\
\text { thinking }\end{array}$ & $\begin{array}{l}\text { Shared } \\
\text { responsibility }\end{array}$ & $\begin{array}{l}\text { Provide } \\
\text { time for } \\
\text { students } \\
\text { to reflect }\end{array}$ \\
\hline & & $\begin{array}{l}\text { Specifying a } \\
\text { better way }\end{array}$ & $\begin{array}{l}\text { Student suggests } \\
\text { ways to improve }\end{array}$ & \\
\hline & & \multicolumn{3}{|c|}{$\begin{array}{l}\text { Tell students what } \\
\text { they have/have } \\
\text { not achieved }\end{array}$} \\
\hline
\end{tabular}

Teacher Interviews

Teacher interviews occurred separately at the end of the observation cycle with individual teachers. Each interview lasted approximately 45 minutes. Interview items were based upon the work of Luft and Roehrig (2007) where they described science teaching pedagogy ranging from a traditional to reform-based approach. The Teacher 
Belief Interview (Luft \& Roehrig, 2007) instrument utilized a semi-structured format and elicited teachers' beliefs about their instructional practices.

The categories of the instrument range from traditional and instructive, which can be described as teacher-focused instructional practices, to transitional, responsive/early constructivist and reform-based, which are considered to be more student-focused practices. Table 4.19 details the interview items and provides a brief description of a teacher or student behavior for each of the five teaching beliefs. Appendix B contains the entire interview instrument with expanded definitions and sample responses. 
Table 4.19

Interview Items with Explanations

\begin{tabular}{|c|c|c|c|c|c|}
\hline & Teacher-F & ocused & & Student-Fo & ocused \\
\hline & $\begin{array}{l}\text { Traditional } \\
\text { (TD) }\end{array}$ & $\begin{array}{l}\text { Instructive } \\
\text { (IN) }\end{array}$ & $\begin{array}{l}\text { Transitional } \\
\text { (TS) }\end{array}$ & $\begin{array}{l}\text { Responsive } \\
\text { (RS) }\end{array}$ & $\begin{array}{l}\text { Reform-based } \\
\text { (RB) }\end{array}$ \\
\hline $\begin{array}{l}\text { Q1-How } \\
\text { do you } \\
\text { students } \\
\text { maximize } \\
\text { student learning }\end{array}$ & $\begin{array}{l}\text { Structured } \\
\text { environment } \\
\mathrm{g} \text { ? }\end{array}$ & $\begin{array}{l}\text { Monitoring } \\
\text { student } \\
\text { actions }\end{array}$ & $\begin{array}{l}\text { Involve } \\
\text { in learning }\end{array}$ & $\begin{array}{l}\text { Students } \\
\text { interact with } \\
\text { one another }\end{array}$ & $\begin{array}{l}\text { Feedback } \\
\text { from } \\
\text { yields } \\
\text { varied } \\
\text { lessons }\end{array}$ \\
\hline $\begin{array}{l}\text { Q2-How do } \\
\text { you describe } \\
\text { your role as } \\
\text { a teacher? }\end{array}$ & $\begin{array}{l}\text { Focus on } \\
\text { information }\end{array}$ & $\begin{array}{l}\text { Focus on } \\
\text { experience }\end{array}$ & $\begin{array}{l}\text { Teacher/ } \\
\text { student } \\
\text { relationships }\end{array}$ & $\begin{array}{l}\text { Collaboration } \\
\text { between } \\
\text { teacher and } \\
\text { student }\end{array}$ & $\begin{array}{l}\text { Mediating } \\
\text { student } \\
\text { knowledge }\end{array}$ \\
\hline $\begin{array}{l}\text { Q3-How } \\
\text { do you know } \\
\text { when your } \\
\text { students } \\
\text { understand? }\end{array}$ & $\begin{array}{l}\text { When } \\
\text { receive } \\
\text { information }\end{array}$ & $\begin{array}{l}\text { Reiterate } \\
\text { what was } \\
\text { learned }\end{array}$ & $\begin{array}{l}\text { Respond/ } \\
\text { explain what's } \\
\text { been learned }\end{array}$ & $\begin{array}{l}\text { Students } \\
\text { utilize } \\
\text { knowledge }\end{array}$ & $\begin{array}{l}\text { Apply } \\
\text { knowledge } \\
\text { novel ways }\end{array}$ \\
\hline $\begin{array}{l}\text { Q4-How do } \\
\text { you decide } \\
\text { what to } \\
\text { teach and what }\end{array}$ & $\begin{array}{l}\text { Curriculum- } \\
\text { based } \\
\text { not? }\end{array}$ & $\begin{array}{l}\text { Teacher } \\
\text { focus }\end{array}$ & $\begin{array}{l}\text { Use some } \\
\text { student } \\
\text { feedback }\end{array}$ & $\begin{array}{l}\text { Feedback } \\
\text { from } \\
\text { students }\end{array}$ & $\begin{array}{l}\text { Student- } \\
\text { focused and } \\
\text { standards }\end{array}$ \\
\hline $\begin{array}{l}\text { Q5-How do } \\
\text { you decide } \\
\text { when to } \\
\text { move on to } \\
\text { a new topic? }\end{array}$ & $\begin{array}{l}\text { Teacher } \\
\text { decisions }\end{array}$ & $\begin{array}{l}\text { Student } \\
\text { under- } \\
\text { standing } \\
\text { of facts }\end{array}$ & $\begin{array}{l}\text { Using some } \\
\text { student } \\
\text { feedback }\end{array}$ & $\begin{array}{l}\text { Student } \\
\text { feedback and } \\
\text { revisiting } \\
\text { concepts }\end{array}$ & $\begin{array}{l}\text { Using a } \\
\text { feedback } \\
\text { loop to alter } \\
\text { lessons }\end{array}$ \\
\hline $\begin{array}{l}\text { Q6-How do } \\
\text { your students } \\
\text { learn science } \\
\text { best? }\end{array}$ & $\begin{array}{l}\text { From the } \\
\text { teacher }\end{array}$ & $\begin{array}{l}\text { Mimicking } \\
\text { the teacher }\end{array}$ & $\begin{array}{l}\text { Using } \\
\text { adopted } \\
\text { procedures }\end{array}$ & $\begin{array}{l}\text { Students } \\
\text { interpret }\end{array}$ & $\begin{array}{l}\text { Constructing } \\
\text { ideas about } \\
\text { phenomenon }\end{array}$ \\
\hline $\begin{array}{l}\text { Q7-How do } \\
\text { you know } \\
\text { when learning } \\
\text { is occurring } \\
\text { in your } \\
\text { classroom? }\end{array}$ & $\begin{array}{l}\text { Actions of } \\
\text { students } \\
\text { during } \\
\text { instruction }\end{array}$ & $\begin{array}{l}\text { Correctness } \\
\text { of responses }\end{array}$ & $\begin{array}{l}\text { Subjective } \\
\text { conclusions } \\
\text { about students }\end{array}$ & $\begin{array}{l}\text { Interact with } \\
\text { one another }\end{array}$ & $\begin{array}{l}\text { Students } \\
\text { initiate } \\
\text { interaction }\end{array}$ \\
\hline
\end{tabular}


After interviewing each teacher, the recorded transcript was coded and a determination was made about how the responses fit the five categories of traditional, instructive, transitional, responsive/early constructivist or reformed-based/experienced constructivist. To verify the interpretation of the responses, an interrater coding was conducted to confirm consensus about beliefs regarding science instruction.

\section{Case Study Results by Teacher}

\section{Virginia}

Virginia had been teaching for 13 years with five of those years in her current school. She taught 3 rd and 4 th graders $(n=21)$ in a combined class. She had obtained National Board Certification, was a team leader and served on interview committees for new hires. In addition to teaching 3 rd and 4 th grade levels, she had also previously taught in the 2nd and 6th grades.

Self-reported professional development in the area of formative assessment was from training provided by the local district, collaborating with other teachers, having read articles about formative assessment, and having studied this topic in college courses.

Responses to questionnaire statements. Responses to the short-response statements provided additional insight into her understanding of formative assessment. Following are her responses (see Table 4.12 for question prompts):

Q1 - I am using it as the driving force behind instruction. Q2 - When I am being inefficient at collecting data - not having enough time to review student work.

Q3 - When I use conversation regularly and have students talk about their science schema and questions and reflect on their learning. Q4 - I have tools that make it easy and other forms of technology. Q5 - I have time to review and be thoughtful about work. Q6 - I commit time during the week for reflection and thinking. 
Responses to value/use. Virginia indicated she valued formative assessment selecting 25 "very valuable" 4 "valuable" and 1 "no strong view" on the questionnaire. The one "no strong view", response was to item F5 regarding making a conscious decision to avoid saying a student is wrong.

As to use of formative assessment, she indicated 12 "most lessons", 2 "most days", 11 "weekly", 4 "quarterly" and 1 "never". The "quarterly" responses were in the modeling quality sub-construct $(\mathrm{Q} 6, \mathrm{Q} 7)$ about showing students a range of other students' work; in the giving feedback sub-construct (F3) about providing rewards for satisfactory achievement; and in the self-assessment sub-construct (S5) about helping students to understand their achievement and knowing next steps in order to make progress. The one "never" response was in the self-assessment sub-construct (S2) about negotiating a way to improve some piece of work.

\section{Observations of Virginia}

Virginia was observed four times, each observation lasting just over an hour. The following analysis is a combination of the four observations (Lessons 1, 2, 3 and 4 were all on subsequent days, and so represent a connected multi-day sequence of instruction) with examples of each of the defining formative assessment criteria

Clarifying learning intentions. In each lesson Virginia would state the guiding question of the day. During the first observation she posed, "Our guiding question today is, how does design impact the distance that an airplane is able to travel?" Throughout the lesson other elements of this criterion were made evident to the student. To clearly state the goal of the lesson she said, "Today our task is to test our airplanes." Webbing student ideas on a marker board, creating a data table, recording flight distances 
traveled by the paper airplanes and having the students reference the schema box on their worksheets were ways that Virginia maintained student focus on the schema of the lesson.

Students were often reminded about what they had previously completed and any new direction for the lesson. To keep them focused on the outcome during Lesson 1 she explained the value of having one variable; asked them about things to consider when measuring how far the airplanes would fly in Lesson 2; and specifically stated "we're controlling design today" in Lesson 3.

To complement the focus of where the lesson was going, Virginia also reminded students of "where they had been." At the end of Lesson 1 she assigned students to "write a hypothesis about how and why your two planes fly." Flight distances were added to a data table in Lesson 3 and then updated in Lesson 4. Students could observe what had been recorded from the previous day and compare that to new data added from continued testing of the airplanes.

While students were flying their paper airplanes in the hallways, she cautioned students "You cannot like how a plane flies and not record data." She explicitly stated, "Scientist can't not accept data just because they don't like it!" This was interpreted as her way of specifying "what quality work looked like."

Engineering discussions. Asking high-quality questions is the hallmark of engineering valuable classroom discussion. Virginia effectively used questions to guide instruction and conversation about learning. Reflective questions, probing questions, stimulating questions, hot-seat questions and the use of wait time were ways she 
engineered classroom discussion. Student responses to these questions were evidence of how well constructed her questions had been.

In Lesson 1 a reflective question was posed, "How do you think you're going to do this? Turn and talk with a partner." Hypotheses were shared and expanded upon by other students as they voiced their thoughts. In the second observation a stimulating question, "Does anyone notice a trend?" was responded to by a male student who said, "The numbers seem to be proportionally the same." In the third observation, the question, "Can you think about other variables that might affect the flight of the airplane?" was posed. The students responded about paper type, speed of the throw, placement of their hand grip, weight of the plane and the location of the test. In Lesson 4, a probing question was put forward, "Let's talk about our results. What conclusions have you drawn today?" Student responses were either a new idea, or an extension of what another student had said. As data were shared, Virginia acknowledged each contribution by writing what had been said on a white board.

Providing feedback. Providing feedback involves comments on the quality of student work, directions to improve, and responses to student misconceptions. The feedback engaged students' thought processes about what had and had not been achieved during the lessons.

In Lesson 1 students were engaged in class discussion when reference to a video was made. Students were asked to reveal their schema for an airplane design and responded by providing a variety of suggestions about unique airplane designs. In the following lesson, specific directions were given about how to measure the distance the plane had flown by using floor tiles as the unit of measurement. Virginia commented, 
"There's a lot of thinking going on here," in response to how the students were counting the floor tiles, measuring the fraction of the last tile, and then mentally calculating the total distance. Even though some students were able to quickly determine the distance, students received feedback from the teacher in their small groups and later in whole group discussion. A misconception, "The math did confuse some of you today," was addressed by Virginia due to observations she had made during the trials.

One small group of students observed their plane flying backwards when the toss was too rambunctious and the plane curved behind the thrower. Virginia asked the student to "think about how you might handle this," and then suggested using a negative number. This feedback prompt gave students the impetus needed to quickly count the tiles and calculated the negative flight data. The following day this group received intensive guidance and feedback on where to stand, how to throw the plane, and how to calculate flight distances. The students were able to collect detailed data at the end of these trials.

Activating students as owners of learning. This criterion of formative assessment focuses on how students engage in their own learning and communicate that learning to the teacher. Methods included the ability to restate lesson goals, ask questions, set the pace of the lesson and provide additional feedback to the teacher. When Virginia asked the students what a hypothesis was, one gave a definition, the next refined that definition, the third replied "educated guess" to which Virginia remarked, "Love the way you said that."

Virginia used a strategy called "turn-and-talk" where students would have a brief moment to chat with a partner about a question or prompt posed by the teacher. 
After asking, "Think about how you are going to do this," a short conversation ensued and the students shared the comments they generated. In Lesson 3, the teacher had introduced the term, inertia, and how this might have impacted the flight of the planes. One student mentioned momentum; another detailed his flight plan mentioning weight and lift; one discussed style of throwing, and another compared weight to that of a real airplane. All of these responses gave the teacher detailed information about what the students were thinking. This type of conversation also provided peers with insights into others' thinking.

In two of the four lessons, Virginia asked the students, "Can we handle popcorn today?" This "popcorn" session was a no-hands-up discussion session where specific criteria had previously been established to guide the conditions under which students could respond. On both occasions the students enthusiastically, but appropriately, volunteered comments in response to her prompt about what conclusions they had drawn as a result of their data gathering that day. Students reported which plane flew the longest distance and provided some explanation about confirming or not confirming their hypotheses. Comments such as "many variables," "variables are sometimes hard to control," referencing a video viewed earlier in week where they had learned that scientist had "to do trials over and over again," and one who remarked that "different planes thrown differently will fly differently" were made with confidence and enthusiasm.

Peer and self-assessment. Providing time for students to talk in a purposeful manner, generated much conversation about learning. Students were able to reflect upon their learning through a variety of venues: turn-and-talk, popcorn sessions, small group 
and whole class discussions. The daily worksheet had been formatted where students wrote what schema they had at the beginning of the lesson. These beginning ideas were discussed and then re-visited at the end of the lesson. Upon concluding the lesson, Virginia would pose to the students, "Take a minute and read your hypothesis and then write your answer in the box."

When first learning how to fold the airplanes, the students were encouraged, but also self-motivated to assist one another, make remarks to partners, and generally share thoughts about folding techniques. On another occasion when data were being reported in a whole group discussion, there were suggestions generated by the students about how to improve the recording of the data for future lessons. Virginia took advantage of this suggestion and asked for other thoughts about improving the data-collecting procedures. The students reflected upon their own data tables and shared how they determined flight distances by using mental math or using a calculator. The groups worked cooperatively with one another.

\section{Interview with Virginia}

Recalling the five categories from the Teacher Belief Instrument (Luft \& Roehrig, 2007), that is, traditional (TD), instructive (IN), transitional (TS), responsive (RS) and reform-based (RD), none of the interview responses which Virginia gave met the traditional or instructive criteria. Her responses were primarily in the responsive and reform-based category with some evidence of transitional.

Maximizing student learning. Virginia reflected,"You have to be a kid watcher and listen to their discussions and see to what extent are they saying what you want to hear versus what they understand" (RB). To enable students to interact with the content, 
Virginia remarked, "With science I try to work hard not to leave themes behind and keep things interconnected because their ideas are so powerful" (RS).

Role as a teacher. To this question Virginia immediately responded, "I'm the facilitator." She interpreted this to mean she was a reflective teacher and used reflection in an active manner with the students. "I come back at the end of the lesson and have long discussions with them about what went well and what didn't" (RS). "There was probably more powerful learning in that mistake and having to re-think how better to make the experiment work" (RB). These last two responses referenced the paper airplane design and flight trials. The discussions utilized the popcorn strategy which allowed open discussions about what had been observed and conclusions drawn as a result of small group and whole group conversations.

When students understand. "When I hear them using the vocabulary powerfully in conversations; when they're able to communicate their ideas in writing. Writing is very foundational in everything they do. It's like writing it into your mind" (RS). Virginia says, "I really look for their schema and if they have questions. If they only have questions, then we're near a blank slate. If we do an activity, I want them to know how it relates to the bigger picture." These statements provided sufficient evidence to believe that Virginia was fairly confident about knowing what her students understood.

What to teach and what not to teach. Virginia recalled reading about designing lessons that left a lasting impression. Her comment about what to teach and what not to teach was, "I look for ways to make it memorable. I want kids to go away with a lasting impression; I'm not looking at teaching for the day, but rather a way to represent longevity by adding depth to POS" (TS). (POS is the Program of Studies adopted into 
law by the state of Kentucky.) To this she added, "I want to make it lasting through an inquiry approach and using questions; they have the power of replication when they go home and show it to their parents" (RB).

When to move on to a new topic. Virginia was very exact in responding to this question. Her only remark was, "I look for general activity and to what extent they are on task and general discussion instead of puzzled expressions and lots of questions" (RS). Discussion and responses to the other interview questions had been rather lengthy and more clues to her decision-making with regard to this question seemed to have already been addressed.

How students learn science best. Without hesitation, Virginia remarked, "Discrepant events especially when they get results other than what they expected it to be, that can be profound learning. When they can remember that discrepant event, then they can connect it to something. It's like giving them a coat hanger for a concept" (RB). She expanded by saying that her students were very excited about science and proposed such since, "It's really in the pedagogy and techniques" (RS).

When learning is occurring. Again, without much hesitation, Virginia remarked, "When I read their writing I can see the insight." She gave an example of a student's understanding about sound, energy and vibrating molecules that had been studied earlier in the year. "I am happiest when I see them making the connections; they're going to remember. If it's in isolation, they're not going to remember it" (RB). Summary of Data Sources for Virginia

Data from the FAQ responses, classroom observations and teacher interview were very consistent. On the questionnaire items Virginia indicated that formative 
assessment was "very valuable" and used "most days". The short-responses were personalized statements indicating Virginia's beliefs about how she enacted formative assessment strategies. Indicating in her first response to "I find formative assessment works well when ..." by stating that it was the "driving force" in her daily instruction became a benchmark by which to compare her actions within the classroom.

The observations provided evidence for all five formative assessment criteria. Clarifying learning intentions, engineering discussion and providing feedback were more frequently observed. Even though Virginia had perceived her usage of student self-assessment as less frequently used, it remained a strong element in each of the classroom observations. The teacher interview data analysis indicated that her beliefs were consistent with a student-focused approach and were coded primarily in the responsive and reform-based categories. The focus of her instruction was modeled upon an inquiry-based approach to science instruction. Her careful analysis of what her students had learned through the student-centered discussion exemplified the feedback defined by Black and Wiliam (1998a).

Tina

Tina was just completing her second year of teaching, both years in her current school. She taught 19 third grade students. Having just completed her KTIP (Kentucky Teacher Internship Program) year, Tina had begun work to obtain her Master's degree taking an on-line course. She was also certified to teach special education. Self-reported professional development had involved collaborating with other teachers, having read articles and having studied the topic in college courses. 
Responses to questionnaire statements. Responses to the short-response

statements provided additional insight into her thinking about formative assessment (see Table 4.12 for question prompts).

Q1 - I want to check students' learning so far, to see if they are "getting it." Q2 - They are very lengthy - takes time to grade.

Q3 - They are passionate about what they are learning.

Q4 - They are having a hard time writing or completing a task.

Q5 - No response provided

Q6 - No response provided

Responses to value and use. Tina indicated that she valued formative assessment circling 13 very valuable, 12 valuable, 3 no strong view and 2 of little value. One of the "no strong view" responses and both "of little value" responses were in the modeling quality work sub-construct (Q6, Q7, Q8) which pertained to showing students a range of other students' work. The second "no strong view" response was about feedback (F7); the item entailed telling students what they had not achieved with specific references to learning. The third "no strong view" response was to item S2; this item involved negotiating with a student in a self-assessment modality.

As to use, Tina indicated 7 "most lessons," 4 "most days," 10 "weekly," 5 "quarterly" and 4 "never" frequency responses. Three of the five "quarterly" responses were in the modeling quality work sub-construct $(\mathrm{Q} 1, \mathrm{Q} 2, \mathrm{Q} 4)$ as were three of the four "never" responses (Q6, Q7, Q8). These would strongly suggest that Tina infrequently modeled quality work to her students, especially considering that both value and use were marked with lower values. These responses are somewhat contradictory to her short-response answer about finding easy ways to model quality work for students where she indicated that modeling quality work was utilized when students were experiencing difficulty with writing or completing a task. 
Another "quarterly" use response was in the feedback sub-construct (F7); the other was in the self-assessment sub-construct (S6) about students assessing their own and others' work. The final "never" response was to item S2 about negotiating a way to improve some piece of work. Tina was consistent in her Likert responses; lower value and lower used patterns were discerned for items Q6, Q7, Q8, F7, and S2.

\section{Observations of Tina}

Tina was observed on three occasions, each lasting about an hour. Whereas the observations of Virginia occurred over four consecutive days, these observations did not. The first two lessons were observed in the same week; however, these were consecutive lessons (science instruction did not occur each day); the third lesson occurred after a series of interruptions to the regular schedule due to state testing. Clarifying learning intentions. Upon beginning each lesson, Tina consistently asked students to write the guiding question of the day in their science/math notebook. The guiding question was part of a power point presentation she had created. In Lesson 1 students were asked, "What's your schema about the parts of a plant?" Student responses included stem, petal, pollen, flowering plants, pollination, buds and seeds. One student clearly had "a lot of schema" as he related how pollination occurred and mentioned photosynthesis. Tina re-directed him and the discussion back to parts of a plant and away from plant processes. In Lesson 2 the guiding question addressed plant adaptations. As students wrote hypotheses about this new content, Tina visited each table group to inquire about what the students were writing thus reinforcing the learning intentions. In Lesson 3 students were asked to turn-and-talk about the characteristics of an ecosystem. 
Five minutes before the end of the first observation, students were directed to draw a simple plant and label the parts (roots, stem, leaves and flower) and state a reason why each part was important. Though the intent of this activity was to clarify lesson goals, there was inadequate time for the students to complete the task. However, at the beginning of Lesson 2 the students were asked to, "Turn and talk about our big idea from Friday; I want to add to our poster," The poster was entitled, "What schema do we have for plants?" Large post-it notes were added to the poster as the students reflected upon the parts of a plant to set the stage for the upcoming discussion of plant adaptations. This review of the previous lesson's learning goal was a direct attempt at formative assessment—clarifying what had been learned.

Engineering discussion. Following the introduction of the guiding question for the day, Tina began by asking students to discuss background knowledge about the lesson topic. Other than that initial, purposeful guiding question to engineer discussion, Tina more frequently used reflective questions and once posed a stimulating question; subsequent questions were not engineered per the formative assessment criteria for this study. Fact-based questions were included in the power points which guided Tina's direct instruction. A question such as, "What does adaptation mean?" was posed more often than questions that would cause students to think beyond a factual level. Tina generally called upon students who volunteered; students would sit for long periods of time with their hands raised. Of the three observations, few questions were coded as reflective, stimulating or probing to purposefully stimulate or guide classroom discussion. 
When students were engaged in small group work, Tina would move from one group to the next checking on progress. Her comments generally re-focused students from off-task behavior. Typically she did not ask questions to these groups; instead she more frequently repeated directions that had not been clarified. Her intention seemed to stress having students write information into their notebook, or onto a poster, rather than developing a deeper understanding of stated learning goals designed for the lesson.

Providing feedback. Tina did attempt to have students to think about what notes they wrote in their notebooks by insisting that the statement from the power point be read aloud and having students discern which words were more important. She did guide students word-by-word through a definition; choral responses included "important" or "not important". A final condensed version of the original definition was record in the science notebook.

A misconception was addressed in Lesson 3 when responses to the question, "What is an ecosystem?" resulted with incorrect guesses as students volunteered. All responses were written on the board without discriminating which was correct or incorrect. A dictionary was consulted and Tina wrote the definition as the student read. She then led a discussion comparing what the students had previously volunteered with the dictionary definition. Student responses were accepted or rejected using the definition as the accepted criterion.

In Lesson 2, Tina gave specific feedback about a student's approach to understanding the term adaptation by commenting, "I like the way you broke up that word," and to the whole class, "Abby was familiar with the word adapt." 
When checking for student understanding about the parts of the plants presented in the first lesson, Tina reviewed student work. She generally made comments about the quality of the pictures the students were drawing and paid compliments to the students about the appearance of the drawings. Through this she obtained a general idea of what the students knew; however, since students were not receiving quality feedback about their work these incidents were not coded as providing feedback.

Activating students as owners of learning. There were two occasions in the three observations when these specific strategies occurred; the interview reinforced what had been observed. Tina mentioned considering the degree to which students were having fun as a measure of success of her lesson. Investigations, hands-on learning, real-life applications were provided as examples.

In Lesson 1 students responded to the question, "Why do plants need roots?" with "suck up water," "nutrients," and "like a house ... a foundation." This same acceptance of familiar student language was reinforced when taking notes and using their words to create definitions. In this introductory lesson, the students freely gave background information to Tina about their knowledge of plant parts.

Quite the opposite occurred in Lesson 3 when small groups began constructing an ecosystem on poster paper; class progress was halted often to add directions. In response to the question, "What would be important information to know about [your ecosystem] to tell others?" the students provided many responses. Tina was evidently considering other norms, consequently, when responses did not meet her criteria she declared, "I'll let you decide what you want to put down." This indecision regarding the 
learning objectives suggested that the assessment for student work may not have been previously clarified.

An interesting characteristic of this classroom environment was student readiness to consult resources, such as a dictionary, an encyclopedia, or other resource books within the classroom. It was encouraging to see students quietly get up from their seats, go to a bookshelf and look up a word or fact about the topic of discussion. Sometimes, however, it added a distracting element to the flow of instruction and became a classroom management issues.

Peer and self-assessment. Tina did consistently use a strategy called "turn-andtalk" to engage her students in conversations about the lesson topic. Whole group review of student responses from these partner discussions was brief, but an attempt had been made to help students acquire a broader view of what others were thinking. Interview with Tina

Most of Tina's responses were Instructive (IN) with Traditional (TD) tendencies. A few of her responses had Transitional (TS) ideas and trended toward being Responsive (RS). Themes of time limitations and use of exit slips permeated her responses.

Maximizing student learning. Tina responded, "The day is limited and time is at a minimum," (TD) as she explained how entry slips and morning work affected her decision about what students had learned. "I like to read the exit slips and see what the kids have written. It depends on their responses as to whether I review the next day" (IN). This indicates that review was a regular feature of her instruction and a regular formative assessment strategies she used. 
Role as a teacher. Like Virginia, Tina saw herself as a facilitator of information and added, "I am one who provides the information and skills and then monitors them [students] for attaining basic skills before they move to the next grade" (TD). However, unlike Virginia, Tina did not always take the time to ensure that students had the knowledge and skills indicated by her lesson plans.

When students understand. Tina used an Instructive approach to determining what students had learned by, "Monitoring and asking questions, and listening to the kids during turn-and-talk. I will sometimes join in their discussions." She concluded by stating that, "I generally have an idea by the end of the year who gets it and who doesn't" (IN).

What to teach and what not to teach. A more Traditional approach was used for planning and teaching purposes. "The focus of the school is the Big Ideas from Core Content and we fill in with other stuff." She continued with, "We take the information, plan the facts and basic skills the students would need during the months of August to December. We also used the IOWA and the CATS scores to see where the kids werelow-medium-high" (TS). This last statement was more transitional based upon the fact that the school does have a designated time to pull students who are struggling and give them additional instruction; they were using specific data to make determinations about an individual student's progress.

When to move on to a new topic. The time the school had set aside for remediation occurred 40 minutes two days per week. The teachers used a team approach; one pulled the recommended students for additional help while the homeroom teacher provided enrichment activities with the other students. Tina's 
approach to this aspect of teaching has been determined to be evenly distributed between an Instructive and Transitional.

How students learn science best. "Investigations are extremely helpful and they do hands-on learning especially when I can find real-life applications" (TS). Tina continued by proudly proclaiming that she is the "power-point person" for the team and this responsibility gave her control over images and content. She provided an example of a previous unit of study which contained abstract concepts. Her approach to making it more realistic for the students was to include pictures of the 1937 Ohio River flood. Her rationale was that students could discuss this with their parents and grandparents (TR). This example is considered ill-advised since the parents of these students in all likelihood did not personally experience the 1937 flood.

When learning is occurring. Tina decides learning is occurring when, "I look and see if there is complete engagement, or I see a look on their face; it's hard to make some things exciting" (TD). She did give students opportunities to work together adding, "Group work is exciting and the kids were so engaged; they're having a good time. I like to listen to the kinds of conversation they get into and questions they ask" (TS). She then added, "Exit slips play a huge role" (IN).

\section{Summary of Data Sources for Tina}

Evidence collected from the questionnaire indicated that Tina, like Virginia, found formative assessment strategies "very valuable" and used "most days"; however, the difference resided in the actual implementation of those beliefs and values expressed through the questionnaire. Tina only responded to four of the six short-response statements, and those were mostly generalized statements and lacked a personalized 
focus. Data collected during the three observations revealed evidence congruent with some of the formative assessment criteria, primarily clarifying learning intentions and providing feedback to students. Her power point presentations gave students a clear pathway for intended learning and helped sequence the content. Responses to the teacher interview indicated her beliefs aligned more with the traditional and instructive categories with some evidence of transitional and responsive instruction. Use of constant comparative analysis of the three data sources confirmed her beliefs and formative assessment strategies as a more teacher-focused approach to science instruction.

Leigh

Leigh had been teaching for six years with the previous two in her current school. She taught 24 students in a combined 1st/2nd grade classroom. She retains her 1 st graders for a second year; her 2nd graders move on to a new teacher. Each year she receives new 1 st graders. In another school she taught 2 nd grade. Leigh had become certified as a Reading Specialist in addition to her standard elementary certification. Self-reported professional development included all choices presented on the questionnaire; her training has encompassed both formal and informal trainings.

Responses to questionnaire statements. Responses to the short-response statements provided additional insight into Leigh's thinking about formative assessment (see Table 4.12 for question prompts).

Q1 - Checklists and note-taking.

Q2 - When I am overwhelmed by the number of students in my class.

Q3 - When they are engaged and truly understand.

Q4 - I am in a conference one-on-one.

Q5 - I am working one-on-one.

Q6 - We have completed an activity over an extended period of time. 
Responses to value/use. Leigh indicated that she valued formative assessment circling 27 "very valuable" items; two items Q6 and Q7 were marked as "no strong view" and one item F5 was circled as "of little value".

As to use, Leigh indicated 23 "most lessons", 2 "most days", 3 "weekly" and 1 "never" response. The one "never" response was in the modeling quality work subconstruct (Q6). It was interesting to note that Q7 was marked "weekly" and Q8 was marked "most lessons". All three items regard showing students a range of other student's work to make better judgments about performance or progress. Leigh did not respond to use item $\mathrm{F} 5$.

Observations of Leigh

Leigh was observed five times with the first four lessons being consecutive and the final lesson occurring after a short interruption to the regular schedule and a field trip to the zoo. Each lesson lasted an average of 40 minutes. Science was the last formal lesson of the day. Leigh co-taught with another $1^{\text {st }} / 2^{\text {nd }}$ grade teacher in an adjoining classroom. During the first and fifth observations, her partner teacher's class came to join Leigh's students; during the third observation, Leigh's students joined the other class. This moving of students was uneventful and considered part of a normal classroom routine; it did not appear to interfere with the lesson presentation.

Clarifying learning intentions. In clarifying learning intentions to the students, Leigh would often combine several strategies by stating learning goals, determining what schema the students had about the topic, discussing what had been done or what was going to happen as she began the lesson. In the first observation she read a book to the students about how energy moves through a food chain while the partner teacher 
scribed notes on an overhead projection system. She posed, "Yesterday we learned how animals move. Here's the big idea for today, predator and prey, who can talk about those?" Student responses were noted. In Lesson 2 Leigh stated, "Today, you will research about your animal and your animal's prey." In Lesson 3, "Today we'll talk about sorting vertebrates and invertebrates," and followed up in Lesson 4 with "We had a chance yesterday to sort animals; you're going to learn tons more today." And finally, in Lesson 5 she began with, "Friday we went to the zoo! Anybody see a mammal?" While reading the book to students in Lesson 1, she employed a pre-reading strategy asking students to listen for that word "predator" as the video played. During the second observation she provided the whole group an explanation about how to look up "predator" or "prey" in the index or table of contents; she then reinforced this process skill with each small group especially when they asked for assistance. Before repeating her original directions, she asked the group was to relay what had they attempted and results before re-guiding them through this exploratory process of finding their special animal. This checking for understanding was well within the parameters of formative assessment strategy usage.

Engineering discussion. In a deliberate effort to connect the lesson from the previous day, Leigh posed, "What are some reasons why animals move?" to which the students responded, "escape danger" and "to get food." In Lesson 2 a student had selected spiders as his special animal and was having difficulty finding what ate spiders. Leigh asked, "What do you think is the reason some animals might not eat spiders?" This first grade boy was able to come up with several reasons. Using his words, she directed him to the index and table of contents of his "All About Spiders" book to see if 
what he had just said might give him clues about where to find the answer to his own question.

When arriving to observe the third lesson, Leigh was finishing a math lesson with a small group of students seated on the carpet in the front of the room. She asked these students, "What are you thinking about to solve this?" also, "How else can I solve this?" in an attempt to encourage alternative methods of problem solving.

One hot-seat question was addressed to a student. "Alexander, when you were sorting, what did you notice? What did we realize insects have?" Alexander commented about walking stick insects and body shape. This prompted another student in his group to add, "exoskeleton!" The vocabulary for these first/second graders was quite sophisticated at times.

Providing feedback. Engaging students was a consistent behavior exhibited by Leigh. When reading the book entitled, "Who Eats What," she said, "Little fish are eaten by big fish; big fish are eaten by ..." to which the students chorally responded, "bigger fish." In Lesson 2 she prompted students with, "All food chains begin with ..." to which all readily replied, "green plants!" Again in Lesson 5, reinforcing the concept of classification students were asked to listen for the word "sorting, or ..." and students responded, "classifying."

During the second observation Leigh reinforced the quality of student work as they constructed food chains; she stipulated that students label their drawings. In Lesson 5 she announced to the students, "We are a little behind and I don't want to rush and not do our best work" indicating that quality was paramount to time. 
More often than not, Leigh engaged in one-on-one conversations with her students in order to give and receive feedback about student work. She often initiated these discussions with questions about what they were doing, how they were doing it, and how they might improve the product or approach to the task. Asking a question such as, "How else can you go about solving this problem?" gave students specific feedback. In Lesson 2 a small group of boys discovered when reading that cows had multiple stomachs. After a series of questions Leigh asked, they realized the purpose of this anatomical feature. In Lesson 4 she prompted a student saying, "Use something from your schema about an ant; think about the video."

Activating students as owners of own learning. Whereas Tina's students readily looked up information in resource texts, Leigh's students were full of questions. Her responses like, "What have you noticed so far?" or "Can you give me an example?" encouraged students to either ask more questions, or to proceed more confidently with their task. In checking for understanding, Leigh asked students both in whole group and small group discussions whether they had noticed an arrow in a food chain diagram. A female student asked, "Where is the sun in the food chain?" This was followed by two partner students recounting the energy flow through the food chain. Leigh simply observed this interaction and nodded approval of their efforts.

In Lesson 2 a student inquired, "What if our animal doesn't eat animals?" In Lesson 3 one asked, "How can you tell if an animal has a backbone?" And finally in Lesson 5 a boy wondered, "Is a crawdad a reptile?" Leigh was uncertain about this last question and addressed questions to the student to inquire about inherent characteristics of a crawdad. The student was able to give additional background information to help 
clarify his understanding of its classification. This was followed by, "How long do tortoises live?" Leigh's responded, "I could guess, but if I look in the "Turtle and Tortoise" book, we could find out for sure." This response satisfied the student learner to begin to look for herself.

Peer and self-assessment. There were clear incidents of reflective thinking and questioning by students. One occurred during the first observation while closing the lesson. Leigh asked, "What questions do you have?" The students were ready with, "Are monkeys eaten?" and, "Do all food chains start with green plants?" (this was in reference to an ocean food chain), and "What do whales eat?"

During group work students were often noticed and commented upon their partners' work and they readily joined in small group adventures to answer one another's question. In Lesson 2 when a boy could not find a predator, a few probing questions by Leigh led the group to research the index to look for keys words that may help them find the predator and prey relationship; they were confidently able to do so. Interview with Leigh

Maximizing student learning. With a mixed classroom of $1^{\text {st }}$ and $2^{\text {nd }}$ graders, Leigh dealt with a wide range of student abilities. "I had two non-readers - some will be totally oral, and some read on the $6^{\text {th }}$ grade level and have been able to read just about anything I give them." (RS/RB) "I really know my students' strengths and weaknesses and start each unit with a pre-assessment" (TS); with this information she determined the level of student learning. "I try to see what we're working with, prior knowledge, and that way I know where we need to go." (TS) 
Role as a teacher. When asked about her role as a teacher, Leigh immediately responded, "I see myself as a guide, not an all-knowing." She then added, "I push students to always be wondering; you're not going to be able to know everything. We try to do everything so there are Aha's throughout the day; we plan strategically." (RB) When students understand. When determining what students understood about science, Leigh's responses were more consistent with a Transitional approach. "We're really trying to push them more to show us with their writing. They don't necessarily do that with ease. We push them to write to demonstrate knowledge ... especially when their reading level has come up." (TS) Considering whole group discussion or group work, she added, "With discussion I'm trying to probe more, to see what they're thinking and not just looking for an answer. We're trying to be thinkers this year. They can talk about it, but eventually you want them to be able to write about it." (RS)

What to teach and what not to teach. All of the teachers that were interviewed work with a grade-level team of teachers. Therefore, Leigh's responses were similar to the others. "On our team, we'll have planning meetings, look at Core Content and Program of Studies and pile it all on table and then decide; but sometimes we go above that." (IN) For very practical reasons she stated, "We have a Plan A and a Plan B "Year-at-a-Glance" and it's a time issue because we teach different lessons in different years since we keep our students for 2 year. Our paces are different, but we coordinate with other teachers and teams." (TD)

When to move on to a new topic. Before a final assessment, a formative assessment was given to see what the students knew. "Based on how that looks, we'll decide if they're ready to move on to the next unit or not." (IN/TS) Then after the final 
assessment, Leigh commented about going back again to review with some students, "I could but I don't. I figure they've gotten as much as they're going to get." (TD)

How students learn science best. Leigh believed students learn science best, "When we're doing hands-on things; we have kits. We bring in field trips and technology." (TS) Adding about moving on to a new topic in relation to learning science, she said, "We're doing a turning point quiz with clickers and use these for a review before we give a test. It's another kind of formative assessment before we finish the unit to see where they are." (TS) These attempts to utilize a variety of formative assessment strategies confirmed a commitment to giving students multiple opportunities to demonstrate learning.

When learning is occurring. There was little doubt about Leigh's recognition of student learning. "There's a certain excitement you can feel; they're so eager to learn. They still have the enthusiasm; they can hardly wait. Hearing them at the zoo, giving them vocabulary that they can use in a real life setting, that's more powerful than having them do a written assessment. She related how a parent commented at the conclusion of the field trip to the zoo saying, "Wow, they really know this stuff!' Watching and seeing the light bulb go off; this is all making sense." (TS) Summary of Data Sources for Leigh

Data collected from the FAQ indicated that Leigh found formative assessment strategies "very valuable" and that she used them in "most lessons"; her short answer responses indicated an awareness of how she implemented formative assessment strategies with her students during instruction. From the five observations the data revealed evidence for all five formative assessment criteria with clarifying learning 
intentions, engineering discussions and providing feedback being the strongest. Leigh had indicated in her short responses that self-assessment was utilized though it was infrequent. Her interview indicated that her beliefs spanned the teacher-focused and student-focused categories with transitional and responsive-like behaviors occurring more frequently. Leigh was the only case study whose instructional practices spanned the five categories of the Teacher Belief Instrument (see Table 5.1). All data sources triangulated to verify this intentional approach to science instruction.

Jordan

Jordan was a 5 th grade teacher and had been teaching four years all in the current school. Jordan had also taught a $3 \mathrm{rd} / 4$ th grade combined class. Having recently obtained principal certification, Jordan indicated a desire to move into an administrative position by applying for an available assistant principal's position. Participation in formative assessment professional development has been provided by the local district, through collaboration with other teachers, from reading articles about formative assessment, and having studied the topic in college.

Responses to questionnaire statements. Responses to the short-response statements provided additional insight into the understanding of formative assessment. Following are the responses from the FAQ (see Table 4.12 for question prompts):

Q1 - Teachers are intentional and they use the information in a timely manner. Q2 - They sit and I don't grade them.

Q3 - I do a good job planning. Q4 - You can relate the material to them.

Q5 - The problem or exemplary work is obvious!

Q6 - There is limited time for me to do it.

Responses to value and use. Jordan indicated value of formative assessment circling 21 "very valuable", 7 "valuable", 2 "no strong view" items on the 
questionnaire. The two "no strong view" responses were in the self-assessment subconstruct $(\mathrm{S} 5, \mathrm{S6})$ regarding helping students understand their achievement and providing opportunities to assess work and give feedback.

As to use, Jordan did not circle any of the "most lessons" items. Instead circling 15 most days, 11 weekly and 2 quarterly items. Two items, 13 and I4, were not ranked.

\section{Observations of Jordan}

Jordan was observed twice within a four-day period. These two, two hour-long lessons had a physical science theme and were designed as end-of-the-year learning activities for 5 th grade students $(\mathrm{n}=54)$. Jordan co-taught science with another teacher. Like Leigh, they combined their classes, though these rooms opened by means of a foldable wall which otherwise would have separated their rooms. During an initial visit to this school to introduce myself and distribute the FAQ, and when interviewing Jordan, this wall was open; presumably this was a common feature of these classrooms.

Clarifying learning intentions. Lesson 1 was designed to give students background information about roller coaster physics to prepare them to design their own roller coaster. The students were to use flexible Styrofoam-like tubing which served as the track, and a marble which represented a race car. After 20 minutes into the lesson, Jordan's partner teacher stated, "It's what we want you to learn, potential energy." Prior to this statement of the learning goal, there had been a computer simulation showing how manipulation of height of the roller coaster track slope would have a direct effect on the potential energy of the race car to maintain speed and complete the course. Lecturing throughout this demonstration was the primary method of information delivery. Though the demonstration seemed entertaining, and the students appeared 
engaged in listening to the lecture, there was very little student-teacher interaction. After several minutes, Jordan informed the students, "Here's your job today; I only want you to manipulate one variable." Before distributing materials to construct a roller coaster, Jordan drew a diagram on the board explaining how the ramp should look and how to measure the height of the ramp, thus clarifying learning intentions.

In Lesson 2 a similar method of presenting information was utilized. This lesson pertained to pendulums. The partner teachers had constructed an elaborate demonstration model to show how kinetic energy of one pendulum would be transferred to another pendulum suspended from a cord strung between two poles. Early in the lesson a reference to the roller coaster event was made to recall the definition of potential energy. The question for the day was, "If a force is applied to pendulum \#1, what will happen to pendulum \#2?" This was immediately followed with, "It's the only question, and it's vague." The students were instructed to record all thoughts about this demonstration on a piece of paper and to use science vocabulary as they made observations of the swinging pendulums.

Engineering discussion. The intent of engineering discussion is to increase student-teacher interaction through questioning. There was little or no classroom discussion during either of the observations. In Lesson 1, a total of four questions were posed: "Who has been on a roller coaster?", "What kind of energy is that?", "If you change the mass?" and "Can you make a prediction about manipulating variables?" These low-level questions were responded to with one-word responses. In addition, these questions were directed to 54 students. Likewise, Jordan's replies to student questions were: "Yes," and, "kinetic energy". A more vigorous attempt was made at the 
beginning of Lesson 2 when it was announced that, "We're not going to tell you anything yet. Name some things you see." To this the students responded aloud, "the strings are parallel to each other," "fishing weights," "strings are same length," and "it's shaped like a trapezoid." Unlike Virginia and Leigh, nothing was done with these responses; they were not recorded or repeated or otherwise indicated as relevant to the question.

During Lesson 2, after having the students quietly watch several iterations of the pendulum demonstration, the question, "Can you tell me what was happening?" was posed to the whole group. One boy said, "too loose" and was cut off by Jordan who clarified, "Can you use science terms?" The boy resumed with "the pendulum was moving across the string" when again his response was cut short, but then allowed to resume and finished with, "and caused the string on the other pendulum to move."

Providing feedback. As with engineering discussion, there was little opportunity for the students or the teacher to give or get feedback from one another during the two observed lessons. In Lesson 1 quality of student work was addressed when the students were shown how to measure and record the height of their roller coaster ramp design. It was not obvious to this observer that students were recording information on the worksheet. In Lesson 2 when a student engaged Jordan with a question about what he was supposed to be writing, the teacher responded with, "Explain what happened and why it happened." This was a reiteration of the original direction presented to the class. One student did offer evidence of thinking by commenting, "I don't see a difference between Trial 1, 2 and 3." Neither Jordan nor the partner teacher responded. 
Activating students as owners of their own learning. At the conclusion of both observed lessons, worksheet hand-outs were collected by Jordan to learn what the students had been thinking with regard to the roller coasters and pendulums. During Lesson 1 the whole group was asked to make predictions about the actions of the roller coaster as variables were manipulated with the computer program. Students remarked with comments such as, "more speed," "higher hills" and "more mass." As Jordan manipulated the variables on the computer demonstration, the students would call out predictions.

In Lesson 2, a student asked, "Were they [the pendulums] supposed to give energy to one another?" Since the demonstration did not work as planned, it was difficult to discern, but this one student did demonstrate some independent thinking. A female student related how a roller coaster she had ridden at an amusement park had qualities similar to that of the demonstration. Both of these comments were unsolicited.

Peer and self-assessment. There were no observable incidents of peer or selfassessment during Lesson 1. In Lesson 2 the students had been writing observations on a sheet of paper throughout the demonstration trials and time was provided for this reflective writing; however, there was no student-to-student interactions.

Interview with Jordan

Maximizing student learning. Jordan responded to interview questions with a decidedly traditional approach to all aspects of teaching. Claiming to be, "Immersed in best practices. [You] have to figure out where your students are and design assessments." When directly addressing student learning Jordan said, "Really you have to know how you're going to get your kids there. That's how your lessons are going to 
be differentiated. For your higher-end students [they] can maybe do more independent work, hands-on lessons, and giving them vocabulary words. For your lower-end students you have to expose them to the vocabulary and make sure they are recalling it. You have to make sure they know the words and be able to use them." (TD) Use of the word "you" seemed somewhat impersonal as if Jordan was not taking ownership for student learning.

Role as a teacher. "I really like to guide them. I don't like to serve curriculum up on a platter. I could just tell them, some kids learn better that way. You've got to wrap it up, pull out the important ideas, like in social studies." (TD/IN) To reinforce this traditional approach Jordan added, "It's my job as a teacher to facilitate and design lessons that will get them where I want them to be in the end. I have to design the formative and summative assessments, [it's] my job to recognize whether they got it or not." And later, when prompted about multiple intelligences, "Some kids need handson, but others need to read it in a textbook, or need to hear me say it. I think I hit them (multiple intelligences) all over a course of a unit but I don't plan for it." (TD) When students understand. "At the beginning of the year, there is more monitoring and checking for understanding. There's the vocabulary that has to be taught, using the words, and quick exit slips to check for understanding of vocabulary." Jordan then expanded into a dialogue about special education students and how this core group generally needs remediation on a regular basis. Jordan commented, "Whatever your circumstance (SES, learning ability, etc.) is, it's your problem and maturity helps. We're here to help you, but ... the kids that take it in it really helps, but others will take a few more years of hearing (vocabulary) then it's up to them. Pray it's 
not too late, and aren't in too deep of a ditch." (TD) This evident detachment from special needs students was of concern throughout the interview process.

What to teach and what not to teach. Like the other case studies teachers, Jordan reinforced that Kentucky Core Content and Program of Studies were the main focal points of all instruction. Instead of science, a social studies example was given. "Kids have to understand the big reasons for social studies concepts. These big ideas become open response questions, and we hope that kids will mention names of explorers, but getting the big idea is more important." (IN)

When to move on to a new topic. Summing up Jordan's feelings about moving on to a new topic was stated in the initial response to fifth question from the FAQ; "Time constraints are the deciding factor, if the bulk of the kids get it, then you have to move on." Adding, "I try to spiral the information back and ask the same questions again, but don't completely stop teaching it. I guess in hope that they might get it." $(\mathrm{TD} / \mathrm{IN})$

How students learn science best. Jordan believed that, "Hands-on is the way to learn science and then write about. The writing helps them to process the end-result." (TS) Illustrating the point, Jordan recalled a lesson about plate tectonics saying, "The kids use the vocabulary and explain what happened when an earthquake hit. $80-85 \%$ of the kids after a one hour mini-lesson could use the vocabulary (faults, tectonic plates, Pangaea) that they had never heard before in previous lessons." (IN) This example contradicted stated efforts for hands-on learning.

When learning is occurring. "When they do the work independently. We give them the materials or an experiment and see what they can do." (IN) This was in 
reference to the roller coaster experiment that had been observed and the collected worksheets the students had completed.

\section{Summary of Data Sources for Jordan}

Evidence collected from the questionnaire Likert responses indicated that Jordan rated formative assessment strategies "very valuable" and used them "most days". The responses to the short statements were impersonal in the use of "they" and "you" to describe what was intended to be an individualized perspective of formative assessment practices (The statement prompts began with "I find formative assessment ..."). From two observations, the data displayed consistency regarding the use of formative assessment strategies which revealed that clarifying learning intentions was the primary strategy utilized. The interview indicated that Jordan's beliefs were predominantly teacher-focused with most responses firmly situated in the traditional category with some characteristics consistent with an instructive approach. 


\section{CHAPTER V \\ DISCUSSION OF FOUR CASE STUDIES}

Each teacher has previously been introduced to the reader and what follows is a comparison of those teachers' philosophies and instructional strategies to provide a finer-grained analysis of how formative assessment was used in their classrooms. Each case study details general instructional characteristics, unveiling traits unique to each teacher, along with an examination of how formative assessment strategies were utilized during the observations to draw conclusions about beliefs and utilization relative to formative assessment practices. Particular attention has been paid to how each teacher prepared students to learn and responded to student learning needs as described by Bruner's (1966) Theory of Instruction.

\section{Case Study Introduction}

To further clarify how each teacher presented a lesson to students and utilized formative assessment, the "non-negotiables" of assessment for learning strategies presented by Leahy et al., (2005) (which included Wiliam on the writing team) have been further analyzed and addressed here. This analysis also utilized Bruner's (1966) Theory of Instruction due to its constructivist stance. This theory of instruction (see Figure 5.1) stated that students must be (a) predisposed to learning by creating an environment that is conducive to the learner; (b) knowledge must be structured to be grasped by the learner; (c) careful attention is paid to the sequencing of learning events 
utilizing questioning and pacing; and finally, (d) students need corrective feedback to move them toward more complex learnings.

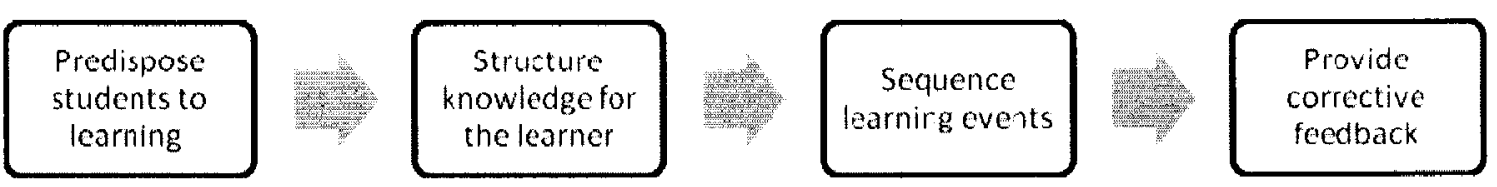

Figure 5.1. A sequential representation of the four elements of Bruner's Theory of Instruction.

This theoretical framework aligned particularly well with the more practical framework detailing assessment for learning (Leahy et al., 2005). When predisposing students to learning, the instructor clarifies learning intentions by involving students. When structuring knowledge, sequencing and pacing learning events, the instructor engineers and guides discussions with a variety of questions and activities to reinforce stated learning intentions. While providing corrective feedback or, "knowledge of results" (Bruner, 1966, p. 50), the instructor includes individual feedback about the work being done and specifies what students have or have not yet achieved. When teachers use student self-and peer-assessment, they activate students as owners of their learning, and ideally use student self-reflection to move learners to the next level of understanding.

Teacher-Focused and Student-Focused Approaches to Instruction Whereas Bruner's Theory of Instruction and the "non-negotiables" of formative assessment were used to discern the intricacies of the case studies observations, the Luft and Roehrig (2007) Teacher Belief Instrument (TBI) was used to distinguish science instructional beliefs during the case studies interviews. The TBI clusters 
instructional styles as teacher-focused, transitional or student-focused. Figure 5.2 is a graphic representation with science instruction examples.

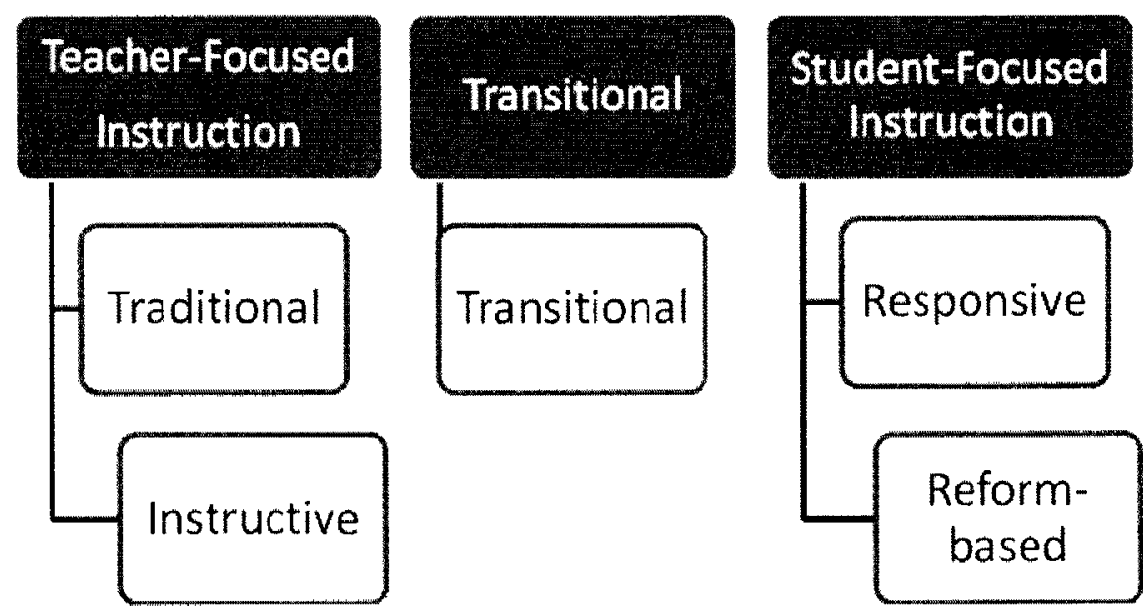

Teacher-Focused Approaches

The focus of instruction is transmission of information from teacher to student.

Science is based upon facts and skills to be learned.

Transitional

Instruction builds upon student-teacher relationships by providing learning experiences for students.

Science is has themes that can be connected to our lives.

Student-Focused Approaches

The focus of instruction is inquiry-based and planning is flexible based upon identified student learning needs.

Science is an active and interactive process.

Adapted from Luft, J. A., \& Roehrig, G. H. (2007).

Figure 5.2. A visual representation of the five instructional styles categorized as teacher-focused, transitional and student-focused with example statements regarding science content and instructional ways of thinking.

How a teacher approaches science instruction and the belief system that frames how learning events are presented to students are somewhat predictive of how a teacher 
uses formative assessment strategies. As the case study interviews were coded utilizing the TBI, distinctive patterns emerged. Table 5.1 presents a particularly interesting pattern.

Table 5.1

Case Study Teachers' View about Their Teaching

\begin{tabular}{lccccc}
\hline & \multicolumn{2}{c}{ Teacher-Focused } & \multicolumn{3}{c}{ Student-Focused } \\
& Traditional & Instructive & Transitional & Responsive & Reform-based \\
\hline Jordan & IIIli & Illi & li & & \\
Tina & IIli & IIIlii & liii & liii & \\
Leigh & li & III & IIlii & IIIli & II \\
Virginia & & & liii & IIIli & IIII \\
\hline
\end{tabular}

Note. $\mathbf{I}=\mathbf{a}$ strong interview statement $\quad \mathbf{i}=\mathbf{a}$ less strong interview statement

When coding the interview responses a differentiation was made between strong statements (I) and less strong statements (i). To illustrate, when responding to the fourth interview question, How do you decide what to teach and what not to teach?, Tina's response contained both traditional and transitional characteristics. However more of her response was traditional and less was transitional, therefore that response was coded as I for traditional and ii for transitional.

Following are detailed discussions for each case study. First, the teacher-focused case studies are presented and then the student-focused case studies (the order presented in Table 5.1). General instructional characteristics for each teacher, their use of formative assessment strategies and the effect of professional development are examined in greater detail. 


\section{Two Teacher-Focused Case Studies}

\section{Jordan}

\section{General Instructional Characteristics}

Each teacher in this study had unique personal and professional characteristics which likely influenced their pedagogical practices. Each had different educational backgrounds and teaching experiences that had apparently influenced their instructional pedagogy. This first case study is about Jordan who had five years of teaching experience, all at the same school, and who had experienced two different teaching assignments within that tenure. Two consistent themes characterized the observations and interview with Jordan, that is, unrealistic expectations when developing a lesson plan and a persistent sense of impatience with students.

Unrealistic planning and expectations. Jordan commented prior to the beginning of the first observation that the formative assessment, which would occur later in the week, would be based upon the roller coaster experiment and write-up the students were about to carry out. Jordan explained that the questions were generally the same, but tailored to meet the science concept under study. During the interview in response to the question, "How do you know if your students understand?" Jordan commented, "If we run out of time and can't do an exit slip, we'll do an admit slip. It's a good way to start a lesson or bring closure to a lesson. It's our main form of formative assessment." Unfortunately neither an exit slip nor an admit slip were ever observed.

The first lesson had a 45-minute lecture-demonstration component and a much shorter activity period characterized by students randomly designing roller coaster tracks that were contorted and disorganized. Materials were readily available for the 
teacher and the students, however, expectations for student work were not clarified. While students were designing their marble roller coasters, Jordan would remind them to measure and draw their model while constructing and carrying out trials. The handout contained an error with regard to the definitions of potential and kinetic energy. Of the student work reviewed, fewer than half of the students corrected these definitions even after it was called to their attention. In a constant effort to reinforce vocabulary, Jordan and the partner teacher commented to the students that in middle school if they didn't know the vocabulary words they would appear poorly prepared to do the higher level science.

Considering expectations for students, the second observation began with a question and answer session, but the parameters or guidelines for answering were not initially stated. This led Jordan to respond negatively to student behaviors that were deemed unacceptable, such as when they did not raise their hands to answer questions.

After the construction of the elaborate pendulum demonstration, the students were instructed to write a prediction and then script observations. The students had observed the kinetic energy of Pendulum 1 being transferred to Pendulum 2 (one pendulum was put into motion and the movement of the string from which both were suspended caused the other to swing as energy was constantly being passed back and forth). The partner teacher then read what should have happened, however what he read and what the students observed were in opposition. Reviewing student responses that Jordan provided confirmed that the execution of the demonstration and the intent of this lesson were not well-planned and ultimately caused student confusion since their responses did not reflect the transfer of kinetic energy between the pendulums. 
Toward the end of the lesson Jordan began lecturing about potential and kinetic energy, and energy transfer to address misconceptions which had occurred. Anticipating possible malfunctions or errors in the lesson had not been taken into account; the student work provided by Jordan revealed confusion about transfer of energy. The students hypothesized and wrote exactly what they observed, and did not incorporate what should have happened because they had not seen it.

A statement from the FAQ became foretelling. In response to "I find it easiest to model quality work for students," Jordan wrote, "You can relate the material to them." Though the goals of this lesson were well-intended, the actual demonstration failed to show transfer of energy. In addition, Jordan's response to the prompt "I find it easiest to involve students in their learning," was completed with, "I do a good job planning." In hindsight this became a foretelling statement about the teaching style and relationship with students that were observed.

Impatience with students. At times Jordan seemed more concerned with behavior management than the science content or use of formative assessment strategies as had been indicated as valuable on the FAQ. Jordan's interactions with the students were limited. Lecturing was the primary mode of instruction. A particularly annoying habit was "shushing" of students if they made any noise while lecturing. Jordan's lecturing revealed a solid understanding of the content but rarely allowed students to interact or solicit their thoughts or questions about the content. When visiting small groups to observe progress, Jordan quickly assessed the problem or issue, would make a suggestion, or take control over the work. During the roller coaster design phase, there was no questioning or inquiry about what the students had planned; rather there were 
quick judgments made and direct intervention. There was seldom an opportunity given for students to engage in reflective thinking or to exchange ideas with the teacher.

During the lecture, when a question was posed, whether open-ended or fishing for a specific answer, the reactions to students' responses were (a) a reminder that they should have raised a hand, (b) an interruption mid-sentence, or (c) the student response was not acknowledged or confirmed as correct or incorrect.

A frustration with students identified with special learning needs became apparent during the interview. "You can always count on 5-15 of the 5th grades (of 113) who are not getting it. They struggle with the content and you may have to teach the whole unit again, in a different fashion." Jordan thought that, "They would still be in the exact same place," if the unit were re-taught. Interestingly, Jordan knew many of these students having taught them in the 3 rd grade. There was a sense of pre-determination about those students "who would pick up the material and who wouldn't. You have to move on. Sometimes they dig too deep of a hole for themselves," Jordan concluded. Using Formative Assessment Strategies

A review of Jordan's FAQ responses is provided in Table 5.2. Jordan had indicated high value for formative assessment strategies and that these strategies were used on a weekly basis. 
Table 5.2

Jordan's Reported Value and Use of Formative Assessment Strategies

\begin{tabular}{lll}
$\begin{array}{l}\text { Formative Assessment } \\
\text { Constructs }\end{array}$ & $\begin{array}{c}\text { Reported Value } \\
\text { (mean) }\end{array}$ & $\begin{array}{c}\text { Reported Use } \\
\text { (mean) }\end{array}$ \\
\hline Involving Students & 5.0 very valuable & 2.6 weekly \\
Modeling Quality Work & 4.8 very valuable & 3.0 weekly \\
Providing Feedback & 4.1 very valuable & 3.5 most days \\
Using Self-Assessment & 5.0 very valuable & 3.6 most days \\
\hline \multicolumn{1}{c}{ Mean } & 4.7 very valuable & 3.2 weekly \\
\hline
\end{tabular}

There is a disconnect between value and use for all four sub-constructs. One would expect more frequent use of formative assessment strategies if all were reported as very valuable as they have been. Reviewing responses on the FAQ in the modeling quality construct, Jordan selected "quarterly" for the item "getting student to suggest ways something can be improved." This impatience with students became foretelling in that Jordan did not take the time to investigate students' thoughts about the work they were doing.

In the providing feedback sub-construct, more selected responses were "most days" however, there was one "quarterly" response about making a conscious decision to avoid saying a student is wrong. There were three "weekly" responses about items that addressed analyzing student work, giving rewards for successful work, and telling students what they had achieved. This variation from "most days" revealed and was confirmed by the observation and interview suggesting that these formative assessment strategies may not have been as highly valued as had been indicated. Jordan made only one feedback response to students during the two observations. 
In the self-assessment sub-construct, items related to helping students to understand their achievements, knowing what to do to make progress, and providing opportunities for students to assess their own and another's work with feedback were ranked as "weekly" responses. To the short-response statement, "I find it easiest to give students opportunities to self-assess when ..." Jordan wrote, "There is limited time for me to do it." Once again, the value for formative assessment and the use of formative assessment were at odds. The FAQ items, the short-response statements, the observations and interview provided strong evidence in this disparity about making a conscious decision to plan and to involve students in the lesson.

Preparing Students to Learn and Responding to Student Learning

To corroborate this difference, data are presented in Table 5.3 accounting for the occurrences of formative assessment strategies that were observed.

Table 5.3

Jordan's Detailed Use of Formative Assessment Strategies

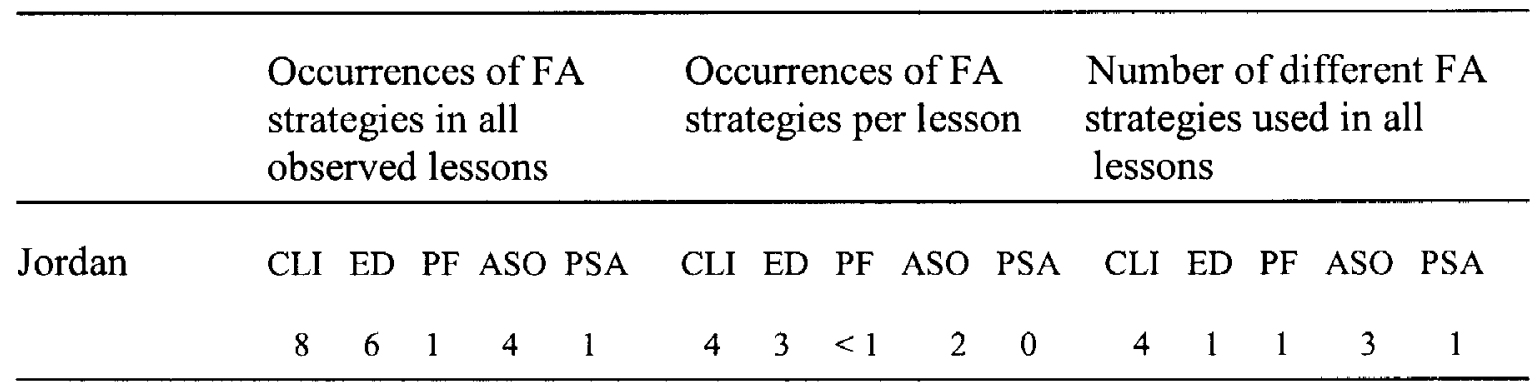

Note. See Table 4.18 for a detailed description of five formative assessment strategies.

To prepare students for the lesson, considerable time was spent lecturing and stating goals to the students (CLI). Typically there was mention of what had been done and where the lesson was going; there was heavy reinforcement of vocabulary which students were expected to use when writing predictions, observations, and write-ups associated with the lessons. At the end of the second observation Jordan relied upon the 
partner teacher to clarify learning intentions about the pendulum demonstration, by disengaging from the discussion and beginning to prepare for the upcoming social studies lesson; the partner teacher completed the science lesson wrap-up. There was little transition time for the students as Jordan launched into a review of what had been done the previous day in the history lesson.

As the values in Table 5.3 indicate, the other formative assessment strategies were observed minimally if at all. Due to the lecture format, it appeared that engineering discussion (ED) to structure knowledge and sequence learning events was not a preferred method of preparing students to learn. Either/or questions were posed such as, "What are you looking at, potential energy or kinetic energy?" When questioning students about the pendulum demonstration, the whole class was asked, "If you were going to re-design this experiment to make it work better, what would you do?" Two students raised their hands; however, the student called upon was not one of them. This particular student had not been paying attention and was unable to respond to the question. It appeared that this was a classroom management strategy and not a true assessment of student knowledge.

Later in the lesson, Jordan stood with a teacher's aide who had entered the room. Together they watched the students work, chatted but did not check on progress, read responses, or give any feedback (PF). When students did ask for help, Jordan repeated the original directions asking, "What is happening? Why did it happen that way?" Jordan did not wait for responses to these questions. 
Students were sometimes discouraged from engaging in any kind of peerassessment as data in Table 5.3 indicates. During the pendulum demonstration, they were told specifically not to talk with one another (ASO/PSA).

It is interesting to note that a common instructional strategy utilized by this particular school is termed "turn-and-talk" which encourages students to have conversations about what they are learning. In Jordan's class it was obviously not being encouraged which is contradictory of how the partner teachers behaved while instructing. During lesson presentations, the partner teachers interacted freely and exchanged ideas, but these same behaviors were not encouraged for the students other than during the marble course design.

\section{Professional Development and Concluding Statements}

Jordan had indicated that formative assessment training had been from the district due to his position as a lead teacher; collaborating with other teachers, having read articles and taking college level courses were the other areas indicated on the FAQ.

The FAQ value and use responses along with the professional development opportunities would seem to indicate that Jordan would have exhibited more formative assessment strategies during instruction that would lead students toward the lesson goals; this was clearly not the case as observed. As has also been reported, Jordan preferred a traditional and instructive style of teaching with an emphasis on vocabulary, lecturing and demonstrations.

Jordan's high energy teaching style, where being in complete control of the learning environment was important, coupled with high, but unrealistic, expectations for the students is not necessarily contradictory of formative assessment usage. There was a 
pervasive sense of impatience, both with the lesson as planned, and with the students. Jordan's teaching style seemed to be that of 'putting on a performance'. Using Bruner's Theory of Instruction as a lens to examine Jordan's pedagogy, the use of formative assessment strategies may be enhanced by a slower, more carefully planned and paced lesson. Planning that incorporates more intentional interactions with students would predispose them to learn; the learning environment was non-constructivist and learners were unable to interact except when given permission. The information presented was intentionally sequenced and paced; however, it seemed to better serve the needs of the instructor and not necessarily the needs of the learners. The learning events would need to incorporate interactive questioning and actual discussion of topics to allow students to construct knowledge. Providing feedback to students and opportunities for self- and peer-assessment were essentially absent.

Tina

\section{General Instructional Characteristics}

There were consistent instructional themes-time constraints, misinformation and uncertainty, and inexperience - that occurred repeatedly throughout the three observations of Tina. These observations occurred over a 7-day period due to end-ofthe-year state assessment that interfered with her normal routine for science lessons. Each are presented separately, but ultimately all three had a direct influence on her use of formative assessment strategies.

Time constraints. The first characteristic was Tina's frequent reference to time limitations. Upon examination of the FAQ to what hindered her from using formative assessment she indicated that "it takes much time to grade the assessments." 
Throughout the three observations, Tina frequently referred to time as a limiting factor. Less than fifteen minutes into the first observation, with many student hands waving in the air to respond to the question, "Why do plants need stems?" Tina stated, "We need to get through this so we can go to recess." She did not have time to complete the exit slips, postponing it by stating, "We need to go outside; I want to get through this." An initial effort to have students analyze her power point notes to create their own studentfriendly definition by discerning which words were more important was abandoned after about 30 minutes of instruction along with her frequent reminders that they "had to get through this lesson".

As Tina neared the end of the second observed lesson, a planned summative statement about plant adaptations to environmental conditions was suddenly abandoned after looking at the clock. She informed the students that, "When we get back from recess we'll do an exit slip." During the third observation she again announced that they were running out of time and needed to, "get as much done as possible because I need to teach you more science before the end of the school year." In response to the first interview question Tina lamented, "The day is limited and time is at a minimum."

Misinformation and uncertainty. The second theme that recurred in two of the three observed lesson was misinformation and uncertainty with regard to the science content being taught. Tina related in the interview that she did not like teaching science the previous school year and had been learning along with her students. However during this second year of teaching, she "liked teaching science and relied heavily upon the organizational aspects of the power points" which she had created for herself and her team; she took great pride in this achievement. 
During the first observed lesson she acknowledged a student response as correct when actually it was incorrect. The student had responded to her question, "Why are leaves so important?" with "Water drips on leaves and goes into the stem." Later in the same lesson she identified an apple as a flower (a fruit is the ripened ovule of the flower, and perhaps this is where the confusion lies). A well-informed student tried to argue this point with her, but she insisted she was correct. The student persisted but did not seem to have the confidence to correct her.

Tina mishandled some information in the third observed lesson while the students were discussing plant adaptations. Tina often seemed to be creating in-themoment examples revealing inadequate preparation and poor anticipation of student questions. The adaptation example she chose dealt with how people adapt to cold weather by wearing boots and warmer clothes. Though this could be considered a form of adaptation, it is not one equivalent to how plants respond to climatic changes.

During the discussion of alpine plants, Tina chose a small, potted plant from the classroom window sill; the plant was a succulent. She had previously outlined typical alpine plant characteristics such as thick, waxy leaves and then provided the succulent as an example. While reading the label and struggling with pronunciation of the scientific name she said, "I don't know what kind of name that is. It just says 'protect from frost.'”

Inexperience. Along with in-the-moment examples, she seemed to have sudden bursts of ideas but not necessarily the resources to carry out these ideas. During the first observed lesson, she considered using a mobile notepad linked to her overhead 
projection system; she went to a storage closet to retrieve it, but discovered the batteries were dead.

The third observed lesson included plans for small groups of students to investigate characteristics of one of seven biomes. Criteria for what to include in the biome drawing were outlined during a whole group discussion, but later in the lesson she told students to "decide whatever you want to put down". She had not comprehensively listed the tasks the groups were to achieve; these were interjected into the lesson as the students worked. Tina did have drawing paper and coloring materials ready for the students, but other research materials needed to complete the project (e.g. informational resources about the assigned biome) were not readily available. As to resources, she said, "I forgot, we've got encyclopedias." Apparently she had not previewed the information contained within these books since some of these $3^{\text {rd }}$ graders were able to find information but others were unable to find information for their biome poster. She resorted to helping one group look for information on the World Wide Web, but even then there was random searching instead of using pre-selected sites. Tina had told the students they would share results with the whole class, but presentation guidelines were not provided and she did not specify how or when this event would occur.

Announcing during the last ten minutes of the lesson, "If you use resources, be sure you write down where you got ideas and make a research note in your notebooks, and give those people credit" did not seem to happen. There was no indication that the students were doing anything other than looking up information and drawing plant and 
animal pictures. Checking the clock she proceeded to the presentation phase of her lesson plan saying, "I'm not sure we'll have time to share, but we'll get started."

Using Formative Assessment Strategies

Use of formative assessment strategies were previously reported in the data analysis chapter. Here the three data sources are compared and a clearer picture of her instruction emerges. Table 5.4 summarizes the FAQ data.

Table 5.4

Tina's Reported Value and Use of Formative Assessment Strategies

\begin{tabular}{lll}
$\begin{array}{l}\text { Formative Assessment } \\
\text { Constructs }\end{array}$ & $\begin{array}{c}\text { Reported Value } \\
(\text { mean })\end{array}$ & $\begin{array}{c}\text { Reported Use } \\
(\text { mean })\end{array}$ \\
\hline Involving Students & 4.7 very valuable & 3.5 most days \\
Modeling Quality Work & 3.8 valuable & 1.9 quarterly \\
Providing Feedback & 4.6 very valuable & 4.2 most lessons \\
Using Self-Assessment & 4.2 very valuable & 2.8 weekly \\
\hline \multicolumn{1}{c}{ Mean } & 4.3 very valuable & 3.1 most days \\
\hline
\end{tabular}

Though these data indicate Tina values formative assessment, her use differs for three of the four sub-constructs: involving students, modeling quality work and using self-assessment. Upon further investigation of observation notes and FAQ responses, Tina's use of formative assessment strategies were not as strong as her responses indicated with the exception of modeling quality work. She seemed to have understood that this was not an instructional strategy that she used, and indeed it was never observed. As to the other three sub-constructs, the use mean values are predictive of 
inconsistencies represented. Table 5.5 presents the coded results of the observed lessons for the occurrences and frequency of formative assessment strategies.

Table 5.5

Tina's Detailed Use of Formative Assessment Strategies

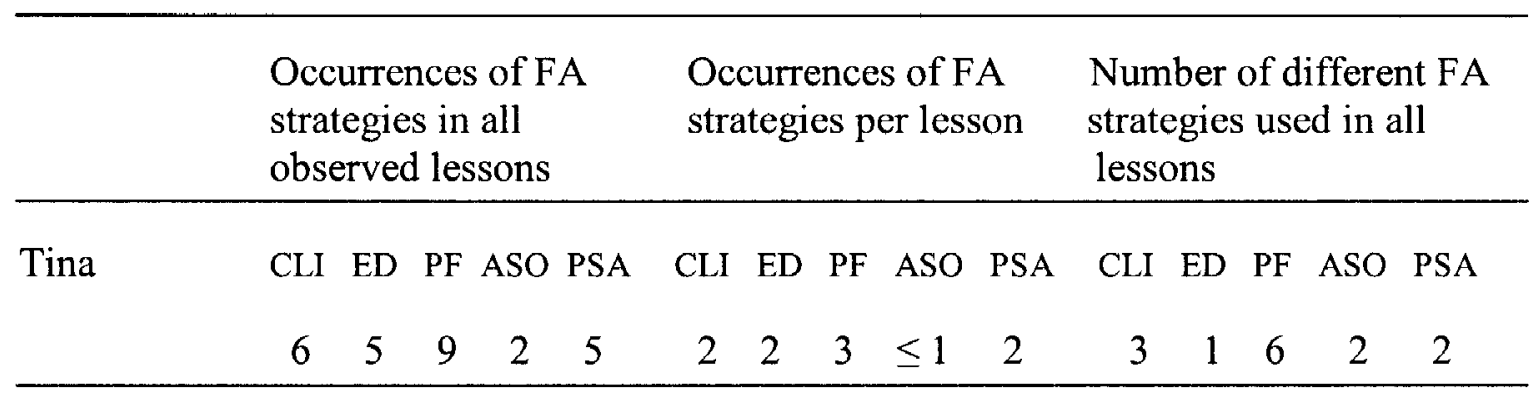

Note. See Table 4.18 for a detailed description of five formative assessment strategies. Preparing Students to Learn and Responding to Student Learning

At the beginning of each lesson Tina stated her goals. However, with the exception of one occurrence of stating what had been done in a previous lesson and once posting a schema for the students to reference, stating goals was the only CLI strategy consistently used during the three observed lessons. This observation was reinforced by an interview statement when Tina responded to the question, "How do you describe your role as a teacher?" She responded, "I see myself as a facilitator of information, one who provides the information and skills and then monitors them for attaining basic skills before they move to the next grade." Having just finished her internship year, it seemed apparent that Tina knew that stating goals at the beginning of the lesson was important. Like Jordan, preparing students to learn was one of Tina's stronger characteristics.

In response to the interview question, "How do you know when learning is occurring in your classroom?" Tina responded, "I look and see if there is complete engagement, or I see a look on their face." This transitional (TS) response to student 
engagement reinforces the inexperience quality of her teaching along with her more teacher-focused approach to science instruction.

Using the power point presentations did appear to assist her with sequencing and pacing her lessons. Information was presented in an orderly manner and the concepts built upon one another. Science content in the presentations was accurate. When Tina went "off script" by interjecting examples or information not on the power point was when her inexperience with scientific knowledge became more obvious.

Sequencing and pacing were negatively affected by her time management skills. The sense of the lesson being "rushed" was predominant. In the first lesson she addressed a great deal of information about plant parts and functions. Her attempt to bring closure to the lesson by having each student draw a plant, label its parts and state why each was important was too much for the students to do in a 5-minute period of time. Though data about student retention of lesson objectives were not collected, it would be interesting to have investigated the long-term affect in the students' knowledge regarding these lesson goals and objectives. There was not enough time for the students to do an adequate job with this task; follow-up on lesson goals with an exit slip or an admit slip could have provided valuable information for Tina. This type of formative assessment could have provided Tina with the information she needed to plan the follow-up lesson.

The data in Table 5.5 would lead one to believe that Tina spent a great deal of time giving feedback to students. Though she utilized six of the eight PF criteria, these remarks were generally made to the whole group. Effective feedback is undertaken with individual students are in small group discussions where the teacher can be assured that 
students have acted upon the information that was exchanged and student work reflects the feedback. The FAQ data also suggested that giving feedback was frequently used as 6 of the 10 responses were marked "most lessons" and 1 of the 10 items was ranked as "most days." Feedback items about giving rewards and specifying a better/different way of doing work, and telling students what they have achieved with references to their learning were marked as "weekly" and "quarterly" respectively, and indeed these kinds of behaviors were not observed within the time frame of these three observations.

\section{Professional Development and Concluding Statements}

Tina had stated her knowledge of formative assessment came from three sources: collaborating with colleagues, reading articles and having taken college courses. During the interview she stated she was enrolled in an on-line master's level course and she offered that she had read articles by Stiggins, Wiggins and Marzano; however, actual works were not specified.

It would appear that the FAQ responses, both Likert values and short-responses, foretold of her actual use of formative assessment strategies. Combined with her inexperience and her self-acknowledged lack of science background knowledge, more specific professional development training would seem to have been beneficial to build her repertoire and ability to use formative assessment strategies. The other teachers had had some district training; Tina had not had the benefit of attending any of these sessions.

It would be presumptuous to assume that young, beginning teachers would not value or use formative assessment strategies as it would also be presumptuous to assume that factors such as time limitations, misconceptions, uncertainty and 
unpreparedness were general descriptors of an inexperienced teacher. Data from the ANOVA confirmed that there was no correlation between years of experience and the use of formative assessment strategies. However, for Tina, it does seem to be true. Her estimation of usage as reported on the FAQ was congruent with that presumption to some extent. Modeling quality work and using self-assessment were reported lower on the FAQ scale and observed infrequently in her classroom. Involving students and providing feedback were over-estimated.

Like Jordan, Tina did attempt to predispose her students to learning by stating the goals of the lesson, and the power point presentation did assist with the structuring of the knowledge, however, these instructional strategies skim the surface of what Bruner's theory proposed as creating a learning environment that is conducive to the learner. Tina's instructional beliefs spanned the teacher-focused category and presented some evidence to indicate a responsive approach to science instruction. Further and deeper learning would require more time structuring and pacing the lesson with intentional feedback to reinforce lesson content. Tina's inexperience, time management skills, and weak content knowledge were detriments to fulfilling this deeper learning that is prescribed by a constructivist approach to instruction.

Two Student-Focused Case Studies

\section{Leigh}

\section{General Instructional Characteristics}

Whereas Tina's and Jordan's classrooms conveyed a sense of hurriedness and impatience with progress of the lesson, Leigh's classroom was the opposite; Leigh was in complete control, but at a relaxed pace. Students were orderly, calm and attentive 
during the five observed lessons, which occurred over an 8-day time period. Her room was a typical elementary classroom with a carpet and small individual student desks; the added element was a picnic table covered by a tablecloth and surrounded by captain's chairs. Science was the last subject of the day, and as class ended the students began their specially-assigned duties of cleaning up, putting supplies away, dusting and other household chores. Her strength was planning with her partner teacher, which wove in skills along with the content to address student learning needs.

Planning with purpose. Like Jordan, Leigh worked closely with a partner teacher where lesson planning and some instruction were done in tandem. Either Leigh or her partner teacher would take the lead when introducing the topic to the students, but then each class would separate to complete the assigned work. (In Jordan's classroom, all 56 students would remain together throughout the lesson). During three of the five observed lessons, the students either moved from Leigh's room to the partner's or vice versa.

The introduction of the lessons revealed Leigh's strength as a planner. Due to the fact that Leigh taught both first and second grade students, (the first graders "looped" and stayed with her two years) the team teachers had developed a two-year plan where they taught different lessons in different years. To demonstrate independence and responsiveness to her students, Leigh said, "Our paces are different, but we coordinate with the other teachers and teams."

The first observed lesson began with a quick review of the topic about animal movement which progressed to how animals acquired food. Leigh's planning strengths were revealed by the multiple reinforcements to emphasize the lesson topic: (a) an 
opening discussion tying movement to acquiring food, (b) a video clip where Leigh asked the students to listen for the words predator and prey as they watched, and (c) reading the book "Who Eats What" at the conclusion of the video. The follow-up lesson reinforced the predator/prey lesson when students began research of their speciallychosen animal for the "All About" books they were creating. Using a document camera (a technology piece to project the pages of the booklet) to clarify assignment criteria, Leigh told her students that "the goal is to finish two pages today".

This intentional purpose and planning characteristic continued throughout the other observations where a variety of instructional strategies were mixed with the use of technology and team teaching. The third observation began with a review of the previous lesson using an overhead projection system. As students responded to reflective and probing questions, the partner teacher organized their responses onto a chart labeled "Vertebrate and Invertebrates". When students returned to their own classrooms, this concept was reinforced with the next segment of their "All About" books. During the fourth observation, the students were in a workshop setting coloring stamp-sized pictures of vertebrates and invertebrates. They cut the pictures apart and placed them in their books in the appropriate column (see Figure 5.3). Music was playing in the background while they colored and chatted appropriately with one another. 


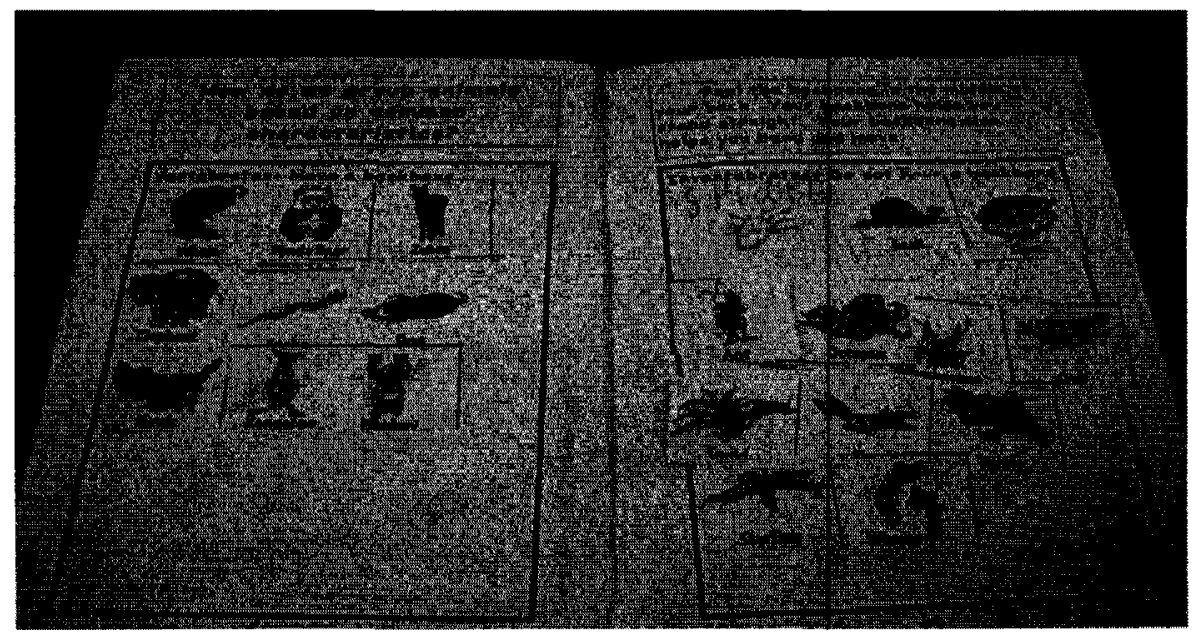

Figure 5.3. A photo of two pages in the "All About" books.

The final observation again revealed multiple layers of planning and

reinforcement of lesson topics. The students had visited the local zoo the previous week and this lesson was a review of the five classes of animals, followed by a video where the word "classify" was the word of the day. Leigh had large posters of each of the five classes of animals and engaged the students in an animated discussion about key characteristics. During the interview, in response to the question about how her students learn science best, Leigh remarked, "If we had done something like this earlier in the year, it would have been more me telling the students" how to do a particular skill or "giving them vocabulary to work with." Even though this remark sounded more traditional (lecturing to students) it may be an indication that Leigh transformed with her students; she may have needed to begin the year in a more traditional mode and became more responsive as she watched her students gain requisite skills. One key student skill she encouraged was the use of recent vocabulary. Leigh remarked, "Hearing them at the zoo, giving them vocabulary that they can use in a real life setting; that's more powerful than having them do a written assessment." 
Understanding student needs. Two of Leigh's responses on the FAQ were an indication that her students' needs were at the core of her decision making. To the modeling quality work and the feedback statements she focused on conferencing and working with students in one-on-one situations. This individual attention was evident throughout Leigh's instruction. Even though both first and second grade students were in this classroom, the difference was not discernable. She perceptibly revealed that she felt like she really understood her students' learning needs. Leigh, who also had certification as a Reading Specialist, was looking more at what her students could do, rather than what each could not do. In addition, this comment was made late in the school year, indicating that she had not given up on assisting two students who were below-grade reading levels.

Leigh did not hesitate to reveal that "Science is not my strong suit; reading and writing are my thing." To reinforce this point, the students were given free choice about the animal for their "All About Animals" books. The students were paired intentionally to give each a positive working relationship. Only one special-needs boy worked alone. He had a vivid imagination and seemed to be distracted by his own creative thoughts. Leigh's response was to re-direct him with probing questions and gentle reminders. Focusing on giving students the time needed to accomplish the task at hand was more important than finished on a prescribed time table. This attitude was in direct contrast with how Tina operated in her classroom.

In the interview, Leigh referred to a student's "All About" book sitting on the table, and read a few sentences from his work. Reflecting she said, "He writes with 
great voice, it all fits together. He's your average first grader." Comments such as this revealed Leigh's high expectations for her students' progress.

\section{Using Formative Assessment Strategies}

Of the 60 items on the FAQ, Leigh answered 50 of them with a " 5 " for either very valuable or used in most lessons (see Table 5.6). The exceptions were in the modeling quality work sub-construct; these were the three items about judging student work that were linked together when analyzing the data in the SEM model. The one relative weakness for Leigh was using strategies in the self-assessment sub-construct; she recognized that she did not give students enough time to review their own or other's work.

Table 5.6

Leigh's Reported Value and Use of Formative Assessment Strategies

\begin{tabular}{lll}
$\begin{array}{l}\text { Formative Assessment } \\
\text { Constructs }\end{array}$ & $\begin{array}{c}\text { Reported Value } \\
\text { (mean) }\end{array}$ & $\begin{array}{c}\text { Reported Use } \\
\text { (mean) }\end{array}$ \\
\hline Involving Students & 5.0 very valuable & 5.0 most lessons \\
Modeling Quality Work & 4.5 very valuable & 4.8 most lessons \\
Providing Feedback & 4.7 very valuable & 4.5 most lessons \\
Using Self-Assessment & 5.0 very valuable & 4.0 most days \\
\hline \multicolumn{1}{c}{ Mean } & 4.8 very valuable & 4.6 most lessons \\
\hline
\end{tabular}

Comparing the FAQ responses (Table 5.6) with the use of formative assessment strategies during instruction can be seen in Table 5.7, Leigh's stated beliefs about the value and use of formative assessment and the actual occurrence in her instruction were well-aligned. 
Table 5.7

Leigh's Detailed Use of Formative Assessment Strategies

\begin{tabular}{|c|c|c|c|c|c|c|c|c|c|c|c|c|c|}
\hline \multirow[b]{2}{*}{ Leigh } & \multicolumn{3}{|c|}{$\begin{array}{l}\text { Occurrences of FA } \\
\text { strategies in all } \\
\text { observed lessons }\end{array}$} & \multicolumn{5}{|c|}{$\begin{array}{l}\text { Occurrences of FA } \\
\text { strategies per lesson }\end{array}$} & \multicolumn{5}{|c|}{$\begin{array}{l}\text { Number of different FA } \\
\text { strategies used in all } \\
\text { lessons }\end{array}$} \\
\hline & CLI ED & PF ASO & PSA & CLI & ED & $\mathrm{PF}$ & ASO & PSA & CLI & ED & $\mathrm{PF}$ & ASO & PSA \\
\hline & $13 \quad 15$ & $13 \quad 10$ & 3 & 2 & 3 & 3 & 2 & $<1$ & 4 & 4 & 6 & 3 & 2 \\
\hline
\end{tabular}

Note. See Table 4.18 for a detailed description of five formative assessment strategies.

Preparing Students to Learn and Responding to Student Learning Needs

Like Jordan and Tina, Leigh was very attentive to preparing her students at the beginning of each lesson to understand the goals and clarify learning intentions (CLI). The distinctive difference between those teachers was her adeptness at planning and carrying out those plans in her instruction. Leigh made use of schemas, telling or questioning students about what had been done, and where they were going with the lesson; all of which are components of CLI.

Once introduced to the goals and intentions of the lesson, Leigh did what is more representative of student-focused instructors; she asked students many questions to check for understanding. She recognized that she did ask more probing questions to engineer discussion (ED) or to determine what her students were thinking. Leigh added, "Letting them talk to each other, explaining to someone else is the best way to really prove you understand." Unlike Jordan, who did not seem to value what students had to say, Leigh demonstrated patience when listening to student responses and used those responses to phrase the next question. When engaged in instructional conversations, she was able to provide immediate feedback to the individual student, but also to the whole group especially when they were seated on the carpet engaged in science-specific 
discussions. She used these opportunities to implement six of the eight feedback (PF) strategies (see the Table 4.18).

During one of these discussions a student asked a question to which she did not know the answer, Leigh instead manipulated this opportunity to encourage more scientific exploration by asking the student to think about key characteristics of reptiles while pointing to the reptile poster. She encouraged future questions by saying, "That's a really good burning question." She did follow up the next day with the correct answer for this student.

Activating students as owners of their own learning (ASO) revealed how safe it was for students to ask questions in her classroom. She modeled for students how to use resources to answer what she referred to as "burning questions". She stressed in the interview that she wanted students to provide evidence to support their thinking, adding, "It will help in their writing to show what they're thinking; it's that kind of probing."

Planning to use formative assessment was evident with the "All About" books. Leigh purposefully exposed them to different texts when using the non-fiction books and simultaneously reinforced skills such as using a table of contents and an index. She was very conscientious about "knowing when they're ready" to use multiple resources including one another (PSA). "They know the conventions like using an index and a table of contents and so they can be more independent."

\section{Professional Development and Concluding Statements}

Leigh checked all forms of professional development on the FAQ. She was also certified as a Reading Specialist and indicated in her interview that she thought of herself as a language arts teacher first and foremost. She was very aware that one aspect 
of the school's PD focus was on reading and writing; she wanted and needed feedback through training to reinforce that she was doing the right things to improve her instruction. Her self-awareness became evident again when she admitted that, "I like hearing about PD practices but I need to see it in action."

Though Leigh's beliefs about her teaching spanned from teacher-focused to student-focused (see Table 5.1), this analysis more strongly points toward a studentfocused approach. There appeared to be some difference between observations and interview responses with some interview responses coded as traditional and responsive however, coupled with the FAQ and the observations those responses align more with a student-focused approach. As Leigh clarified her views about professional development training and how she incorporated that training into her teaching, she provided more convincing evidence that her beliefs, her training and her instruction were congruent.

Leigh was consistent in predisposing her students to learn and sequencing and pacing her instruction for optimal classroom experiences. Feedback to the students was a positive characteristic that was absent in Jordan's instruction and developing in Tina's instruction. Leigh did spend time giving feedback to individuals using a variety of methods, however, as often as not, the feedback was given to the whole group. Overall, her responsive style of teaching aligned well with Bruner's Theory of Instruction and the data provided on the FAQ was fairly predictive of her use of formative assessment strategies. 


\section{Virginia}

\section{General Instructional Characteristics}

As with the other case studies, there were strong, obvious characteristics about Virginia's teaching that were consistently displayed throughout each observation. Virginia's classroom was the busiest room of the four teachers; it certainly was not the quietest, except when she expected it. It was the more transformational classroom of all teachers observed due in part to her control and confidence, her willingness to listen and learn from her students, and giving students ownership of their learning.

Control and confidence. One of the most evident qualities was Virginia's control and confidence about science teaching. Virginia was a member of a team that had wellorganized, written science units with essential questions, guiding questions, a materials list, and a brief outline of instructional procedures. Like Leigh she had tailored the lesson to meet the needs of her combined grade students (e.g., $3^{\text {rd }}$ and $\left.4^{\text {th }}\right)$. She saw the required state curriculum standards as,

Not a boundary for me, it's not a hurdle to cross, there's a lot of joy in teaching, and they have that joy when they're learning. I' $m$ comfortable enough in my shoes as a teacher that when things don't go as well as I like, we can come back and revisit.

Indeed, prior to the first observation, Virginia and one of her partner teachers were practicing how to fold a paper airplane from an instruction manual before the students returned to the classroom from lunch.

She had clear ideas about how she wanted to use science vocabulary, but recognized the need to "move beyond that and see if they are using the vocabulary." In the first observed lesson when she asked the class to clarify the definition of hypothesis, one student gave a partial response, the next student refined that definition, and the third 
replied "educated guess". This environment of openly expressing and listening to one another exemplified how instructional conversation was a normal part of her classroom activity.

Virginia proclaimed that she was a proponent of hands-on learning, and "Even though there's lots of talk, it's still a very structured classroom. I don't have to be in the midst of it at this time of the year. My third graders are now becoming the leaders for next year. It's very powerful." Indeed, the four observations which occurred over a 4day period were ultimately about scientific method that used flying paper airplanes to reinforce the concepts of hypothesis, asking questions, controlling variables and drawing conclusions.

When the students first began to fold the paper airplanes, Virginia was very precise about technique and encouraged the students to reference a handout. As the lesson progressed, the written directions were almost completely abandoned by the students. Instead they were moving from being investigative, that is, trying to figure out on their own how to fold the plane, to being totally reliant on Virginia as she had witnessed them using multiple methods they had devised themselves. Her ability to regain control of her classroom was respected and expected by the students. Although they seemed to enjoy the creativity, they wanted to do it the "correct way."

Virginia's classroom management was evidenced not only by her instructional style but also by the structure of the worksheet and notebook entries she provided for her students. Every lesson was developed around a schema that had been presented to the students with guiding questions to which they responded on the handout. 
As to summative assessments, Virginia said that, "I usually give them 10-15 multiple choice questions and that gives me a good sampling of their content knowledge. I vary the difficulty of the questions to see who has what knowledge." She elaborated stating that test questions were graduated from simpler to more complex for her to determine who had the deeper understanding. "It's not to trick the students," she added.

Listening and learning. Listening very carefully to what students said in response to her questions was evident in the way she responded with thoughtful, followup questions. She saw herself as a reflective teacher by responding to an interview question with "I like coming back at the end of the lesson and having long discussions with them about what went well and what didn't. I choose to focus on the reflective piece of instruction and pulling it all together." Adding, "Reflective discussion is powerful. Sometimes they know more than I can imagine, I let them go through the experiment and then we pull together at the end." There were other occasions when she realized the students had limited background knowledge and pulled the students together on the carpet to have a very specific discussion about their misconceptions. When students responded to her questions, Virginia was very accepting of their comments and occasionally asked them to clarify their thinking; she encouraged them to use their own words and "school words".

At the beginning of the third observed lesson, it became apparent that the previous day's data had been interpreted differently by different student groups. The confusion lay in the distinction between the names of the types of paper used for the airplanes; Virginia was clarifying the difference between tissue, construction and copy 
paper for the students. The data recorded at the end of the previous day did not accurately represent the flight distance for the different airplanes that were flown. Virginia took this all in stride and had planned a second data collection activity for the students, along with colored papers, commenting that scientist often have to repeat trials and reinforced that they would keep all of the data and not dismiss it just because it did not make sense.

Giving students ownership. Virginia ultimately wanted to build a classroom community stressing that "It's not behavior management; it's more about building community, reducing negative peer interventions and utilizing the mega-skills." Megaskills were prominently displayed on a bulletin board and contained words such as initiative, common sense, perseverance, problem-solving, and team work. Unlike Tina's classroom where similar skill words were displayed, in Virginia's classroom there was clearer evidence of implementation.

"My kids are very excited about science from very early on in the year. I really do love science." This sentiment was evident during the four classroom observations. Virginia's confidence with teaching and with science content inspired confidence in her students to take ownership for their learning. The students did exhibit much enthusiasm and deep thinking especially when they were gathered on the carpet and asked about their thoughts, their data collection techniques and conclusions drawn. Reflection was manipulated through questioning, peer conversations, sharing thoughts with the group, and license to think aloud. Virginia appreciated when her students shared ideas both orally and through writing saying, "I like to read their writing and see to what extent they can explain it." 
In response to the interview question, "How do you know when your students understand?" Virginia responded, "Much of my teaching is tempered by the talking the students do. I like to let them talk; they are able to do some abstract thinking." With regard to gifted learners, Virginia saw her job as one to help "students dream the dream and then my job is to help them realize it." This notion is supported by the "carpet discussion" the students had when "pop-corning" and expressed their observations and conclusions.

\section{Using Formative Assessment Strategies}

The strongest indicator of Virginia's use of formative assessment was stated in her response to the first short-response statement when she wrote, "I am using it (formative assessment) as the driving force behind my instruction." Table 5.8 details her responses to the four sub-constructs.

Table 5.8

Virginia's Reported Value and Use of Formative Assessment Strategies

\begin{tabular}{lll}
$\begin{array}{l}\text { Formative Assessment } \\
\text { Constructs }\end{array}$ & $\begin{array}{c}\text { Reported Value } \\
(\text { mean })\end{array}$ & $\begin{array}{c}\text { Reported Use } \\
(\text { mean })\end{array}$ \\
\hline Involving Students & 5.0 very valuable & 4.7 most lessons \\
Modeling Quality Work & 4.9 very valuable & 4.1 most lessons \\
Providing Feedback & 4.7 very valuable & 3.5 most days \\
Using Self-Assessment & 4.7 very valuable & 3.2 most days \\
\hline \multicolumn{1}{c}{ Mean } & 4.8 very valuable & 4.6 most lessons \\
\hline
\end{tabular}

Like Leigh most of the FAQ value responses were marked as "very valuable". It was use that had a more significant variation in pattern of responses. Twelve items were 
marked as "most lessons", and eleven marked as "weekly". This under-estimation of her usage is detailed in Table 5.9.

Table 5.9

Virginia's Detailed Use of Formative Assessment Strategies

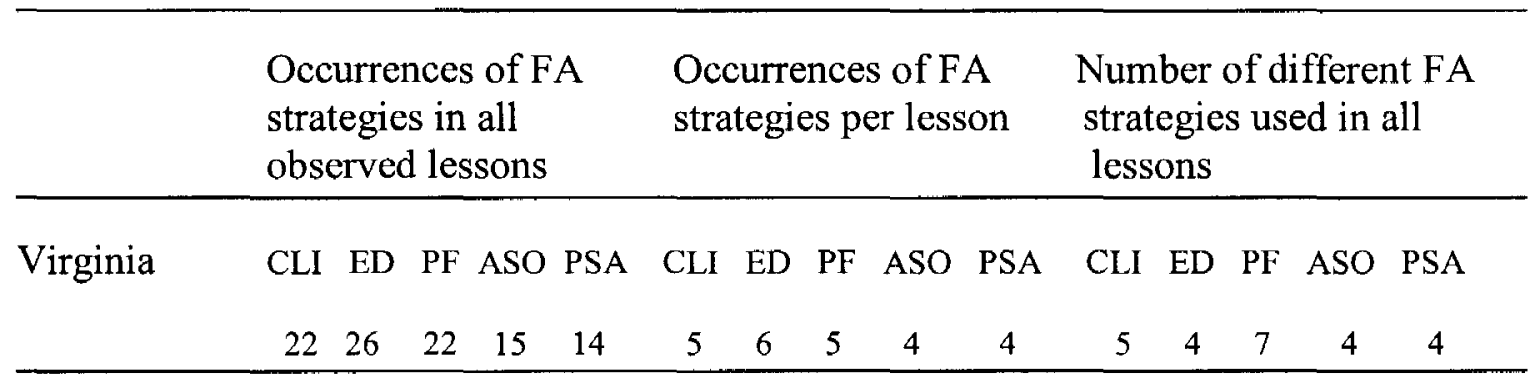

Note. See Table 4.18 for a detailed description of five formative assessment strategies.

Preparing Students to Learn and Responding to Student Learning Needs

Virginia's pattern of use of formative assessment strategies was completely consistent with Bruner's Theory of Instruction and a model for formative assessment usage. In each lesson she (a) stated the lesson goals; (b) posted a model or schema for the students; (c) explicitly stated what had been done; and (d) told the students where they were going in the lesson (see Table 4.18). Predisposing her students to learning by way of clarifying learning intentions (CLI) was not only valuable to her instruction as indicated on the FAQ, but was used with great frequency. In closing her first lesson, she returned to clarifying learning intentions by stating, "I'll leave you with the word 'inertia' as it is something we learned earlier today."

Because of her predisposition for listening to students, Virginia masterfully engineered discussions (ED) by asking a variety of questions. She coupled that with discussion which gave her feedback about what her students knew and understood. She was explicit when telling her students what she expected, about the quality of their work, addressing misconceptions immediately as they occurred, and continually 
challenging them to think beyond the scope of the immediate lesson (PF). Questions such as, "Think about how you are going to do this; any ideas?" from the second observed lesson or, "Who has an interesting observation about the data to share?" from the third observed lesson positioned her students to share their thinking aloud (ASO). This was followed by individual reflection when each wrote a concluding statement for the day on the worksheet (PSA).

"Can we handle popcorn today?" was posed to the students in both the first and third observed lessons. This was a time for students to think aloud without much intervention from Virginia. The students would discuss their observations, techniques for throwing the planes, results and connections they had made during their trials. Virginia listened, made notes, asked a question on occasion and received feedback about what her students were thinking; all of these invaluable resources became the source for planning the next lesson and for understanding and responding to her students.

\section{Professional Development and Concluding Statements}

Virginia marked all professional development options other than attending a national or regional conference. However Virginia was the only case study who had national board certification. Though not specifically designed to provide expertise with the use of formative assessment, national board preparation does require a teacher to become more self-reflective. This reflective quality seemed to be one characteristic which distinguished Virginia from the other case studies.

In response to, "How do you maximize student learning in your classroom?" Virginia stated, "I think that is where time and maturity have been so powerful to me, 
because I see the connections and that way I can go back to my wall charts and use past learnings to connect with current learnings—-helping them see how it all fits together." Virginia did seem to realize how to make it 'all fit together' by weaving many elements of formative assessment into each of her instruction utilizing a constructivist, studentfocused approach.

\section{Summary of Case Studies}

To summarize the four case studies, Table 5.10 presents a comprehensive view of each teacher to coalesce all data results and to provide the reader an overall view of the instructional style of each teacher and their use of formative assessment strategies. This view was based upon Bruner's (1996) Theory of Instruction which provided a more constructivist approach to elementary science teaching. 
Table 5.10

Summary of Case Studies

\begin{tabular}{|c|c|c|c|c|}
\hline Teacher & PD Training & $\begin{array}{l}\text { Instructional } \\
\text { Beliefs }\end{array}$ & $\begin{array}{l}\text { Approaches to } \\
\text { Instruction }\end{array}$ & $\begin{array}{l}\text { Effective/Ineffective } \\
\text { Use of FA Strategies }\end{array}$ \\
\hline Jordan & $\begin{array}{l}\text { District } \\
\text { trained }\end{array}$ & $\begin{array}{l}\text { Traditional } \\
\text { Instructive }\end{array}$ & $\begin{array}{l}\text { High energy } \\
\text { Complete control } \\
\text { Put on performance }\end{array}$ & $\begin{array}{l}\text { Did not effectively } \\
\text { plan interactions } \\
\text { with students to } \\
\text { allow construction } \\
\text { or scaffolding } \\
\text { of knowledge }\end{array}$ \\
\hline Tina & $\begin{array}{l}\text { School } \\
\text { trained }\end{array}$ & $\begin{array}{l}\text { Traditional } \\
\text { Instructive } \\
\text { Responsive }\end{array}$ & $\begin{array}{l}\text { Attempted to } \\
\text { predispose students } \\
\text { Used a logical } \\
\text { approach to } \\
\text { present content }\end{array}$ & $\begin{array}{l}\text { Did not effectively } \\
\text { manage time, plan } \\
\text { purposeful feedback } \\
\text { nor confirm science } \\
\text { content knowledge }\end{array}$ \\
\hline Leigh & $\begin{array}{l}\text { District } \\
\text { trained }\end{array}$ & $\begin{array}{l}\text { Spanned the } \\
\text { five belief } \\
\text { categories }\end{array}$ & $\begin{array}{l}\text { Focused on reading } \\
\text { and writing } \\
\text { Self-aware of } \\
\text { instructional } \\
\text { strengths }\end{array}$ & $\begin{array}{l}\text { Effectively used } \\
\text { sequencing and } \\
\text { pacing to guide } \\
\text { student learning; } \\
\text { feedback to students } \\
\text { was targeted and } \\
\text { responsive }\end{array}$ \\
\hline Virginia & $\begin{array}{l}\text { District } \\
\text { trained }\end{array}$ & $\begin{array}{l}\text { Transitional } \\
\text { Responsive } \\
\text { Reform-based }\end{array}$ & $\begin{array}{l}\text { Confident } \\
\text { Self-Reflective }\end{array}$ & $\begin{array}{l}\text { Effectively used } \\
\text { FA strategies as } \\
\text { the "driving force } \\
\text { behind her } \\
\text { instruction" }\end{array}$ \\
\hline
\end{tabular}




\section{CHAPTER VI}

\section{DISCUSSION}

The purpose of this research study was three-fold: to learn what teachers valued about formative assessment; to determine how teachers implemented formative assessment in their instructional repertoire to address student learning needs; and to determine what effect professional development may have had on teacher use of formative assessment strategies. The Formative Assessment Questionnaire (FAQ), observations, and interviews were three data sources used to address these purposes.

The FAQ quantitative data indicated elementary teachers both valued and used formative assessment strategies and these strategies were relevant to their instructional practices. Respondents also indicated through written statements that involving students in their own work, modeling quality student work samples, providing feedback, and giving students the opportunity to peer-and self-assess were used with some frequency, that is, "most days of the week". A noteworthy outcome from all data sources was that all $(n=270)$ teachers in this study believed that formative assessment strategies were valuable and they reported that these strategies were frequently used. Following is a discussion of the larger data set as well as the case study data which revealed some novel findings about how teachers value and use formative assessment strategies, the effects of professional development training, and implications for further study about formative assessment measurement. 


\section{Teacher Value of Formative Assessment Strategies}

The first research question addressed value of formative assessment strategies. The data indicated that formative assessment strategies were "very valuable" for the teachers surveyed $(n=270)$ and likewise, each case study reported similar value of formative assessment (see Table 4.17). Pedder (2006) reported similar results with a much larger sample of teachers in the United Kingdom finding that teachers do place high value on formative assessment strategies.

The elementary teachers uniformly expressed a high value of formative assessment strategies across the four sub-constructs of formative assessment. This uniformity across sub-constructs was confirmed when analyzing the quantitative data using both factor analysis and SEM model-fitting; there was little differentiation among the sub-constructs in the factor-analytic results, and the path loadings in the final SEM models suggested that within a factor of less than 2 , each sub-construct contributed approximately the same to the overall construct of formative assessment. The qualitative case study data provided additional information that revealed nuances about teacher attitudes and deeper, more personal values with respect to how each valued formative assessment.

When coding all participant responses to the first short-response statement on the FAQ, three categories emerged to reveal that determining where students were in their learning was the most important aspect of formative assessment. These categories about "what worked well with formative assessment" centered around the theme of collecting data either through conversations, class discussions, or in one-on-one situations. When involving students, teachers valued student engagement especially 
when students took ownership for their learning and when students could relate their understanding of lesson goals. Regarding feedback, teachers valued the time and opportunity to work one-on-one or in small groups of students to discuss student learning as well as the time to provide immediate feedback to meet learning needs. Modeling quality work for students, though valuable, seemed to be contingent upon having good examples available for students; teacher characteristics such as content knowledge, adequate time and prepared models seemed to be mediating factors. Finally, teachers valued student self-assessment by giving students time to reflect upon their work and conference in small groups or with individuals; but similar to modeling quality work, there were intervening factors that limited the use of self-assessment that is, using it in connection with a summative assessment, or having a rubric available for students.

The quantitative data suggested incongruence in that student self-assessment was valued highly by the larger sample and by the four teachers in the case studies, but the types of activities supporting this mode of formative assessment occurred least often during classroom observations (see Appendix D). This mismatch is discussed further in the next section on teacher use of formative assessment strategies.

\section{Teacher Use of Formative Assessment Strategies}

The second research question addressed use of formative assessment strategies, and teachers reported using these strategies with relative frequency, that is, "most days of the week". However, due to an increased range of data for use, some patterns and trends arose within each of the four sub-constructs. 


\section{Interpretation of Use from the $F A Q$}

Each case study was a member of different grade group (early, middle and late elementary), and their individual responses to Likert use items were compared to the grade groups' responses on the same items revealing some common themes. Both the self-assessment and the modeling quality work sub-constructs saw the lower use patterns; involving students and providing feedback saw higher use. The wording in these questionnaire items suggested teachers would have students collaborate or judge their own work to demonstrate improvement (for self-assessment) and would suggest ways to improve based upon models of student work (for modeling quality work). This trend of lower use across grade groups occurred more frequently in the self-assessment sub-construct; this same pattern was consistent in the case studies in that overall these teachers relied less frequently on student self-assessment strategies. It was noted that these items contained action-oriented verbs suggesting students were active participants in their learning as opposed to being led primarily by teacher-directed instruction. These items also suggested that students were self-assessing and peer-assessing, reviewing their own work and that of others.

Similar to the findings of the first research question, this mismatch between the quantitative data from the FAQ and the qualitative data from the case studies was uncovered; this also occurred when addressing the second research question regarding use of formative assessment strategies. Correlation data had confirmed there was a significance difference between value and use thus suggesting that teachers' value of formative assessment does serve as an indicator of teachers' likely use of those strategies. 
One interpretation of this lower use response pattern centers on the notion of teacher control. Considering that two of the four case studies exercised a substantial degree of teacher-focused instruction (see Table 5.1), it is expected that opportunities for students to engage in self-assessment activities occurred infrequently, if at all. These infrequently used strategies suggested action statements such as "getting students to review their own work" or "getting students to suggest ways they can improve." This type of instruction would be consistent with a student-focused learning environment, one that is responsive to student needs and constructivist in nature. Teachers would need to purposefully plan this type of classroom activity to give students more autonomy and ownership of their learning. The challenge of implementing this level of student-focused activity is highlighted by the mismatch of reported lower frequency of use of such strategies and the reported higher value place on the same strategies.

Another interpretation of this mismatch between value and use of student selfassessment may involve the teachers' general view of assessment. Levin and He (2008) reported in their study of pre-service teachers that three factors (e.g., family/K-12 education, observations of teaching, and teacher preparation education) influenced instructional philosophies with regard to assessment. The teachers' own personal K-12 education had great effect on their own personal views of assessment. This suggests that the other two factors, observing teaching and teacher preparation education, had a less strong effect on their views about and perhaps knowledge regarding how to assess students.

Likewise, Heritage (2007) remarked in her summation of teachers' formative assessment practices, "Assessment is often viewed as something in competition with 
teaching, rather than as an integral part of teaching and learning" (p. 140). These views reported in Heritage's study coincide with and appear to support what Levin and He (2008) found with regard to their teacher candidates. With regard to this study, it suggests that pre-service teachers would benefit from additional training and practice to formatively, and perhaps to summatively, assess student knowledge. This is a definite implication for teacher education programs.

This interpretive lens lends support to the possibility that, in this study, Jordan's and Tina's self-perceived use of formative assessment was less than what they actually implemented during the classroom observations. They spent little time on activating students as owners (ASO) of their own learning along with even less time on peer and self-assessment (PSA). Therefore, it is plausible that this mismatch between selfperceived use and actual implementation may also be systemically present in the larger sample. An exception to this finding was Virginia's beliefs and actions with regard to formative assessment. She ranked the student self-assessment strategies as her lowest sub-construct; however, her actual usage was proportional to usage of the other formative assessment strategies and was congruent with her more student-focused approach to instruction. Uncovering these two opposing trends of mismatch between survey responses and actual implementation (overrating use when it is rarely present and underrating use when it is frequently present) suggests that survey responses may not adequately differentiate between teachers. Combined, these two trends would tend to result in similar survey responses for teachers who are in actuality at opposite ends of an implementation spectrum of formative assessment strategy usage. 
As a group, the case studies spent proportionally more time in their lessons involving students and providing feedback through clarifying learning intentions (CLI), engineering discussions (ED) and providing feedback (PF). Overall they spent less time activating students as owners (ASO) of their work and having students peer and selfassess (PSA). Virginia and Leigh perceived and allocated time for students to learn by involving them in their studies; these kinds of activities are consistent with their constructivist approach to instruction. They also perceived and spent some time modeling quality work and engaging students in self-assessment.

The reverse was true for Jordan. Jordan had ranked use of all formative assessment strategies nearly identical to Virginia; reliance solely upon quantitative data would have positioned these teachers with similar pedagogical styles and attitudes (see Table 4.17). However, when considering the qualitative data collected during the observations and interviews, there is very little evidence to support Jordan's selfperception of high value and high use of formative assessment strategies. None of the formative assessment strategies detailed in the four sub-constructs were enacted in Jordan's classroom. To accept this idea would be a misinterpretation of the FAQ quantitative data. For example, Virginia intentionally gathered her students on a carpeted area to engage them in a Socratic-like discussion of their findings from trials with the paper airplanes. Jordan, however, had students $(n=56)$ quietly watch a pendulum demonstration (that did not work as planned) and write observations in silence. Jordan's students were not personally involved; they received no feedback about the quality of their observations; and they did not have the opportunity to interact with the teacher or with each other. Interestingly, upon re-examination of the short- 
response statements about how student self-assessment was implemented during classroom instruction Jordan wrote, "There is limited time for me to do it."

Tina perceived providing feedback and involving students as the most frequently used strategies. Although she did provide feedback, it was not the individualized feedback as described by Black and Wiliam (1998b). She did make attempts to involve students in their learning; however, Tina was predominantly exercising teacher-focused instructional practices in which the students were passive rather than active learners.

\section{Interpretation of Short-Response Statements}

A distinctive difference was noted in the way the case studies responded to the short-response statements on the FAQ. All of Virginia's statements began with "I" and used active tense verbs, (e.g., I am using, I am being, I have, I commit). Leigh also wrote in the first person and used action verbs in four of six statements. Tina and Jordan responded in the first person for one statement each; the other responses were impersonal and generalized such as, "They are passionate about what they are learning" or "Teachers are intentional and they use the information in a timely manner."

An interpretation for this type of response may be explained by comparing these findings to that of another, similar study. Because there was a personal tone and active verb tense with the two student-focused teachers (e.g., Virginia and Leigh), and a less personal tone from the teacher-focused teachers (e.g., Tina and Jordan), this was reminiscent of the Learning How to Learn Project (LHTL) (James et al., 2006) which is the overarching formative assessment research project which has continued the work of Black and Wiliam (1998b). A distinguishing factor in that study's results were between those teachers who designed lessons to enact assessment for learning (AfL) because it 
was the expectation, termed meeting the letter of formative assessment, and those whose lessons and instruction seriously embodied the spirit of assessment for learning. Considering these notions of letter and spirit with regard to how lessons were designed to encourage student responsibility for learning, teachers such as Jordan, and to some extent Tina, seemed to have taken less responsibility for student readiness to learn. Jordan in particular did not overtly take ownership for the learning of special needs students; Jordan stated that time and maturity were more important factors for successful learning than instructional influences. Writing, "When I do a good job planning," in response to how to involve students in learning, Jordan seemed to suggest that "good planning" was perhaps intermittent and did not always include formative assessment strategies. Jordan's attempts to design lessons that used formative assessment strategies to assist students into productive activity were lacking in spirit. Conversely, Virginia's "I" statements on the FAQ provided evidence to assert that her sense of agency with regard to student learning and student success was very important to her. She not only valued student autonomy but translated this belief into action by facilitating learning activities where students had intentionally planned opportunities to reveal their thinking and learning. There was greater use of formative assessment strategies in Virginia's lessons than the other case studies (see Table 5.9). Marshall and Drummond (2006) noted similar behaviors in their study regarding teachers who "valued pupil autonomy as an explicit aim of their teaching $\ldots$ and the extent to which [they] hold themselves responsible ... for any impediment to children's learning" (p. 144). Those were the teachers who exemplified and embodied the spirit of assessment for learning. 
In retrospect, a useful coding scheme for interpreting teacher responses to the short-response statements on the FAQ would be to examine whether the statements are written in first or third person. The prevalence of "I" statements may indicate the depth of teacher knowledge about formative assessment. A beginning purpose of this study was to uncover what teachers knew about formative assessment and therefore how they enacted or implemented this knowledge through lesson design and instructional actions within the classroom. Having the ability to examine teachers' written responses to openended statements would not only reveal their knowledge of formative assessment but would also aid to uncover what they valued (beliefs) and used (implementation).

\section{Professional Development and Formative Assessment}

From the ANOVA analysis of types of professional development, there was a significant difference between the district-trained group and the school-based trained group with respect to value and use of formative assessment strategies (see Table 4.8). The district-trained trained teachers had higher value and higher use scores than did the school-based trained group. When attempting to use those data to predict the effect of PD training in the case studies, no pattern was discernable for these four teachers (see Table 5.10). Tina was the one teacher in the case studies who had not received district training and indeed her usage of formative assessment was one of the weakest of the four participants. However, even with involvement in the district training, Jordan's use of formative assessment was less in comparison to the two student-focused teachers, i.e., Virginia and Leigh. Each of these four teachers had acquired an additional certification area, which may have indicated more sophistication with formative assessment, but it would be difficult to support that claim with the data that has been 
collected. Nevertheless, either district-provided training might enhance formative assessment implementation, or the selection process for obtaining that training may be sensitive to teachers' existing skill sets. In' either case, the existence of district-level training does not seem to guarantee consistent usage as illustrated in the case of Jordan. As previously noted, personal traits and instructional characteristics of the case studies may be the more influential factors with regard to usage of formative assessment strategies.

Some insight into this mismatch between training and utilization of formative assessment may be provided by again turning to the LHTL Project. Pedder, James and MacBeath (2005) focused their research on training teachers about learning how to learn (LHTL) and identifying factors related to the value and use of this targeted professional learning. Their questionnaire and interview items asked specific questions about how learning occurred in classrooms independent from other teaching and assessment activities. Reported findings indicated that teachers' professional learning was enhanced when it became a natural part of teaching and learning (about learning), and was enhanced primarily through collaborative activities and collegial conversations. Data analysis from the Pedder et al., (2005) study has mirrored this research regarding teachers' value and use of formative assessment.

In an effort to understand the relationship of PD training with regard to the case study data, the researcher focused on the assessment of teacher attitude about science teaching framed by the interview questions on the TBI. One distinction of this present study has been a focused examination of teachers' beliefs concerning science teaching. The interview data have provided information about how a teacher-focused approach to 
science instruction contrasts with a student-focused approach and the subsequent effects on the use of formative assessment strategies. The Luft and Roehrig (2007) instrument employed for this study had direct questions about how the teacher manipulated learning conditions within the science classroom. The TBI interview data supported, and to some degree predicted, teacher usage of formative assessment strategies, that is, the more student-focused approach to teaching, the more likely formative assessment strategies were utilized. These outcomes are congruent with the data from the LHTL interviews about professional learning which revealed higher values about learning for the teacher when the training was focused on ways to improve learning how to learn. This same kind of focused training for formative assessment could be enhanced if and when training was narrowed and allowed teachers to examine their value and use of formative assessment in a more collegial setting with more knowledgeable trainers.

When re-examining the observation and interview data, a distinctive pattern of high use responses for formative assessment strategies directly related to how the teachers in the case studies responded on the TBI. According to observational data, Jordan was the most teacher-focused instructor on the continuum and had the lower use of formative assessment strategies. Virginia was most student-focused instructor on the continuum and exhibited greater use of formative assessment strategies (see Table 5.1 and Appendix D).

\section{Limitations \\ District-Provided Professional Development}

The school district where this study took place had adopted a move toward Professional Learning Communities (PLC) as advocated by DuFour (2004) (see pp. 66- 
67). A major component of PLCs is formative assessment. DuFour et al. (2004) stated, "To create a professional learning community, focus on learning rather than teaching, work collaboratively, and hold yourself accountable for results" (p. 1). The developers of PLC wrote often about the importance of understanding what a student knows, how feedback is critical to student success, and how involving teachers and students in instructional conversations is an integral aspect of gearing all students toward a more rewarding school experience. PLCs endorse individual teacher responsibility as well as team and school responsibility for student success.

One PLC criterion regarding student learning is, "How will we know when each student has learned?" (DuFour et al., 2004, p. 24). PLCs promote an assessment method termed common formative assessments. This type of assessment encouraged teams of teachers to set benchmarks for proficiency on curriculum standards and then collaboratively develop a measurement to judge when students had obtained mastery. Of particular note for this study was that district-trainers were referencing formative assessment while simultaneously introducing the common formative assessment concept.

Therefore, it seemed reasonable to assume that when teachers were learning about PLC's concepts and responsibilities to implement that framework, there may have been confusion between formative assessment and common formative assessments. Evidence for this assumption became apparent in the short-response statements teachers gave on the FAQ. Some respondents expressed constraints that formative assessment hindered their work; they stated, "It must be completed on a timetable-not a natural time of the day or part of a unit" or, "It takes too much instructional time, you can't go 
back and check the specifics of a test." Responses such as, "It takes too much learning time and I've already assessed them in other ways" came from one of the eighteen volunteers. The "it" referenced in the previous statements most likely referenced common formative assessments. Comments about "having no value to student learning" and "taking away teaching time" confirmed suspicions especially when responses to the other short-response statements seemed to indicate how formative assessment was actually being used during instruction. One respondent seemed to have recognized the difference stating, "It is forced. Formative assessment needs to naturally occur."

In three of the four case studies, similar confusion was expressed. Jordan wrote, "They sit and I don't grade them." Tina said, "They are very lengthy - takes time to grade." Leigh lamented, "When I am overwhelmed by the number of students in my class." Virginia, however, seemed to make a distinction by commenting, "When I am being inefficient at collecting data - not having enough time to review student work."

\section{Formative Assessment Observation Form}

A Formative Assessment Observation Form (FAOF) was designed by this researcher based upon other studies conducted about formative assessment. The criteria for each of the five non-negotiables were an amalgamation of strategies that have prevailed in studies of formative assessment. This instrument has not been used outside of this study; therefore verification of its strengths in various contexts would enhance confidence in conclusions drawn from this instrument (see Appendix C).

\section{Researcher's Relationship with Case Study Teachers}

This researcher held an administrative position in the school district where this study was conducted, but not in the schools where data were collected. This researcher 
routinely observed and evaluated teachers as part of normal job responsibilities. Even though participating in the second phase of this study which entailed the observations and interview was voluntary, teachers may have regarded this researcher as an authoritative figure. Though the lessons did not appear to be "dog ' $n$ ' pony shows," there may have been an element of that as the teachers planned their lessons for observation.

\section{Conclusions and Recommendations}

An outcome of this research is a profile of a teacher with regard to being an effective implementer of formative assessment strategies. Each data source has been considered separately and then collectively to support this proposed profile.

\section{The FAQ}

The self-reported ratings of value and use items did not provide convincing evidence to predict a teacher's actual implementation of formative assessment strategies in the classroom. Review of case study data confirmed this notion (see Table 4.17). If one simply reviewed the reported data from the 30 value items, little differentiation was observed among Jordan, Leigh and Virginia (4.73, 4.80 and 4.83 respectively). Their value mean scores placed each in the "very valuable" category. A sole reliance on these value data would present Jordan as being similar to Virginia and Leigh. As to use, Jordan appeared similar to Virginia. The case study discussion of these teachers' practice, however, invalidates this conclusion.

Teacher self-selection of PD trainings on the FAQ did not provide clear indications that could be used to predict actual classroom formative assessment usage. Knowing which grade level the teacher taught also did not provide evidence to 
determine teacher used of formative assessment strategies since all grade levels seemed to have similar variances related to the four sub-constructs. However, one distinguishing element of the FAQ that provided more reliable and useful qualitative data into the distinctive view of a teacher's value and use of formative assessment strategies was in the teachers' responses to the short-response statements. After analyzing the case study observations and interview data, the researcher found the handwritten statements from the FAQ provided additional supportive data that consistently triangulated with observations and interviews. The FAQ short-response statements disclosed a more realistic view of the teachers' use of formative assessment. These responses revealed attitudes with regard to personal philosophies about teaching and student learning. The prevalence of "I" statements, such as in Virginia's responses, were indicative of actual classroom use, not just self-reported use.

The original FAQ used for this study provided both quantitative data and some qualitative data. The quantitative data provided answers to the research questions by confirming through factor analysis and structural equation modeling that this instrument was structurally sound and did adequately measure the overall construct of formative assessment. The spectrum of quantitative data however was not discriminating enough to distinguish between those teachers who reported high use and those who actually implemented more formative assessment strategies into their classroom instruction. This non-discriminating element of the FAQ initially led this researcher to the belief that most elementary teachers in the school district where the study took place valued and used formative assessment. In retrospect when considering the qualitative data collected from the case studies, the researcher would caution anyone in using the FAQ 
quantitative data solely. When analyzing all data sources the researcher considered the qualitative data from the FAQ to be a more interpretable data source. The responses to the short-response statements contained more robust data that aligned with the data obtained from the classroom observations and interviews.

Using a mixed methods approach to gathering data was a valuable approach for this researcher; however, to expand the usefulness of the questionnaire, a reformatted instrument may provide qualitative data that would reveal more knowledge about formative assessment. Suggestions for a revised FAQ would be to restructure the Likert items into a format that asks for more open-ended response questions, and would perhaps use the specific strategies detailed in the original Likert items as descriptive text to operationalize the intent of each formative assessment subcategory. The parameters for each sub-construct are defined by the FAQ items and contain valuable information for teacher respondents to consider. Rather than distinguishing how valuable or how often a strategy was employed, the teacher respondents could use these "definitions" to illustrate how implementation occurred during their classroom instruction. This questioning format would take advantage of short-response statements which were more predictive of use than the quantitative data alone had indicated. This is the approach taken by this researcher in the proposed modified instrument (see Appendix E).

\section{Observations}

Using the assessment for learning framework (i.e., the five non-negotiables) to assess how the teacher provided learning experiences for students demanded considerable data collection time. These five non-negotiables provided a critical lens for 
examining the strength and consistency of formative assessment practices during classroom instruction. Although the Formative Assessment Observation Form (FAOF) has been cited as a limitation, the non-negotiables of formative assessment have seen considerable usage in other studies to validate their critical inclusion as instructional strategies which exemplify a formative assessment instructional approach.

In this particular study, observation data revealed recurring patterns of incidences of implementation of assessment for learning strategies that occurred with relative consistency across all observations. Dominant formative assessment patterns emerged early in each of the case study observations especially when reflecting on the behaviors that had been observed. The interviews confirmed these initial findings by establishing a decidedly teacher-focused or student-focused approach to science instruction for each teacher.

This suggests that the teacher's methodology and beliefs were revealed in the way each teacher began the lesson, the way in which questions were asked and responses given to student inquiries, and how each teacher interacted with students during the lessons. Because formative assessment is an instructional tool to measure student learning, focusing on how a teacher gains this valuable information can be predictive of formative assessment strategy implementation. The observational data coded into the FAOF were more valuable to this researcher than the FAQ Likert selfratings when determining more fundamental values and uses of formative assessment strategies for the case studies. 


\section{Interviews}

The interviews using the Luft and Roehrig's (2007) TBI allowed for another relatively clear indicator about teachers' thoughts with regard to their role as a science teacher and their attitudes toward student learning. This instrument provided a measure of how instruction occurred in the classroom that was consistent with the classroom observation protocol results. Allowing these teachers to respond, as each deemed appropriate, opened a window into their thinking about teaching and meeting student learning needs. As previously stated, the determination of a more student-focused approach to science instruction corresponded with a higher use of formative assessment strategies.

\section{Comprehensive Data Sources}

The questionnaire, observations and interviews data sources have collectively provided reason to create a teacher profile for analyzing a teacher's fluency with implementing formative assessment. First, there is a need to know what the teacher knows about formative assessment (knowledge). Similar to how a teacher would preassess students for background knowledge, so should a formative assessment instrument. Determination of what a teacher actually knows about the basic philosophies, concepts and strategies of formative assessment would provide a more pertinent foundation for initial analysis.

Next, there is a need to understand how and when a teacher decides to utilize formative assessment strategies (implementation). A preliminary observation of instruction could establish a baseline. The teacher evaluator could document how instruction flowed, how the teacher incorporated formative assessment strategies, and 
then collaboratively benchmarks could be established to compare usage; for example, an implementation study could focus on the implementation of formative assessment strategies over a specified time period.

There is a need to determine a teacher's beliefs about the intent of formative assessment (dispositions). Knowledge of formative assessment and implementing formative assessment strategies would become more apparent as the teacher plans for, instructs and assesses student knowledge. Interaction with students should reveal a commitment to a constructivist approach to instruction, one that positions the teacher and students to jointly create deep levels of understanding about science.

Lastly, there is a very practical need to examine the short-response statements on the questionnaire (analytical lens). How the teacher responds to prompts about the four sub-constructs on the formative assessment questionnaire has provided an interpretive lens that helped to establish trustworthy conclusions with regard to the three criteria, that is, knowledge, implementation and disposition.

Creating a Teacher Profile

To determine whether a teacher is an effective user of formative assessment strategies, the following Teacher Profile checklist incorporates the comprehensive data sources previously outlined. This Teacher Profile combines data from the general teaching characteristics of the case studies along with the recommendations that have been made in a framework consistent with Bruner's Theory of Instruction (1966) and with Black and Wiliam's (1998a) research findings into formative assessment. 


\section{Intended Audience and Purposes}

It is proposed that four intended audiences could use this Teacher Profile. First, it is suggested as an evaluation instrument for education administrators who conduct personnel evaluations. The nature of this Teacher Profile instrument is broad in scope to provide the evaluator latitude in interpreting the teaching behaviors observed. The dichotomous aspect of a "yes" or "no" response would allow the evaluator to determine a baseline proficiency with formative assessment strategies and to gauge foundational knowledge and dispositions. These can be considered as "contextualized" yes or no responses. During a post-observation conference the administrator and teacher could discuss the many strategies and dispositions that may guide the teacher toward greater use of formative assessment strategies. From this conversation, explicit professional growth plan goals are documented based upon objectives and targeted actions by which to measure growth over time.

The second potential use for this instrument would be for the professional development trainer whose primary interest is to develop deeper awareness of formative assessment. Each section of the Teacher Profile (knowledge, implementation, disposition and analysis) could be expanded for discussion and training. Because the instrument contains many facets of formative assessment that have been condensed by the researcher, each item could be explored in more depth and detail depending on the trainer's intent. The reformatted formative assessment questionnaire could be used in tandem with this training to measure pre-training and post-training teacher attitudes. Follow-up PD training could expand on selected themes contained within the Teacher Profile to gauge growth over time and used in tandem with professional growth plans. 
A third use of this instrument would be for the classroom teacher. Though not intended as a self-analysis instrument but rather as a comprehensive assessment of many aspects of formative assessment, teachers could reflect and collaborate within professional learning communities (PLC), or with school administrators, to identify and to develop targeted goals to increase knowledge and usage of formative assessment strategies. PLC teams could set group goals and share strategies about implementation. This collective approach to professional development could have the positive impacts identified by Pedder, James and MacBeath (2005) where it was reported that teachers who worked collaboratively and engaged in developing common learning goals achieved greater gains toward their goals.

The last potential use would be as a Teacher Profile for teacher educators. A reason that $\mathrm{K}-12$ classroom teachers report uncertainty about formative assessment may be due to inadequate study in teacher preparation programs. As presented in this study, formative assessment is not only a complex set of instructional strategies that require considerable knowledge of the technical aspects of instructional delivery, but also has a considerably high effect (as reported by Black \& Wiliam, 1998b) on student achievement when these strategies are properly implemented during classroom instruction.

A proposed course of action would be to position assessment as the foundational component of planned lessons; this format is similar to the backward design approach advocated by Wiggins and McTighe (1998). Instructing teacher candidates about the value of a formative assessment, which can clearly define and measure intended learning outcomes, should be the starting point for any well-designed lesson plan. The 
Teacher Profile could serve as a general outline of a constructivist approach to studentcentered instruction. It seems reasonable to assume that a course within the teacher education program could be designed to guide teacher candidates toward a responsive methodology to use formative assessment strategies effectively.

Finally, the language of the Teacher Profile is intentionally written to allow interpretation by the user. The broad and expansively stated descriptive statements serve as a launching pad for discussion by the teacher, the administrator, the trainer or the PLC. Having this built-in latitude intentionally serves as a mitigating factor for the otherwise austere aspect of a yes/no response. Reliability of the Teacher Profile across users is not relevant believing that scenarios for usage will vary; it is not intended as a research instrument.

In consideration of the Teacher Profile that follows, a contextual reminder is appropriate. Figure 5.1 presented a simple visual representation of Bruner's Theory of Instruction. In a separate but related discussion in Toward a Theory of Instruction (1966) Bruner discussed his thinking about evaluation. "It is to teach him to participate in the process that makes possible the establishment of knowledge ... to take part in the process of knowledge-getting. Knowing is a process, not a product" (p. 72). It is with this perspective that the Teacher Profile takes on a decidedly constructivist viewpoint, one that incorporates a social construction of knowledge (Vygotsky, 1978; Good \& Brophy, 2003) and takes full advantage of the formative assessment strategies which position teachers to be effective instructors and students to be productive learners. 
Teacher Profile:

Classroom Implementation of Formative Assessment Practices

\section{Teacher Knowledge}

Planning the lesson/Predisposing students to learning

Yes No
Lesson plan contains essential and guiding questions
Uses appropriate formative assessment data to inform lesson construction Considers time required to deliver the lesson
Anticipates student misconceptions

II. Implementation Skill Set

Clarifying learning intentions/Structuring knowledge

$\begin{array}{ll}\text { Yes } & \text { No } \\ \square & - \\ - & -\end{array}$

Adequate time is spent structuring the knowledge for the students Review of prior learning occurs before presenting new material Pre-assessment of student background knowledge occurs

Engineering discussions/Sequencing

Yes No

$\left[\begin{array}{l}-\quad \begin{array}{l}\text { Multiple learning venues and styles are utilized } \\ \text { Responses to questions are listened to and noted } \\ \text { Interactive questioning and active discussions occur }\end{array}\end{array}\right.$

Providing feedback/Pacing and reinforced learning

Yes No

_ Utilizes a constructivist approach to scaffolding knowledge

_ _ Uses multiple resources to present learning activities

- - Feedback is given about the quality of the student work

- _ - Suggestions for improvement are made

Activating students as owners of learning/Establishing knowledge

Yes No

- _ - Appropriately builds upon what had been done

- _ Clearly communicates learning goals

_ _ L _ Learning activities build upon each other

- _ - Planning includes intentional interactions with students

- $\quad$ I Individualized feedback is connected to content and skills 
Peer and self-assessment/Process and product of knowledge

Yes No

Appropriately places value on time spent in student discussions

Small group, whole group and individual feedback is given

Lesson plan provides time for student reflection

Encourages student feedback for peer and self-assessment

III. Beliefs about Teaching

Yes No

Expresses beliefs that are consistent with a responsive or reform-based way of thinking about science instruction, decidedly constructivist

Exemplifies the 'spirit' of formative assessment rather than the 'letter'

Teacher agency with regard to science knowledge

Teacher agency with regard to meeting individual student needs

Teacher views assessment as an instructional tool

IV. Analytical Lens for Short-Response Statements

Yes No

Responses are written in first person

Responses contain action verbs, such as, I will, I am using, I commit

Responses convey a sense of personal responsibility for student learning

Short- response statements on FAQ are consistent with observation

Figure 6.1. Teacher Profile developed from observations, interviews and examination of FAQ.

Implications for Further Research and Implementation

To conclude, it has become apparent that formative assessment is a complex and intricate suite of skills that pose a challenge for implementation. For teachers to indicate that formative assessment is valuable is certainly a helpful beginning attitude for the inclusion of this important pedagogical approach to effective teaching, but implementation of formative assessment entails much planning and preparation to adequately execute during classroom instruction. The teachers in this study were very clear about having that helpful attitude and belief system with regard to the value of formative assessment. However, results revealed a wide array of uses, or non-uses, with the case studies. The teachers in the case studies clearly valued formative assessment 
strategies and implemented what each thought was best for their students. Having a tool such as the Teacher Profile will provide another structure in addition to the questionnaire, classroom observations and interviews for teachers, administrators and others to enhance formative assessment implementation.

There are three specific implications for further research, professional development training, and for university teacher education programs. Each will be discussed separately, but if implemented collaboratively from a holistic view of university education programs, each implication could add greater value to the effectiveness of formative assessment to enhance teacher preparation.

\section{Determining What Teachers Know About Formative Assessment}

To determine teacher knowledge about formative assessment from a research perspective, it would be advisable to collect qualitative data that would take advantage of open-ended responses. Using the redesigned Formative Assessment Questionnaire as proposed in Appendix E, would perhaps give researchers more valid measures about what teachers know and how they implemented these sets of strategies in their instruction; this may be more meaningful than the overly detailed list in the original questionnaire that tended to result in data that had little variance, and thus little explanatory power. This could be a pre-assessment preparation before a professional development training thus targeting both the professional development provider's work and activating teachers' existing knowledge in anticipation of the upcoming training experiences. 


\section{Targeted Professional Development}

Designing and delivering effective professional development is a task which requires thoughtful and focused goals to be meaningful to teachers. With the practice of professional learning communities (PLC) and collaborative teaming models utilized in many school systems, it would be advisable to use this structure, i.e., PLCs, to critically examine teachers' knowledge, beliefs about and use of formative assessment strategies. The data from this study determined that district-trained teachers had an advantage over school-based trained teachers with regard to use of formative assessment; however, the selection process for which teachers were to be trained was not clearly determined. Therefore a recommendation would be to pre-assess teacher knowledge of formative assessment either through use of the reformatted formative assessment questionnaire or by conducting classroom observations using the Teacher Profile. Professional development trainers could then devise differentiated PD experience to specifically address teacher professional growth needs.

\section{University Education Programs}

As pre-service teachers take courses within a teacher education program, a more intentional effort to include instruction about formative assessment could position teacher candidates to be more effective classroom teachers. As a result of this research, it is proposed that effective use of formative assessment strategies could give classroom teachers better control over the flow of instruction in the classroom by purposefully incorporating the five non-negotiables. These constructivist strategies position students to take ownership of their work and create positive partnerships between the teacher and the student by engaging students in meaningful work. 
It is also proposed that university education programs approach formative assessment from two distinctly different, but strategically compatible venues. The first approach would be to develop coursework curriculum specifically designed to teach pre-service teacher about multiple forms of assessment but particularly formative assessment. Because formative assessment is an instructional tool, instruction about assessment in a general methods-type course could help diminish the uncertainties that research has shown teachers are most uncomfortable with (Black, 2000; Donovan, Bransford \& Pellegrino, 2000; Graue, 1993; Harlen \& James, 1997; Heritage, 2007; Levin \& He, 2008; Popham, 2009; Shepard, 2000; Wiggins, 1992).

The second approach university education programs could undertake would be to design coursework required for principal certification that incorporates instruction about formative assessment using the Teacher Profile. Those aspiring administrators, who will be evaluating teaching personnel need to have clear, unambiguous knowledge about the value and use of formative assessment to help guide teachers into more meaningful and effective uses of this important pedagogical approach.

\section{Closing Remarks}

Fenstermacher and Richardson (2005) stated that "Excellence in teaching means being constructivist. This view requires that a teacher think in a constructivist manner, hold beliefs aligned with constructivist philosophy, and act in ways consistent with such beliefs and thinking" (p. 204). This view of constructivist teaching aligns particularly well with formative assessment in that it places value on how a teacher views her/his role and responsibility for student learning via beliefs and practices. Creating a learning environment that is sensitive and responsive to student learning needs and one that 
allows responsible ownership for their own learning will be a classroom environment where formative assessment is effectively used as an instructional tool to strengthen student critical thinking skills and achievement. The Teacher Profile document that emerged as a result of this study may prove helpful for enhancing teachers' abilities to effectively implement formative assessment in the complex environments of the classroom, thereby strengthening student understanding. 


\section{REFERENCES}

Ames, C. (1992). Classrooms: Goals, structures, and student motivation. Journal of Educational Psychology, 84(3), 261-271.

Andrade, H., \& Boulay, B. A. (2003). The role of self-assessment in learning to write. Journal of Educational Research, 97(1), 21-34.

Aram, R. J., \& Bradshaw, B. (2001). How do children know what they know? Science and Children, 39(2), 28-33.

Aschbacher, P., \& Alonzo, A. (2006). Examining the utility of examining science notebooks for formative assessment purposes. Educational Assessment, 11 (3 \& 4), 179-203.

Assessment Reform Group. (2002). Assessment for Learning: 10 Principles. London: Nuffield Foundation. Retrieved November 14, 2007, from http://www.assessment-reform-group.org.uk

Atkin, J. M., Black, P., \& Coffey, J. (2001). Classroom assessment and the National Science Education Standards. Washington, DC: National Academy Press.

Bandura, A. (1977). Social learning theory. Englewood Cliffs, NJ: Prentice-Hall.

Bandura, A., Barbaranelli, C., Caprara, G. V., \& Pastorelli, C. (2001). Self-efficacy beliefs as shapers of children's aspirations and career trajectories. Child Development, 72(1), 187-206.

Bell, B. (2000). Formative assessment and science education: A model and theorizing. In Millar, Leach \& Osborne (Eds.), Improving science education: The contribution of research (pp. 48-61). Philadelphia: Open University Press.

Bell, B., \& Cowie, B. (1999). A model of formative assessment in science education. Assessment in Education, 6(1), 101-116.

Bell, B., \& Cowie, B. (2001). The characteristics of formative assessment in science education. Science Education, 85(5), 536-553.

Bergan, J., Sladeczek, I., Schwarz, R., \& Smith, A. (1991). Effects of a measurement and planning system on kindergartners' cognitive development and educational programming. American Educational Research Journal, 28, 683-714. 
Black, P. (2000). Policy, practice and research: The case of testing and assessment. In Millar, Leach \& Osborne (Eds.), Improving Science Education: The contribution of research (pp. 325-346). Philadelphia: Open University Press.

Black, P. (2005). Formative assessment: Views through different lenses. The Curriculum Journal, 16(2), 133-135.

Black, P., \& Harrison, C. (2001). Feedback in questioning and marking: The science teacher's role in formative assessment. School Science Review, 82(301), 55-61.

Black, P., Harrison, C., Lee, C., Marshall, B., \& Wiliam, D. (2004). Working inside the black box: Assessment for learning in the classroom. Phi Delta Kappan, 86(1), 9-21.

Black, P., \& Wiliam, D. (1998a). Assessment and classroom learning. Assessment in Education: Principles, Policy \& Practice, 5(1), 7-74.

Black, P., \& Wiliam, D. (1998b). Inside the black box: Raising standards through classroom assessment. Phi Delta Kappan, 80, 139-148.

Bloom, B. S. (1969). Some theoretical issues relating to educational evaluation. In R. W. Tyler (Ed.), Educational evaluation: New roles, new means (pp. 26-50). Chicago, IL: University of Chicago Press.

Bloom, B. S. (1984). The search for methods of group instruction as effective as oneon-one tutoring. Educational Leadership, 4l(8), 4-17.

Brophy, J. (1981). Teacher praise: A functional analysis. Review of Educational Research, 51, 5-32.

Brophy, J. (1999). Toward a model of the value aspects of motivation in education: Developing appreciation for particular learning domains and activities. Educational Psychologist, 34(2), 75-85.

Brophy, J. (2001). Subject-specific instructional methods and activities. New York: Elsevier Science.

Bruner, J. S. (1966). Toward a theory of instruction. Cambridge, MA: Harvard University Press.

Butler, R. (1988). Enhancing and undermining intrinsic motivation: The effects of taskinvolving and ego-involving evaluation on interest and performance. British Journal of Educational Psychology, 58, 1-14.

Butler, D. L., \& Winne, P. H. (1995). Feedback and self-regulated learning: A theoretical synthesis. Review of Educational Research, 65(3), 245-281. 
Byrne, B. M. (2001). Structural equation modeling with AMOS: Basic concepts, applications, and programming. Mahwah, NJ: Lawrence Erlbaum Associates, Publishers.

Cassidy, S. (2007). Inexperienced students' ability to self-assess: Exploring links with learning style and academic personal control. Assessment and evaluation in higher education, 32(3), 313-330.

Chappuis, S., \& Stiggins, R. (2002). Classroom assessment for learning. Educational Leadership, 60(1), 40-43.

Chin, C. (2006). Classroom interaction in science: Teacher questioning and feedback to students' responses. International Journal of Science Education, 28(11), $1315-1346$.

Clymer, J. B., \& Wiliam, D. (2006). Improving the way we grade science. Educational Leadership, 64(4), 36-42.

Cowie, B., \& Bell, B. (1999). A model of formative assessment in science education. Assessment in Education, 6(1), 101-116.

Darling-Hammond, L. (2006). Assessing teacher education: The usefulness of multiple measures for assessing program outcomes. Journal of Teacher Education, 57(2), $120-138$.

Dass, P. M. (2001). Implementation of instructional innovations in K-8 science classes: Perspectives of in-service teachers. International Journal of Science Education, 23(9) 969-984.

Dawson, M. E. (2005). Are they really learning what we're teaching? Journal of College Science Teaching, 34(5), 34-35.

Donovan, M. S., Bransford, J. D., \& Pellegrino, J. W. (2000). How people learn: Bridging research and practice. National Research Council: National Academies Press.

DuFour, R., DuFour, R., Eaker, R., \& Karhanaek, G. (2004). Whatever it takes. Bloomington, IN: Solution Tree.

Duschl, R. D., \& Gitomer, D. H. (1997). Strategies and challenges to changing the focus of assessment and instruction in science classrooms. Educational Assessment, 4, $37-73$.

Dweck, C. (1999). Self-theories: Their role in motivation, personality and development. Philadelphia: Psychology Press. 
Dweck, C. (2007). The promise and perils of praise. Educational Leadership, 65(2), $34-39$.

Edwards, D., \& Mercer, N. (1987). Common knowledge: The development of understanding in the classroom. London: Routledge.

Enochs, L. G., \& Riggs, I. M. (1990). Further development of an elementary science teaching efficacy belief instrument: A preservice elementary scale. School Science and Mathematics, 90(8), 694-706.

Fenstermacher, G. D., \& Richardson, V. (2005). On making determinations of quality in teaching. Teachers College Record, 107(1), 186-213.

Fullan, M. (1991). The new meaning of educational change. London: Cassell.

Gipps, C. (1994). Beyond testing: Towards a theory of educational assessment. London: Falmer Press.

Glaser, B., \& Strauss, A. (1967). The discovery of grounded theory. Chicago: Aldine.

Good, T. L., \& Brophy, J. E. (1986). Educational psychology. White Plains, NY: Longman, Inc.

Good, T., \& Brophy, J. (2003). Looking in classrooms. Boston: Pearson Education, Inc.

Graue, M. E. (1993). Integrating theory and practice through instructional assessment. Educational Assessment, 1(4), 283-309.

Harlen, W. (2003) Enhancing inquiry through formative assessment. San Francisco: The Exploratorium.

Harlen, W., \& James, M. (1997). Assessment and learning: Differences and relationships between formative and summative assessment. Assessment in Education: Principles, Policy \& Practice, 4(3), 365-380.

Hattie, J., \& Timperley, H. (2007). The power of feedback. Review of Educational Research, 77(1), 81-112.

Heritage, M. (2007). Formative assessment: What do teachers need to know and do? Phi Delta Kappan, 89(2), 140-145.

Hiebert, E. H., \& Calfee, R. C. (1989). Advancing academic literacy through teachers' assessments. Educational Leadership, 48(7), 50-54.

Hunt, E., \& Pellegrino, J.W. (2002). Issues, examples, and challenges in formative assessment. New Directions for Teaching and Learning, 89(Spring), 73-85. 
James, M. (2002). Assessment for learning: What is it and what does research say about it? Retrieved November 5, 2007, from Learning how to Learn 2002, www.learntolearn.ac.

James, M., Black, P., McCormick, R., Pedder, D., \& Wiliam, D. (2002). Learning how to learn in classrooms, schools, and networks: Aims, design, and analysis. Research Papers in Education, 21(2), 101-118.

Joseph, N. (2006). Strategies for success: Teaching metacognitive skills to adolescent learners. The New England Reading Association Journal, 42(1), 33-39.

Kline, R. B. (2005). Principles and practice of structural equation modeling, $2^{\text {nd }}$ Ed. New York: The Guilford Press.

Kluger, A. N., \& DeNisi, A. (1996). The effects of feedback interventions on performance: A historical review, a meta-analysis, and a preliminary feedback intervention theory. Psychological Bulletin, 119(2), 254-284.

Lalley, J., \& Miller, R. (2007). The learning pyramid: Does it point teachers in the right direction? Education, 128(1), 64-79.

Leahy, S., Lyon, C., Thompson, M., \& Wiliam, D. (2005). Classroom assessment: Minute by minute, day by day. Educational Leadership, 63(2), 18-24.

Lee, D., \& Gavine, D. (2003). Students' self-assessment of academic attainment: Accuracy and stability from 7 to 16 years and influence of domain and social comparison group. Educational Research, 45(1), 49-59.

Levin, B., \& He, Y. (2008). Investigating the content and sources of teacher candidates' personal practical theories (PPTs). Journal of Teacher Education, 59 (1), 55-68.

Luft, J. A., \& Roehrig, G. H. (2007). Capturing science teachers' epistemological beliefs: The development of the teacher beliefs interview. Electronic Journal of Science Education). Retrieved January 27, 2008, from http://ejse.southwestern.edu

Marshall, B., \& Drummond, M. J. (2006). How teachers engage with assessment for learning: Lessons from the classroom. Research Papers in Education, 21(2), 133-149.

Marzano, R. J., Pickering, D. J., \& Pollock, J. E. (2001). Classroom instruction that works: Research-based strategies for increasing student achievement. Alexandria, VA: Association for Supervision and Curriculum Development. 
McDonald, B., \& Boud, D. (2003). The impact of self-assessment on achievement: The effects of self-assessment training on performance in external examinations. Assessment in Education, 10(2), 209-220.

McTighe, J., \& Emberger, M. (2006). Teamwork on assessments creates powerful professional development. Journal of Staff Development, 27(1), 38-44.

Miles, M., \& Huberman, A. (1994). Qualitative data analysis: An expanded sourcebook. Thousand Oaks, California: Sage Publications.

Morrell, P. D., Flick, L., \& Wainwright, C. (2004). Reform teaching strategies used by student teachers. School Science and Mathematics, 104(5), 199-213.

Morrison, J., \& Lederman, N. (2003). Science teachers' diagnosis and understanding of students' preconceptions. Science Education, 87(6), 849-867.

Mortimer, E., \& Scott, P. (2000). Analyzing discourse in the science classroom. In R. Millar, J. Leach \& J. Osborne (Eds.), Improving Science Education: The Contribution of Research. Philadelphia: Open University Press.

Munns, G., \& Woodward, H. (2006). Student engagement and student self-assessment: The REAL framework. Assessment in Education, 13(2), 193-213.

Natriello, G. (1987). The impact of evaluation processes on students. Educational Psychologist, 22(2), 155-175.

Neesom, A. (2000). Report on Teachers 'Perception of Formative Assessment. London: Qualifications and Curriculum Authority. Retrieved November 5, 2007, from http://www.qca.org.uk/qca 4357.aspx

Orlich, D. C., Harder, R. J., Callahan, R. C., Trevisan, M. S., \& Brown, A. H. (2007). Teaching strategies: A guide to effective instruction, $8^{\text {th }}$ ed. Boston: Houghton Mifflin Co.

Osborne, R., \& Freyberg, P. (1985). Learning in science. Birkenhead, Auckland: Heinemann Education.

Page, E. B. (1958). Teacher comments and student performance: A seventy-four classroom experiment in school motivation. Journal of Educational Psychology, $49,173-181$.

Paris, S. G., \& Paris, A. H. (2001). Classroom applications of research on self-regulated learning. Educational Psychologist, 36, 89-101. 
Pedder, J. (2006). Organizational conditions that foster successful classroom promotion of learning how to learn. Research Papers in Education, 21(2), 171-200.

Pedder, D., James, M., \& MacBeath, J. (2005). How teachers value and practice professional learning. Research Papers in Education, 20(3), 209-243.

Pellegrino, J. W. (2001). Rethinking and redesigning education assessment: Preschool through postsecondary. Retrieve October 28, 2007, from http://www.ecs.org

Pellegrino, J. W. (2002). Knowing what students know. Issues in Science and Technology, 19(2), 48-52.

Popham, W. J. (2009). A process-not a test. Educational Leadership, 66(7), 85-86.

Qualifications and Curriculum Authority. (2000). Teachers use assessment for learning to raise standards. Retrieved November 10, 2007, from the Institute of Education, University of London website http://www.qca.org.uk/qca 4357.aspx

Raider-Roth, M. B. (2005a). Trusting what you know: Negotiating the relational context of classroom life. Teachers College Record, 107(4), 587-628.

Raider-Roth, M. (2005b). Trusting what you know: The high stakes of classroom relationships. San Francisco: Jossey-Bass.

Ramaprasad, A. (1983). On the definition of feedback. Behavioral Science, 28, 4-13.

Reynolds, S., Martin, K., \& Groulx, J. (1995). Patterns of understanding. Educational Assessment, 3(4), 363-371.

Rowe, M. B. (1974). Wait time and rewards as instructional variables, their influence on language, logic and fate control. Journal of Research in Science Teaching, 11, 81-94.

Ruiz-Primo, M. A., \& Furtak, E. M. (2006). Informal formative assessment and scientific inquiry: Exploring teachers' practices and student learning. Educational Assessment, $11(3$ \& 4), 205-235.

Ruiz-Primo, M. A., Shavelson, R. J., Li, M., \& Schultz, S. E. (2001). On the validity of cognitive interpretations of scores from alternative concept-mapping techniques. Educational Assessment, 7(2), 99-141.

Ryan, R. M., \& Deci, E. L. (2000). Self-determination theory and the facilitation of intrinsic motivation, social development, and well-being. American Psychologist, 55(1), 68-78. 
Sadler, D.R. (1989). Formative assessment and the design of instructional system. Instructional Science, 18, 119-144.

Sadler, D. R., \& Good, E. (2006). The impact of self- and peer-grading on student learning. Educational Assessment, 11(1), 1-31.

Sato, M., \& Atkin, J. M. (2007). Supporting change in classroom assessment. Educational Leadership, 64(4), 76-79.

Shavelson, R. J., Ruiz-Primo, M. A., \& Wiley, E. W. (2005). Windows into the mind. Higher Education, 49, 413-430.

Shepard, L. A. (2000). The role of assessment in a learning culture. Educational Researcher, 29(7), 4-14.

Stiggins, R. J. (2002, June). Assessment crisis: The absence of assessment for learning. Phi Delta Kappan, 83, 758-765.

Stiggins, R.J., \& Chappius, S. (2005). Putting Testing in Perspective: It's for Learning. Principal Leadership, 6(2), p. 16-20.

Stiggins, R. J., \& Chappuis, J. (2006). What a difference a word makes. Journal of Staff Development, 27(1), 10-14.

Taras, M. (2003). To feedback or not to feedback in student self-assessment. Assessment \& Evaluation in Higher Education, 28(5), 549-565.

Tashakkori, A., \& Teddlie, C. (1998). Mixed methodology: Combining qualitative and quantitative approaches. Thousand Oaks: Sage.

Tharp, R. G., \& Gallimore, R. (1992). Rousing minds to life: Teaching, learning, and schooling in social context. New York: Cambridge University Press.

Torrance, H. (1993). Formative assessment: Some theoretical problems and empirical questions, Cambridge Journal of Education, 23, 333-343.

Tunstall, P., \& Gipps, C. (1996). Teacher feedback to young children in formative assessment: A typology. British Educational Research Journal, 22(4), 389-405.

van Kraayenoord, C. E., \& Paris, S. G. (1997). Australian students' self-appraisal of their work samples and academic progress. Elementary School Journal, 97(5), 523-537.

van Zee, E. H., Iwasyk, M., Krose, A., Simpson, D., \& Wild, J. (2001). Student and teacher questioning during conversations about science. Journal of Research in Science Teaching, 38(2), 159-190. 
Vygotsky, L. S. (1978). Mind in society. Cambridge, MA: Harvard University Press.

Wenglinsky, H., \& Silverstein, S. (2006). The science training teachers need. Educational Leadership, 64(4), 24-29.

White, B. Y., \& Frederiksen, J. R. (1998). Inquiry, modeling, and metacognition: Making science accessible to all students. Cognition and Instruction, 16, 3-118.

Wiggins, J. (1992). Creating tests worth taking. Educational Leadership, 50(8), 26-33.

Wiggins, G., \& McTighe, J. (1998). Understanding by design. Alexandria, Va.: Association for Supervision and Curriculum Development.

Wilen, W. (2004). Refuting misconceptions about classroom discussion. Social Studies, 95(1), 33-39.

Wiliam, D. (2006a). Assessment. Journal of Staff Development, 27(1), 16-20.

Wiliam, D. (2006b). Formative assessment: Getting the focus right. Educational Assessment, 11(3\&4), 283-289.

Winn, W., \& Snyder D. (1996). Cognitive perspectives in psychology. In D.H. Jonassen, (Ed.) Handbook of research for educational communications and technology, 112-142. New York: Simon \& Schuster Macmillan. 
Appendix A - Formative Assessment Questionnaire for Teachers

\section{Questionnaire for Teachers}

\section{Part One}

Please circle the letter and number that most closely matches your opinion of the following strategies:

\section{Involving students in their learning}

$$
\begin{aligned}
& \text { VALUE } \\
& \begin{array}{l}
\text { Please circle how } \\
\text { highly you value the } \\
\text { following: }
\end{array} \\
& A=\text { very valuable } \\
& B=\text { valuable } \\
& \text { C = no strong view } \\
& D=\text { of little value } \\
& \text { E }=\text { of no value }
\end{aligned}
$$

USE

Please circle how often you use the following:

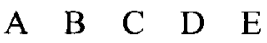
$\begin{array}{lllll}1 & 2 & 3 & 4 & 5\end{array}$ learn and (sometimes) why they are learning it

2. Inviting and building on students' contributions

3. Setting up tasks designed to enable students to work independently

4. Getting students to collaborate in groups on a joint assignment

5. Spurring students on by making encouraging but specific, focused comments

6. Getting one student to help another

\section{Modeling quality}

1. Choosing and showing students examples of other students' work for learning purposes

2. Getting a student to show you how s/he has attempted something so you can diagnose error

3. Getting a student to demonstrate to the class how $s /$ he did something

4. Getting a student to suggest ways something can be improved

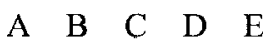
$\begin{array}{lllll}1 & 2 & 3 & 4 & 5\end{array}$

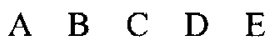
$\begin{array}{lllll}1 & 2 & 3 & 4 & 5\end{array}$

$\begin{array}{llllllllll}\mathrm{A} & \mathrm{B} & \mathrm{C} & \mathrm{D} & \mathrm{E} & 1 & 2 & 3 & 4 & 5\end{array}$

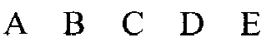
$\begin{array}{lllll}1 & 2 & 3 & 4 & 5\end{array}$ 
5. Providing formats and structures for writing or recording findings

6. Showing students a range of other students' work to make a judgment about performance

7. Showing students a range of other students' work to make a judgment about progress

8. Showing students a range of other students' work to model or exemplify criteria

\section{Giving feedback}

1. Using probing questions to diagnose the extent of the students' learning

2. Analyzing completed work to figure why a student has or has not achieved

3. Giving rewards only when achievement is satisfactory for that student with specific comments referring to student's success

4. Expressing approval when achievement is satisfactory

5. Making a conscious decision to avoid saying a student is wrong

6. Telling students what they have achieved with specific reference to their learning

7. Telling students what they have not achieved with specific reference to their learning

8. Describing why an answer is correct

9. Specifying a better/different way of doing something

10. Writing an evaluative note on student's work for the student
VALUE

$\mathrm{A}=$ very valuable

$\mathrm{B}=$ valuable

$\mathrm{C}=$ no strong view

$\mathrm{D}=$ of little value

$\mathrm{E}=$ of no value

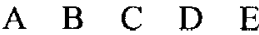

USE

$5=$ most lessons

$4=$ most days

$3=$ weekly

$2=$ quarterly

$1=$ never
A $\quad$ B $\quad$ C $\quad$ D $\quad$ E
$\begin{array}{lllll}1 & 2 & 3 & 4 & 5\end{array}$

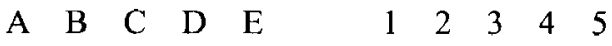

$\begin{array}{llllllllll}\text { A } & \text { B } & \text { C } & \text { D } & \text { E } & 1 & 2 & 3 & 4 & 5\end{array}$
A $\quad$ B $\quad$ C $\quad$ D $\quad$ E
$\begin{array}{lllll}1 & 2 & 3 & 4 & 5\end{array}$

$\begin{array}{llllllllll}\text { A } & \text { B } & \text { C } & \text { D } & \text { E } & 1 & 2 & 3 & 4 & 5\end{array}$
A $\quad$ B $\quad$ C $\quad$ D $\quad$ E
$\begin{array}{lllll}1 & 2 & 3 & 4 & 5\end{array}$

A $\quad$ B $\quad$ C $\quad$ D $\quad$ E

$\begin{array}{lllll}1 & 2 & 3 & 4 & 5\end{array}$

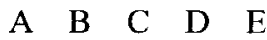
$\begin{array}{lllll}1 & 2 & 3 & 4 & 5\end{array}$

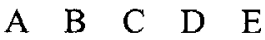

$\begin{array}{lllll}1 & 2 & 3 & 4 & 5\end{array}$

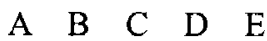
$\begin{array}{lllll}1 & 2 & 3 & 4 & 5\end{array}$

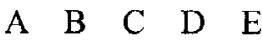
$\begin{array}{lllll}1 & 2 & 3 & 4 & 5\end{array}$

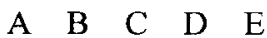
$\begin{array}{lllll}1 & 2 & 3 & 4 & 5\end{array}$ 
VALUE

$A=$ very valuable

$\mathrm{B}=$ valuable

$\mathrm{C}=$ no strong view

$\mathrm{D}=$ of little value

$\mathrm{E}=$ of no value
USE

$5=$ most lessons

$4=$ most days

3 = weekly

2 = quarterly

$1=$ never

\section{$\underline{\text { Self assessment }}$}

1. Getting students to suggest ways they can improve

2. Negotiating a way to improve some piece of work

3. Providing time for students to reflect and talk about their learning

4. Getting students to review their own work and record their progress

5. Helping students to understand their achievements and know what they need to do next to make progress

6. Providing opportunities for students to assess their own and one another's work and give feedback to one another

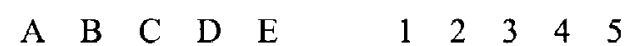

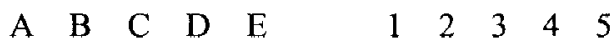

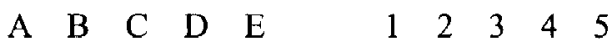

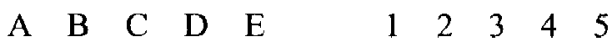

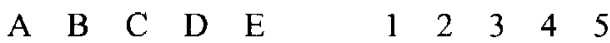

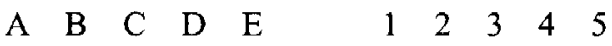

\section{Part Two}

Please complete these short-response statements.

1. I find formative assessment works well when:

2. Formative assessment hinders my work when:

3. I find it easiest to involve students in their learning when:

4. I find it easiest to model quality work for students when: 
5. I find it easiest to give students feedback when:

6. I find it easiest to give students opportunities to self-assess when:

It would be helpful to know the following information about you:

- I teach Grade:

$\mathrm{K}$ 2 3 45

- I have also taught Grades:

- I have been teaching for: years

- I have taught in this school district for: ___ years

- Do you generally teach science? Yes No

- Do you have a specialty area/certification? Performing Arts Special Education Gifted/Talented Reading Specialist

Health/PE__Counselor Other

- What kind(s) of professional development have you had about formative assessment?

Check any/all:

I I have attended a national/regional conference

I I have received training from district administrators or lead teachers

I have collaborated with other teachers about formative assessment

I have read articles about formative assessment

I I have taken college level courses where formative assessment was discussed

$\square$ Other, please describe below:

\section{PHASE II - INTERVIEW AND OBSERVATION}

Because this questionnaire is part of a larger study, I would like to know if you would be interested in continued participation. If you agree, you may be interviewed and observed while teaching a science lesson.

NAME

BEST TIME TO CONTACT

EMAIL ADDRESS

I will contact you about a convenient time to conduct the interview and observations. 


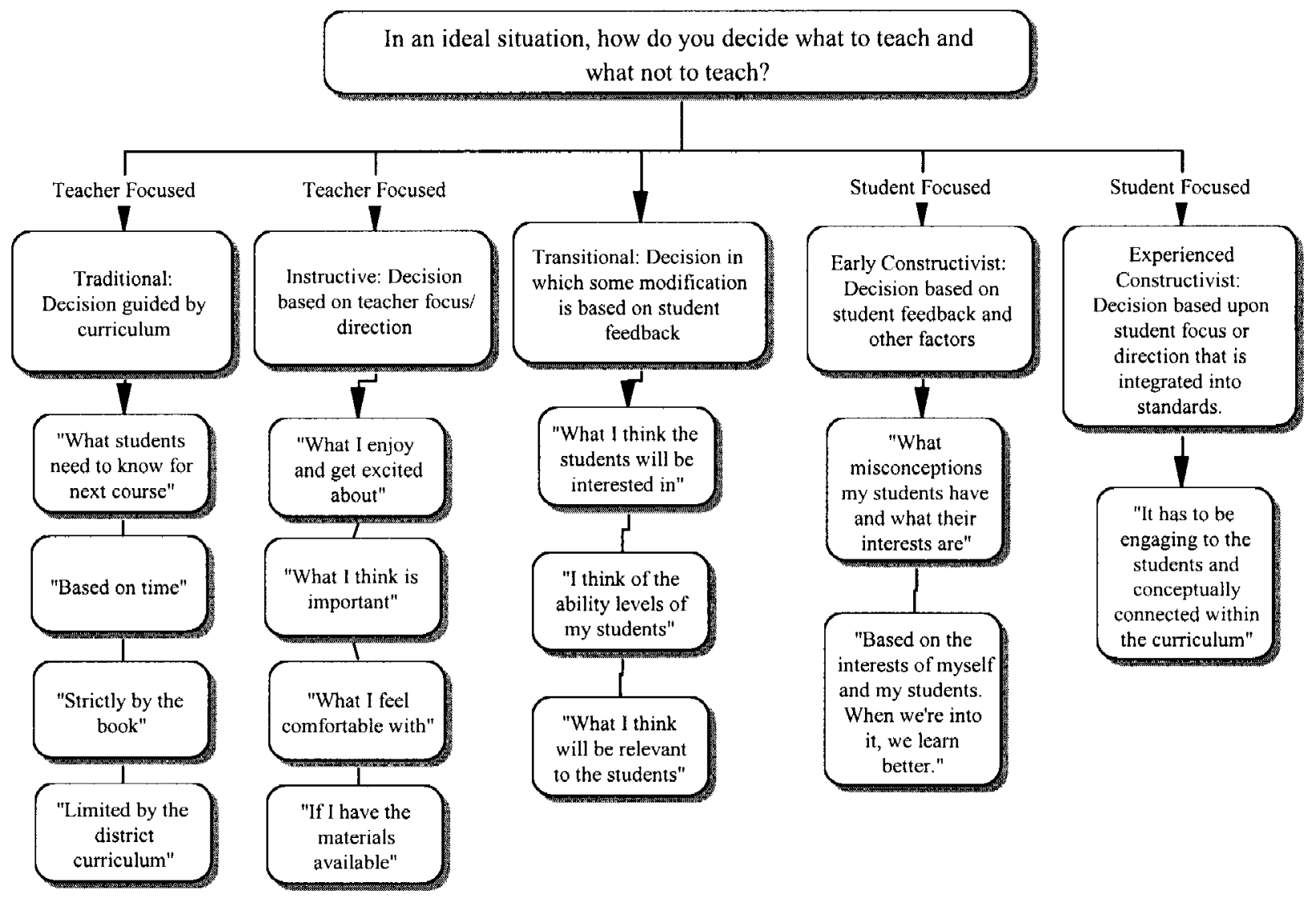

In an ideal situation, how do you decide what to teach and what not to teach?

I. Transitional: Decision in which some modification is based on student feedback

A. "What I think the students will be interested in"

1. "I think of the ability levels of my students"

a. "What I think will be relevant to the students"

II. Experienced Constructivist: Decision based upon student focus or direction that is integrated into standards.

A. "It has to be engaging to the students and conceptually connected within the curriculum"

III. Early Constructivist: Decision based on student feedback and other factors

A. "What misconceptions my students have and what their interests are"

1. "Based on the interests of myself and my students. When we're into it, we learn better.

IV. Traditional: Decision guided by curriculum

A. "What students need to know for next course"

1 . "Based on time"

V. Instructive: Decision based on teacher focus/direction

A. "What I enjoy and get excited about"

1 . "What I think is important"

a. "What I feel comfortable with"

(1) "If I have the materials available"

"Strictly by the book"

i. $\quad$ "Limited by the district curriculum" 


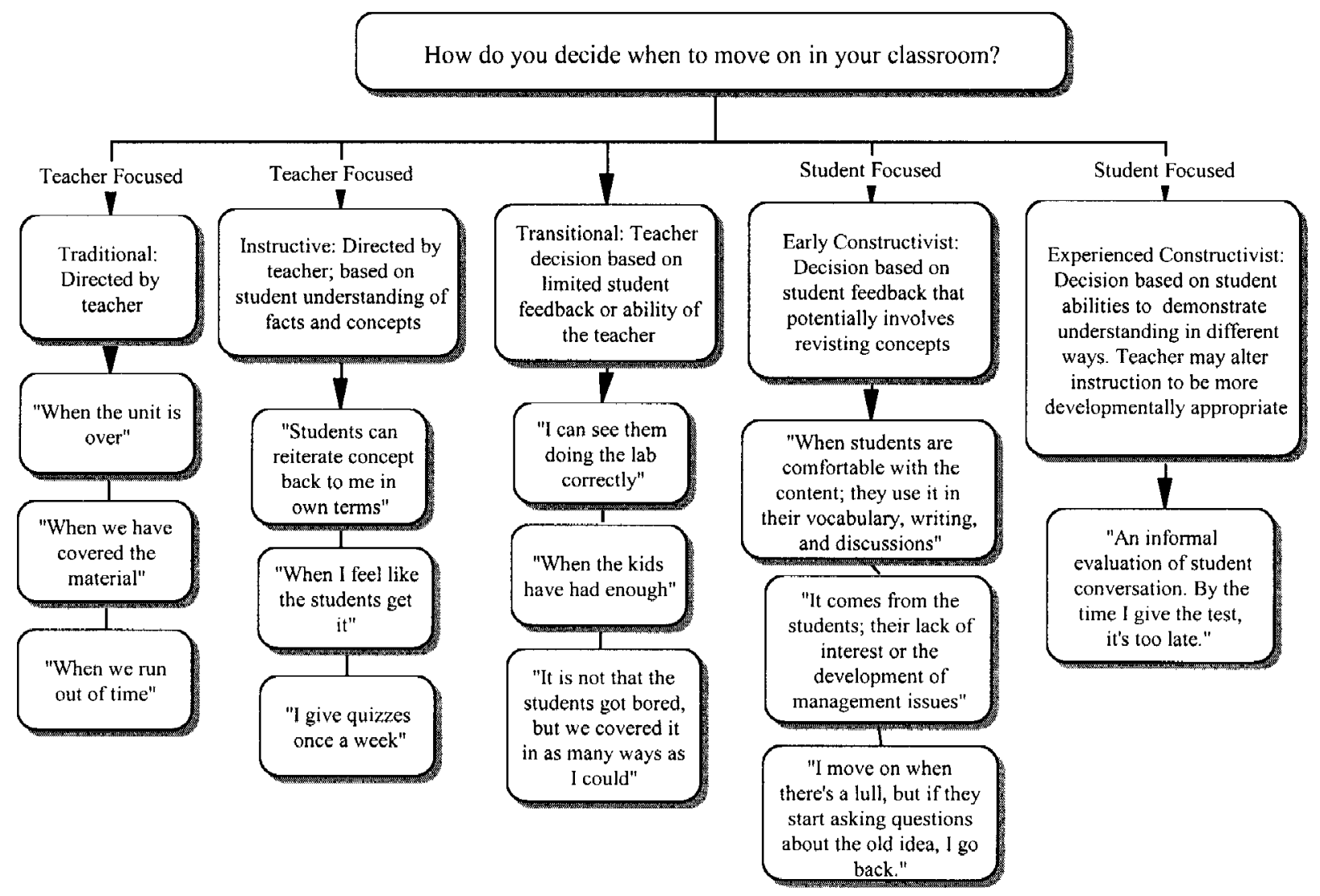

How do you decide when to move on in your classroom?

I. Traditional: Directed by teacher

A. "When the unit is over"

1. "When we have covered the material"

a. "When we run out of time"

II. Instructive: Directed by teacher; based on student understanding of facts and concepts

A. $\quad$ "Students can reiterate concept back to me in own terms"

1. "When I feel like the students get it"

a. "I give quizzes once a week"

III. Transitional: Teacher decision based on limited student feedback or ability of the teacher

A. $\quad$ "I can see them doing the lab correctly"

1. "When the kids have had enough"

a. $\quad$ "It is not that the students got bored, but we covered it in as many

ways as I could"

IV. Early Constructivist: Decision based on student feedback that potentially involves revisting concepts

A. "When students are comfortable with the content; they use it in their vocabulary, writing, and discussions"

1. "It comes from the students; their lack of interest or the development of management issues"

a. $\quad$ "I move on when there's a lull, but if they start asking questions about the old idea, I go back."

V. Experienced Constructivist: Decision based on student abilities to demonstrate understanding in different ways. Teacher may alter instruction to be more developmentally appropriate

A. "An informal evaluation of student conversation. By the time I give the test, it's too late." 


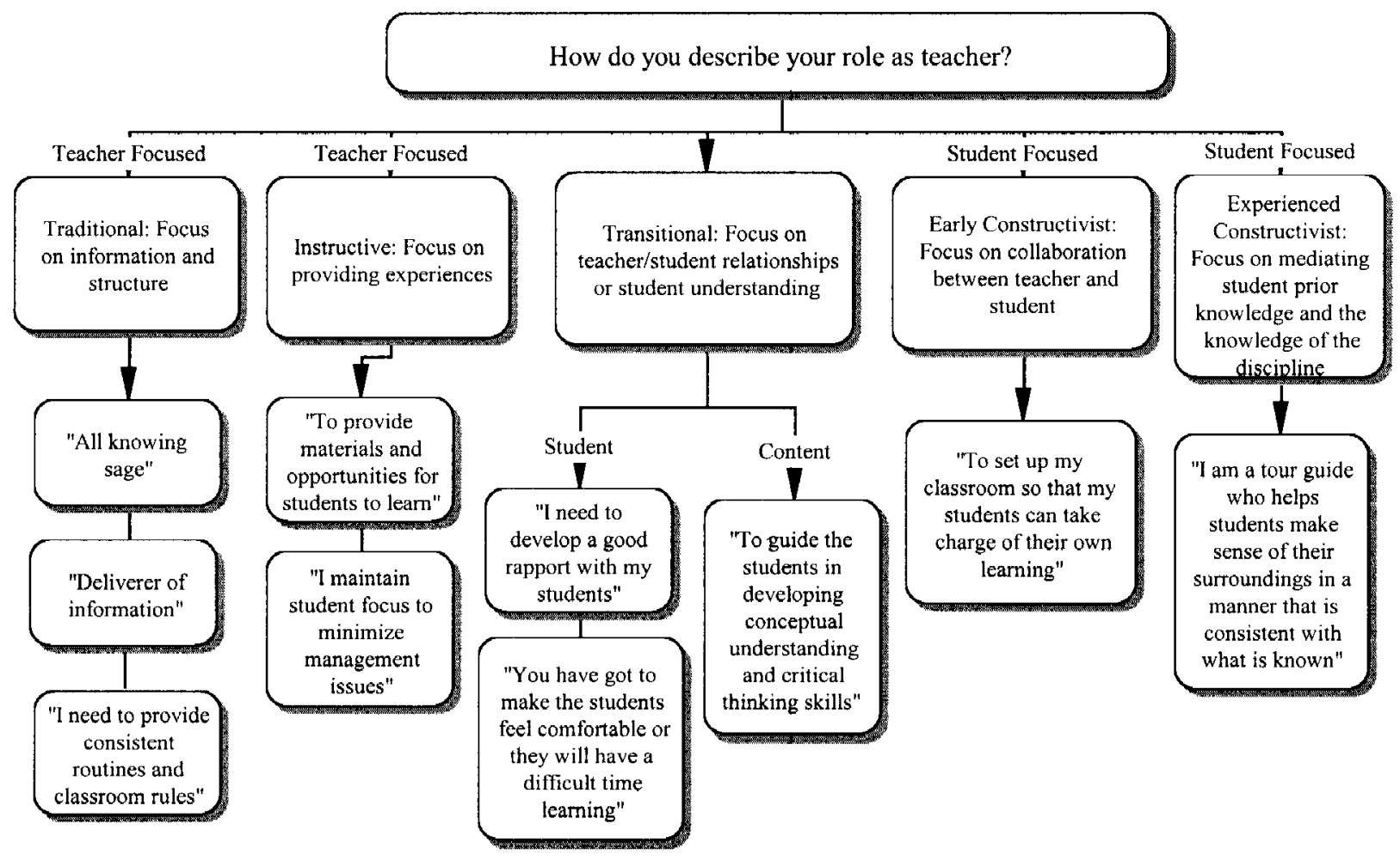

How do you describe your role as teacher?

I. Traditional: Focus on information and structure

A. "All knowing sage"

1. "Deliverer of information"

II. Instructive: Focus on providing experiences

A. "To provide materials and opportunities for students to learn"

1. "I maintain student focus to minimize management issues"

III. Transitional: Focus on teacher/student relationships or student understanding

A. $\quad$ "I need to develop a good rapport with my students"

1. "You have got to make the students feel comfortable or they will have a difficult time learning"

B. "To guide the students in developing conceptual understanding and critical thinking skills"

IV. Early Constructivist: Focus on collaboration between teacher and student

A. "To set up my classroom so that my students can take charge of their own learning"

V. Experienced Constructivist: Focus on mediating student prior knowledge and the knowledge of the discipline

A. II am a tour guide who helps students make sense of their surroundings in a manner that is consistent with what is known" 


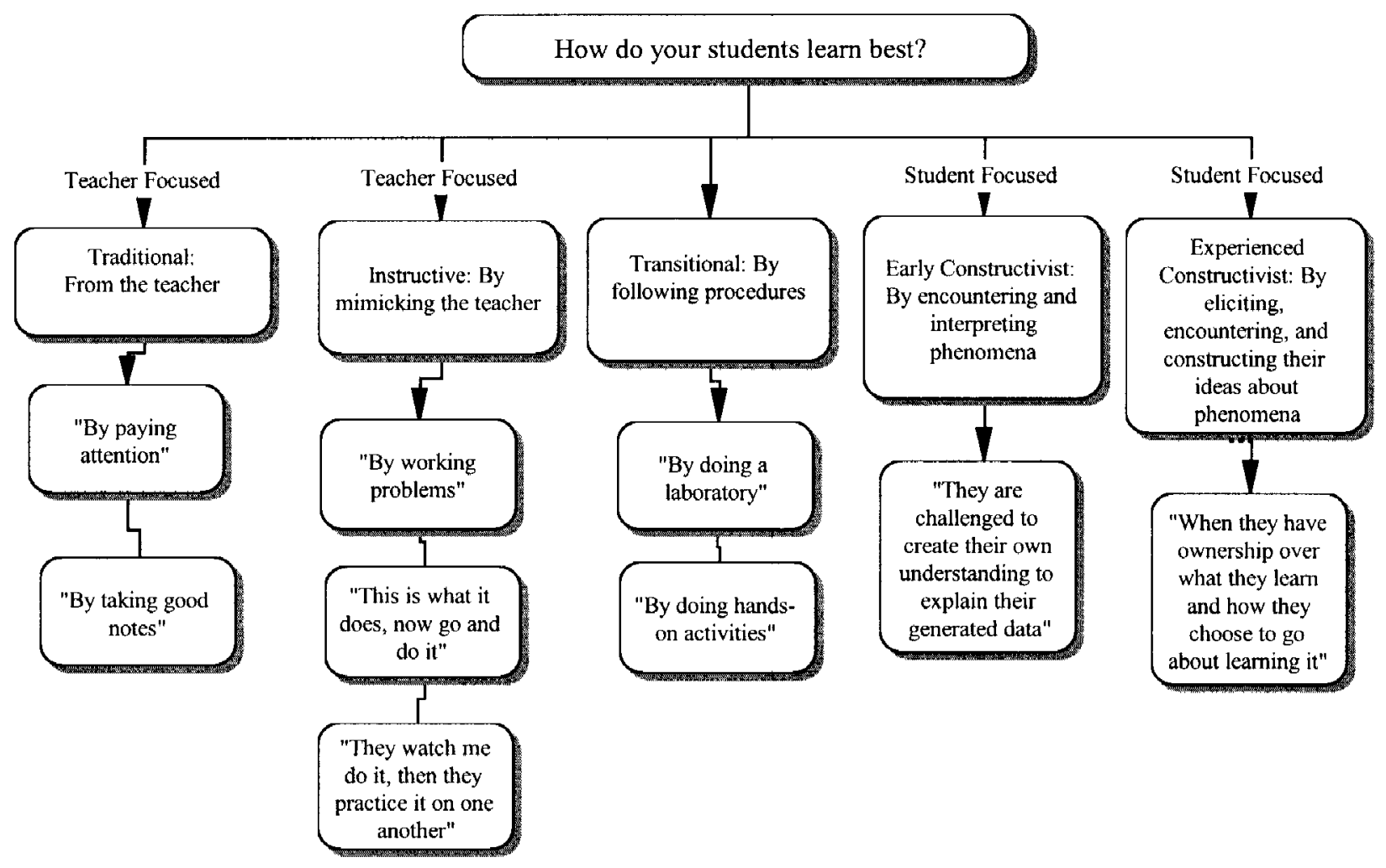

How do your students learn best?

I. Traditional: From the teacher

A. "By paying attention"

1. "By taking good notes"

II. Instructive: By mimicking the teacher

A. "By working problems"

1. "This is what it does, now go and do it"

a. $\quad$ "They watch me do it, then they practice it on one another"

III. Transitional: By following procedures

A. $\quad$ "By doing a laboratory"

1. "By doing hands-on activities"

IV. Early Constructivist: By encountering and interpreting phenomena

A. "They are challenged to create their own understanding to explain their generated data"

V. Experienced Constructivist: By eliciting, encountering, and constructing their ideas about phenomena

A. "When they have ownership over what they learn and how they choose to go about learning it" 


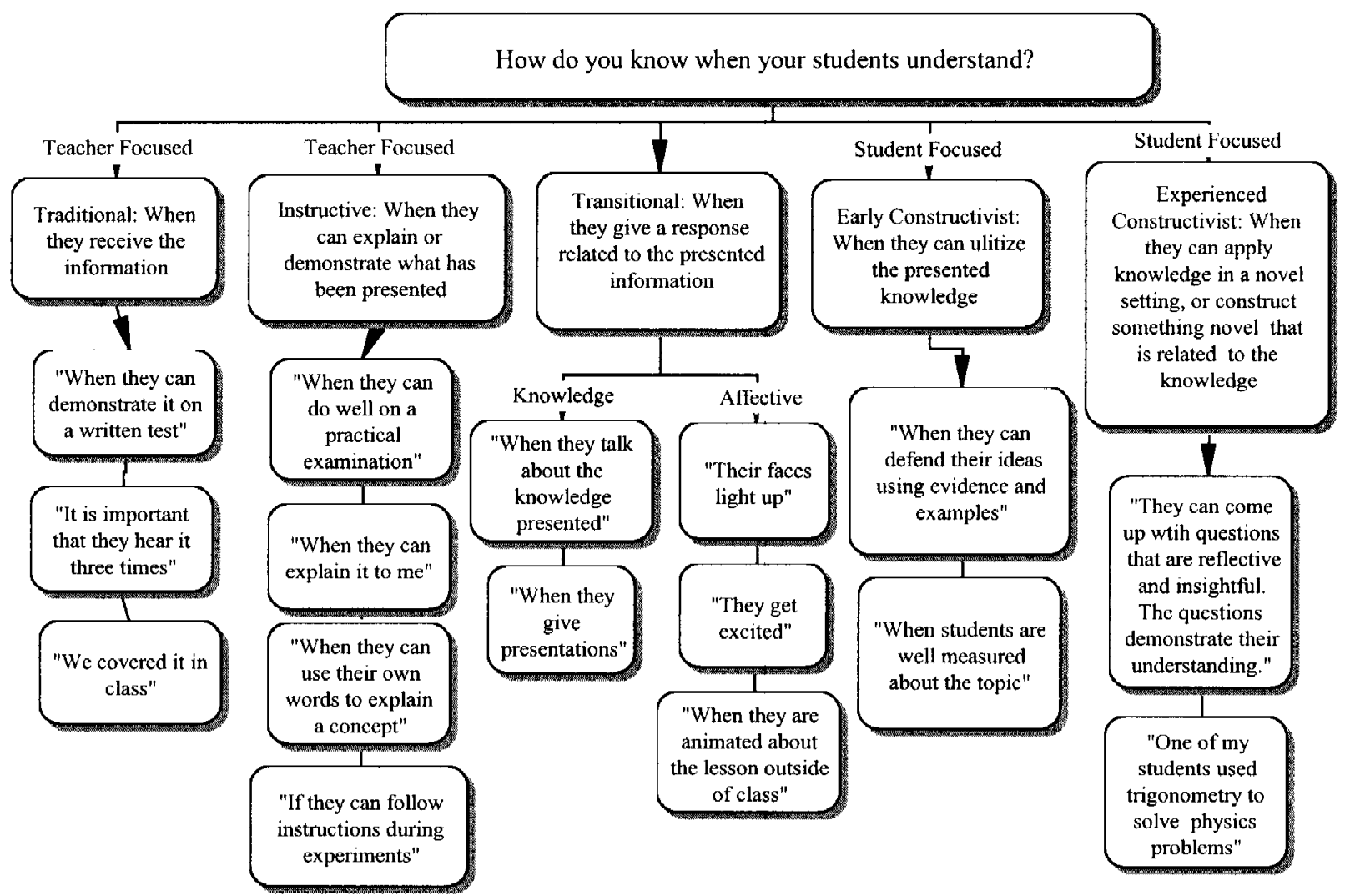

How do you know when your students understand?

I. Traditional: When they receive the information

A. "When they can demonstrate it on a written test"

1. "It is important that they hear it three times"

a. "We covered it in class"

II. Instructive: When they can explain or demonstrate what has been presented

A. "When they can do well on a practical examination"

1. "When they can explain it to me"

a. "When they can use their own words to explain a concept"

(1) "If they can follow instructions during experiments"

III. Transitional: When they give a response related to the presented information

A. "When they talk about the knowledge presented"

$1 . \quad$ "When they give presentations"

B. "Their faces light up"

1. "They get excited"

a. "When they are animated about the lesson outside of class"

IV. Early Constructivist: When they can ulitize the presented knowledge

A. "When they can defend their ideas using evidence and examples"

1. "When students are well measured about the topic"

V. Experienced Constructivist: When they can apply knowledge in a novel setting, or construct something novel that is related to the knowledge

A. "They can come up with questions that are reflective and insightful. The questions demonstrate their understanding."

1. "One of my students used trigonometry to solve physics problems" 


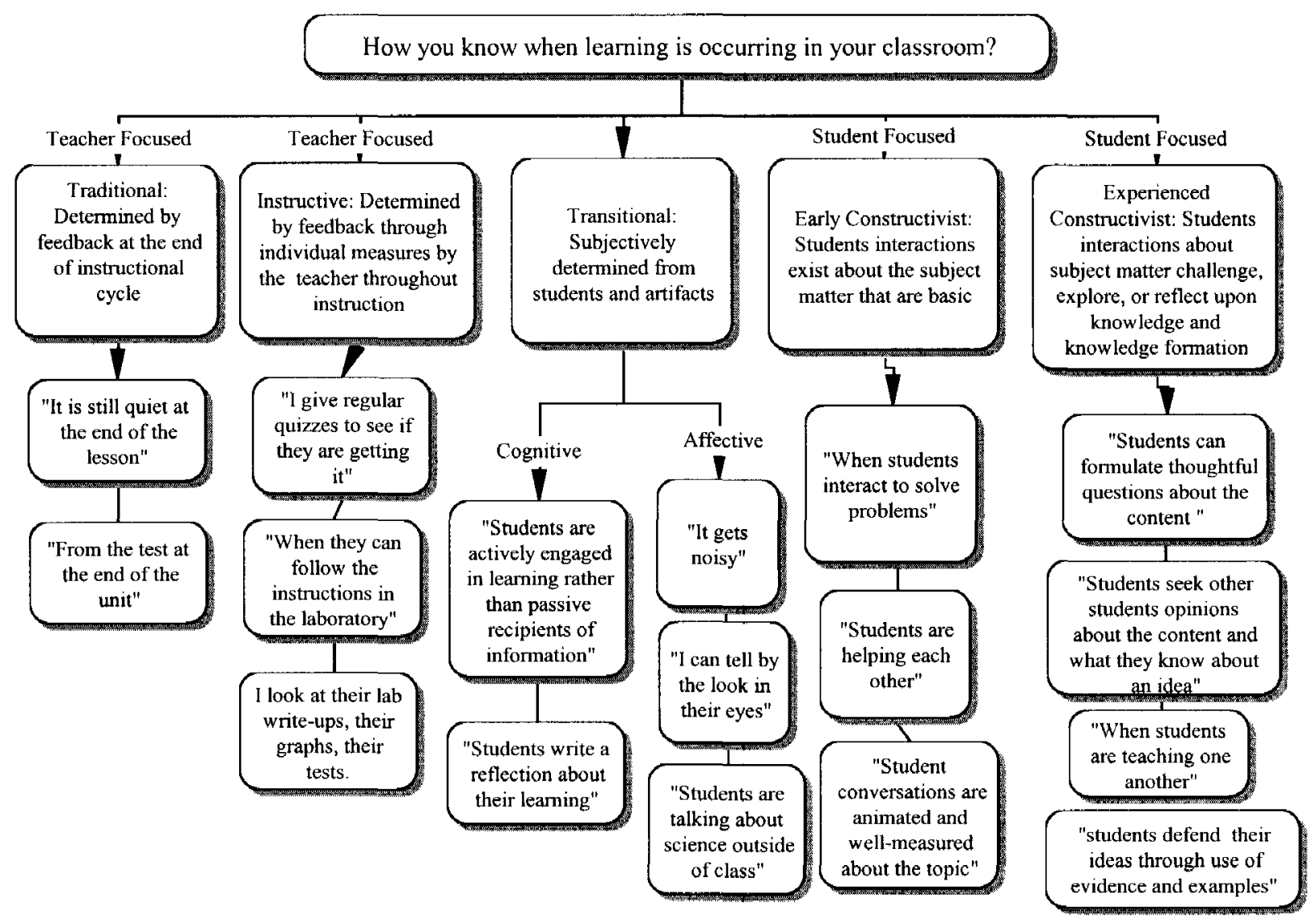

How you know when learning is occurring in your classroom?

I. Traditional: Determined by feedback at the end of instructional cycle

A. $\quad$ "It is still quiet at the end of the lesson"

1. "From the test at the end of the unit"

II. Instructive: Determined by feedback through individual measures by the teacher throughout instruction

A. $\quad$ "I give regular quizzes to see if they are getting it"

i. "When they can follow the instructions in the laboratory"

B. "I look at their lab write-ups, their graphs, their tests."

III. Transitional: Subjectively determined from students and artifacts

A. "It gets noisy"

1. "I can tell by the look in their eyes"

2. "Students are talking about science outside of class"

B. "Students are actively engaged in learning rather than passive recipients of information"

1. "Students write a reflection about their learning"

IV. Early Constructivist: Students interactions exist about the subject matter that are basic

A. "When students interact to solve problems"

i. $\quad$ "Students are helping each other"

ii. $\quad$ "Student conversations are animated and well-measured about the topic"

V. Experienced Constructivist: Students interactions about subject matter challenge, explore, or reflect upon knowledge and knowledge formation

A. 'Students seek other students' opinions about the content and what they know about an idea"

B. "Students can formulate thoughtful questions about the content"

C. "When students are teaching one another"

D. "Students defend their ideas through use of evidence and examples" 


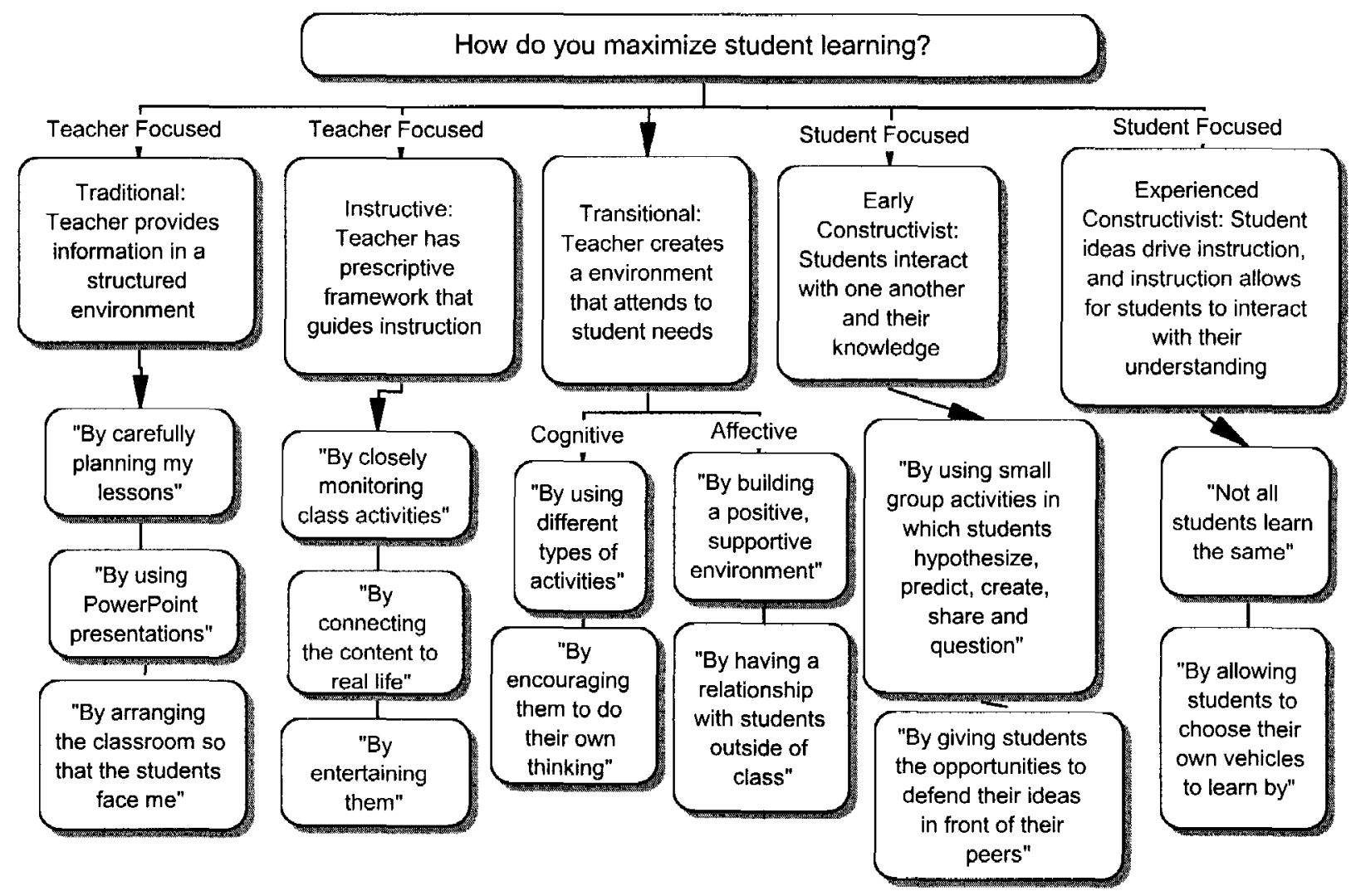

How do you maximize student learning?

I. Traditional: Teacher provides information in a structured environment

A. "By carefully planning my lessons"

1. "By using PowerPoint presentations"

a. $\quad$ "By arranging the classroom so that the students face me"

II. Instructive: Teacher has prescriptive framework that guides instruction

A. $\quad$ "By closely monitoring class activities"

1. "By connecting the content to real life"

a. "By entertaining them"

III. Transitional: Teacher creates a environment that attends to student needs

A. "By using different types of activities"

$1 . \quad$ "By encouraging them to do their own thinking"

B. $\quad$ "By building a positive, supportive environment"

1. "By having a relationship with students outside of class"

IV. Early Constructivist: Students interact with one another and their knowledge

A. "By using small group activities in which students hypothesize, predict, create, share and question"

1. $\quad$ "By giving students the opportunities to defend their ideas in front of their peers"

V. Experienced Constructivist: Student ideas drive instruction, and instruction allows for students to interact with their understanding

A. "Not all students learn the same"

1. "By allowing students to choose their own vehicles to learn by" 
Appendix C - Formative Assessment Observation Form

\section{FORMATIVE ASSESSMENT OBSERVATION FORM}

Teacher name:

Lesson focus:

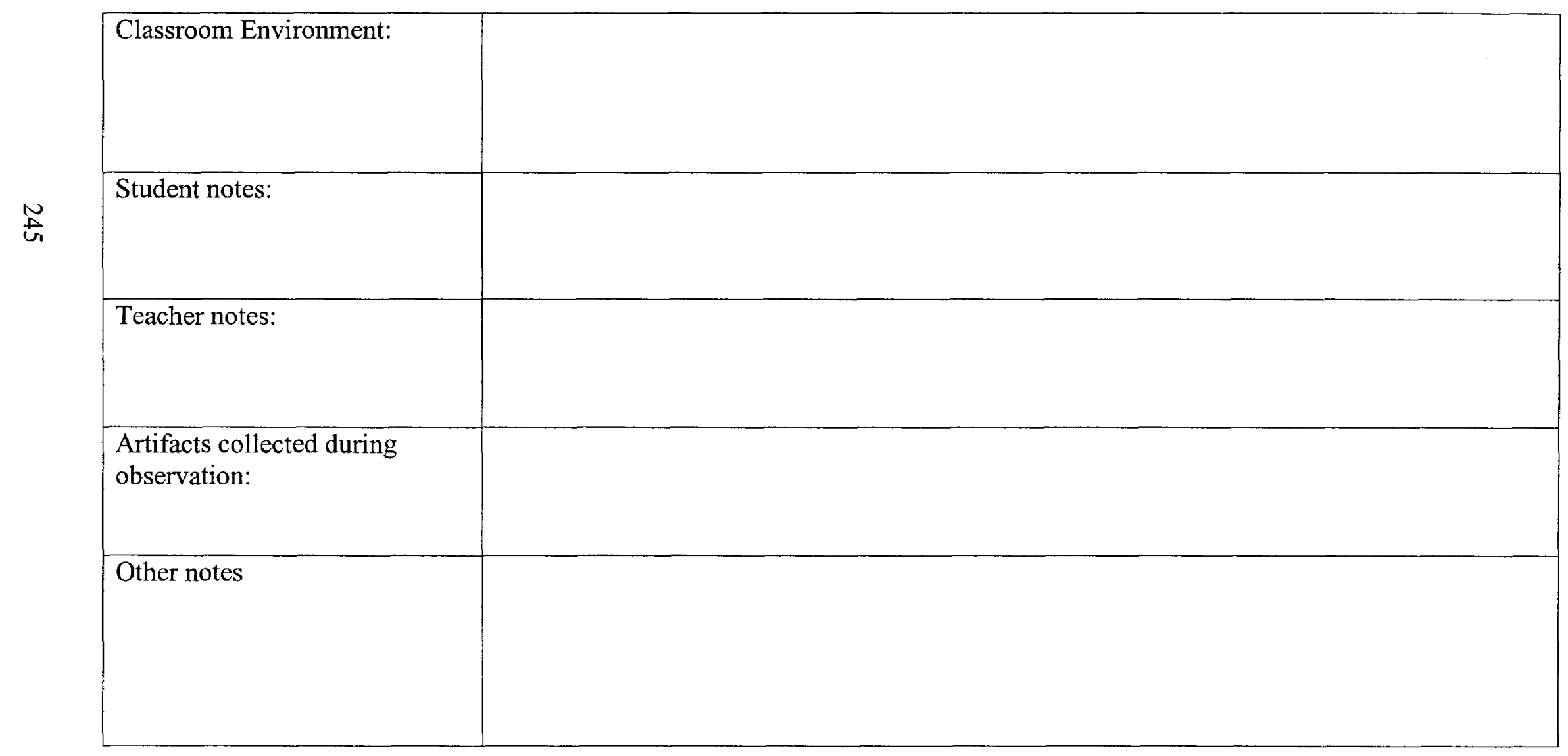

(Page 1)

Time: (beg.)

(end) Date:

School: 
SUMMARY NOTES FROM OBSERVATION

\begin{tabular}{|c|c|c|c|}
\hline Teacher Action: & How do I know? & Student Action: & How do I know? \\
\hline $\begin{array}{ll}\text { Clarifying learning intentions } \\
\text { - } & \text { State goals to students } \\
\text { - } & \text { Posted models or schema } \\
\text { - } & \text { What has been done } \\
\text { - } & \text { Where are we going } \\
\text { - } & \text { What is quality work } \\
\text { - } & \text { Student-friendly language } \\
\end{array}$ & & & \\
\hline $\begin{array}{ll}\text { Engineering discussion } \\
- & \text { Reflective questions } \\
- & \text { Stimulating questions } \\
- & \text { "Hot seat" questions } \\
- & \text { No-hands-up questions } \\
- & \text { Wait time } \\
- & \text { Uses probing questions } \\
\end{array}$ & & & \\
\hline $\begin{array}{ll}\text { Providing feedback } \\
-\quad \text { Quality of student work } \\
-\quad \text { Comments on how to improve } \\
-\quad \text { Addresses misconceptions } \\
-\quad \text { Engages students } \\
-\quad \text { Moves students forward } \\
-\quad \text { Causes thinking } \\
-\quad \text { Tell what have/haven't achieved } \\
-\quad \text { Specifying a better way } \\
\end{array}$ & & & \\
\hline $\begin{array}{ll}\text { Activate students as owners } \\
- & \text { Criteria in student language } \\
- & \text { Exemplars of work } \\
- & \text { Students ask questions } \\
- & \text { Establish lesson pacing } \\
- & \text { Provide feedback to teacher } \\
- & \text { Shared responsibility } \\
- & \text { Student suggests way to improve }\end{array}$ & & & \\
\hline $\begin{array}{ll}\text { Peer / Self-assessment } \\
- & \text { Remarks to others } \\
- & \text { Using grading criteria } \\
- & \text { Tools: red/green lights } \\
- & \text { Providing students time to reflect } \\
- & \text { Reflective responses } \\
- & \text { Student review own/other's work }\end{array}$ & & & \\
\hline
\end{tabular}


Appendix D - Formative Assessment Strategy Use by Case Study for All Observations

\begin{tabular}{|c|c|c|c|c|c|}
\hline & & \multicolumn{4}{|c|}{ FA Strategy - Number of Uses } \\
\hline $\begin{array}{l}\text { Non- } \\
\text { Negotiables }\end{array}$ & $\begin{array}{l}\text { Formative Assessment } \\
\text { Strategy }\end{array}$ & Virginia & Leigh & Tina & Jordan \\
\hline $\begin{array}{l}\text { Clarify } \\
\text { learning } \\
\text { intentions }\end{array}$ & $\begin{array}{l}\text { 1. Stated goals } \\
\text { 2. Posted models or schema } \\
\text { 3. What has been done } \\
\text { 4. Where we're going } \\
\text { 5. What is quality work } \\
\text { 6. Student friendly language }\end{array}$ & $\begin{array}{l}1-4 \\
2-6 \\
3-6 \\
4-5 \\
5-1\end{array}$ & $\begin{array}{l}1-3 \\
2-3 \\
3-4 \\
4-3\end{array}$ & $\begin{array}{l}1-4 \\
3-1\end{array}$ & $\begin{array}{l}1-4 \\
3-1 \\
4-2 \\
6-1\end{array}$ \\
\hline $\begin{array}{l}\text { Engineering } \\
\text { discussion }\end{array}$ & \begin{tabular}{ll}
\multicolumn{2}{l}{ Questions: } \\
1. Reflective \\
2. Stimulating \\
3. Hot seat \\
4. No hands up \\
5. Probing \\
\end{tabular} & $\begin{array}{l}1-15 \\
2-7 \\
3-1 \\
4-2 \\
5-1 \\
\end{array}$ & $\begin{array}{l}1-9 \\
2-1 \\
3-2 \\
5-3\end{array}$ & $\begin{array}{l}1-4 \\
2-1\end{array}$ & $1-6$ \\
\hline $\begin{array}{l}\text { Providing } \\
\text { feedback }\end{array}$ & $\begin{array}{ll}\text { 1. } & \text { Quality work } \\
\text { 2. Comments how to } \\
\text { improve } \\
\text { 3. Address misconceptions } \\
\text { 4. Engage students } \\
\text { 5. Cause thinking } \\
\text { 6. Tell what has / hasn't been } \\
\text { done } \\
\text { 7. Specify a better way } \\
\text { 8. Move students forward }\end{array}$ & $\begin{array}{l}1-4 \\
2-5 \\
3-4 \\
4-2 \\
5-2 \\
6-1 \\
7-3\end{array}$ & $\begin{array}{l}1-3 \\
2-1 \\
3-2 \\
4-3 \\
5-2 \\
\\
8-2\end{array}$ & $\begin{array}{l}1-1 \\
2-1 \\
3-2 \\
4-1 \\
5-2\end{array}$ & $1-1$ \\
\hline $\begin{array}{l}\text { Activating } \\
\text { students as } \\
\text { owners }\end{array}$ & 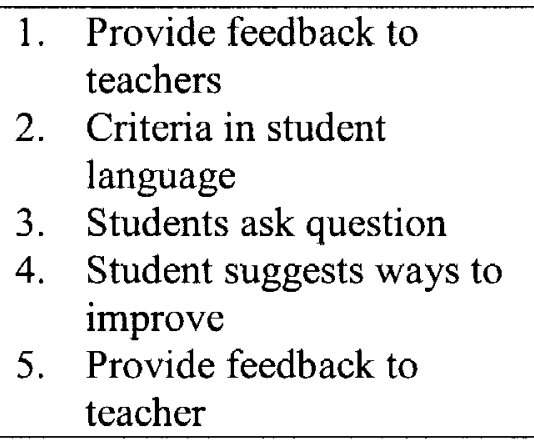 & $\begin{array}{l}1-12 \\
2-1 \\
3-1 \\
4-1\end{array}$ & $\begin{array}{l}2-1 \\
3-5 \\
5-4\end{array}$ & $2-1$ & $\begin{array}{l}1-2 \\
2-1 \\
3-1\end{array}$ \\
\hline $\begin{array}{l}\text { Peer and } \\
\text { Self- } \\
\text { assessment }\end{array}$ & $\begin{array}{ll}\text { 1. } & \text { Remark to other } \\
\text { 2. } & \text { Students reflect } \\
\text { 3. } & \text { Reflective responses } \\
\text { 4. } & \text { Students review own } \\
& \text { work }\end{array}$ & $\begin{array}{l}1-7 \\
2-2 \\
3-1 \\
4-4\end{array}$ & $\begin{array}{l}1-1 \\
3-2\end{array}$ & $\begin{array}{l}1-4 \\
3-1\end{array}$ & $2-1$ \\
\hline
\end{tabular}


Appendix E - A Reformatted Formative Assessment Questionnaire

FORMATIVE ASSESSMENT QUESTIONNAIRE FOR TEACHERS

Directions for teachers: Read the qualities of the four areas listed in the left column. Then complete the sentences for each as indicated.

\section{Involving students in their learning} entails the following:

1. Telling students what you hope they will learn and (sometimes) why they are learning it

2. Inviting and building on students' contributions

3. Setting up tasks designed to enable students to work independently

4. Getting students to collaborate in groups on a joint assignment

5. Spurring students on by making encouraging but specific, focused comments

6. Getting one student to help another

\section{Modeling quality work to students} includes the following:

1. Choosing and showing students examples of other students' work for learning purposes

2. Getting a student to show you how $\mathrm{s} /$ he has attempted something so you can diagnose error

3. Getting a student to demonstrate to the class how s/he did something

4. Getting a student to suggest ways something can be improved

5. Providing formats and structures for writing or recording findings

6. Showing students a range of other students' work to make a judgment about performance

7. Showing students a range of other students' work to make a judgment about progress

8. Showing students a range of other students' work to model criteria
I find it easiest to involve students in their learning when ...

I find it easiest to model quality work for students when ... 
Giving feedback to student includes the following strategies:

1. Using probing questions to diagnose the extent of the students' learning

2. Analyzing completed work to figure why a student has or has not achieved

3. Giving rewards only when achievement is satisfactory for that student with specific comments referring to student's success

4. Expressing approval when achievement is satisfactory

5. Making a conscious decision to avoid saying a student is wrong

6. Telling students what they have achieved with specific reference to their learning

7. Telling students what they have not achieved with specific reference to their learning

8. Describing why an answer is correct

9. Specifying a better / different way of doing something

10. Writing an evaluative note on student's work for the student

\section{Student peer and self-assessment} occurs when:

1. Getting students to suggest ways they can improve

2. Negotiating a way to improve some piece of work

3. Providing time for students to reflect and talk about their learning

4. Getting students to review their own work and record their progress

5. Helping students to understand their achievements and know what they need to do next to make progress

6. Providing opportunities for students to assess their own and one another's work and give feedback to one another
I find it easiest to give feedback to students when ...

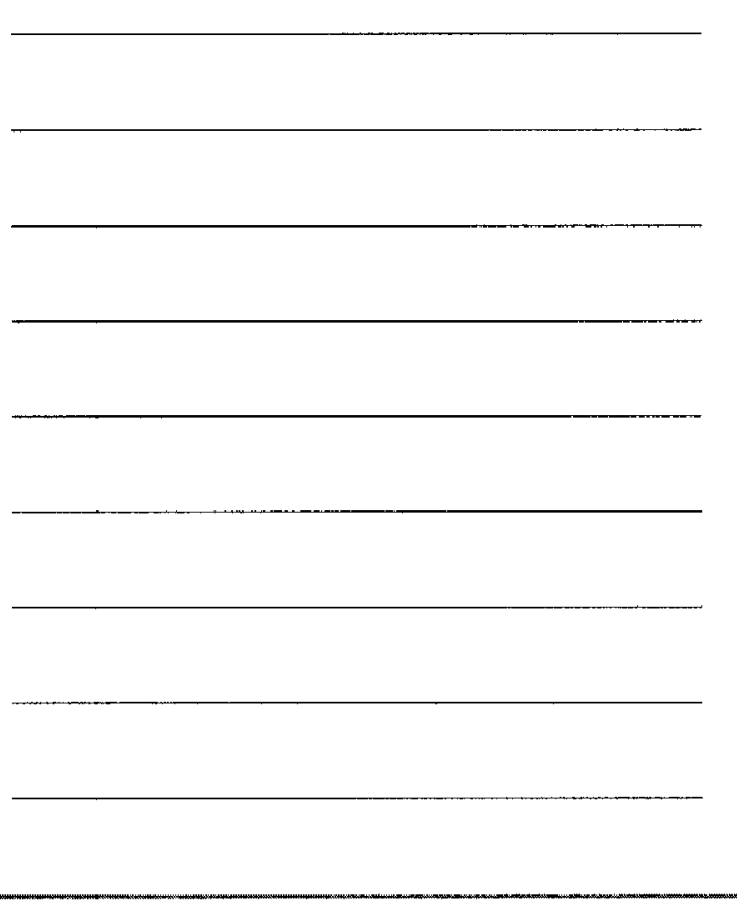

I find it easiest to allow students to selfassess when ... 
Overall, I find formative assessment works well when:

Formative assessment can hinder my work when:

It would be helpful to know the following information about you:
- I teach Grade: $\mathrm{K}$ 1 3 ${ }^{5}$

- I have also taught Grades:

- I have been teaching for: years

- I have taught in this school district for: years

- Do you generally teach science? Yes No

- Do you have a specialty area/certification? _._. Performing Arts Counselor Special Education Gifted/Talented Reading Specialist Other

- What kind of professional development have you had about formative assessment? Check any/all:

$\square$ I have attended a national/regional conference

I have received training from district administrators or lead teachers

I have collaborated with other teachers about formative assessment

$\square$ I have read articles about formative assessment

I have taken college level courses where formative assessment was discussed

$\square$ Other, please describe:

Thank you for completing this questionnaire and providing information about your instruction.

Note. This format takes advantage of the "definitions" contained within the four sub-constructs of Formative Assessment and allows the teacher respondent to use this information to express knowledge, implementation strategies and dispositions in creating a Teacher Profile. This format also provides extensive qualitative data for further analysis by the implementor. 


\section{Pamela M. Jett}

\section{CURRICULUM VITA}

119 N. Galt Avenue

Louisville, KY 40206

502-897-3350 (h), 502-609-6798 (c)

Email:pmjett01@louisville.edu

\section{ACADEMIC BACKGROUND}

Doctoral Candidate

Education Specialist

Master of Science

Bachelor of Arts
University of Louisville, Ph.D. Program Department of Teaching and Learning Dissertation Focus: Formative assessment practices Co-chairs: Dr. Thomas Tretter, Dr. Sherri Brown Anticipated completion: May 2009

University of Louisville, 2001

Major: Education Administration

Certifications:

Principalship, K-12, University of Louisville, 1996 Supervision of Instruction, University of Louisville, 1992

Spalding University, Louisville, Kentucky, 1988

Major: Secondary Education

Spalding University, Louisville, Kentucky, 1973

Major: Biology, Secondary Education

Minor: Art

\section{PROFESSIONAL EXPERIENCE}

Oldham County Schools

2004-Present Assistant Principal, North Oldham High School Director of Guidance, North Oldham High School

$2002-2004$ Campus Assistant Principal, North Oldham Campus Schools

1996 - 2002 Assistant Principal, North Oldham Middle School

1986 - 1996 Science Teacher, South Oldham Middle School 
Private School Experience

1982 - 1984 Science Teacher, Caravel Academy, Bear, Delaware

New Castle School District

1975 - 1982 Life, Earth Science Teacher, New Castle Middle, Delaware

Jefferson County Schools

1973 - $1974 \quad$ Life Science Teacher, T.T. Knight Middle, Louisville, Ky

\section{UNIVERSITY TEACHING}

General Methods, University of Louisville, Summer 2006 - Present

This course encourages teachers to challenge and support all students. This course will familiarize students with a variety of curricular and instructional strategies to meet the needs of a diverse group of students. It will also familiarize students with content enhancement strategies, models of teaching, Multiple Intelligences, learning styles, approaches to classroom management, lesson planning, and assessment and serve as a foundation for the content-specific methods courses.

- Initially taught this course to satisfy the internship component for the Professional Subspecialty for my Ph.D. Program

Orientation and Readings, University of Louisville, Summer 2008

This course is the beginning area of study for M.Ed./Rank 1 programs in P-12 Education. It is designed to provide opportunities for students to analyze, synthesize, evaluate, and articulate issues related to their subject-specific discipline as well as important topics in education that span disciplines and grade levels. Students examine current literature that address the key Program Concepts, analyze and evaluate those readings in light of issues specific to their teaching, consider their own instructional transformations, and develop a proposal for a study focused on an issue in their own classroom or school

- Invited by Dr. Diane Kyle to teach this course. Dr. Kyle has served as my Ph.D. Program Chair, and as a Dissertation Committee Member.

\section{PUBLICATIONS \& OTHER MEDIA}

Johnson, H. A. \& Jett, P. (1993). Making the connection. Science Scope (16) 6, 4-6.

"Inside Kentucky Schools" - Spokesperson for a feature story about North Oldham Middle School produced by Kentucky Department of Education, January 2003.

Featured in an article about health education in The Courier-Journal, April 1998.

Featured in an educational series in The Courier-Journal, April 1996.

"Making Science the Heart of the Middle School Curriculum," published by Scholastic Middle Years, January 1995. Article featuring the Hum-Bio curriculum as implemented by our middle school team. 


\section{SELECTED PROFESSIONAL WORK}

2004-2006 Statewide Committee Member to Redesign Mathematics Curriculum sponsored by the Kentucky Department of Education.

2001-2003 Principal Mentor for Middle School Initiatives' Mentor Network Program, Sponsored by the Kentucky Department of Education Administrator for a $\$ 10,000$ grant from Kentucky Department of Education to help underachieving middle schools raise test scores by directly working with school principals.

1991-1995 Selected by Stanford University to pilot the Human Biology Middle School Curriculum with 13 teams of middle school teachers from across the country.

Designed curriculum, instruction and assessment strategies for middle schools to develop a multi-disciplinary approach to teaching thematic science units.

1991 - 1993 Writer/Researcher, Curriculum Framework - Science Curriculum Committee for Kentucky Education Reform Act Transformations Manual

1990 - 1993 Board of Directors, Kentucky Science Teachers Association

\section{HONORS}

Acceptance into the Future Faculty Program, University of Louisville, 2006 State Finalist, Presidential Awards for Excellence in Science and Mathematics Teaching, awarded specifically for science teaching, 1995

Stanford University's Human Biology Middle School Curriculum Developer, 1991-95

Science Teacher of the Year Award, Oldham County Schools, Kentucky, 1989

\section{SERVICE OPPORTUNITIES}

\section{University Level:}

Invited Participant (Dr. Karen Karp), NCATE Part-time Faculty Interview Team, 2008 Invited Participant (Dr. Sam Stringfield), New Doctoral Student Orientation, 2008 Invited Speaker (Dr. Sam Stringfield), EDAP 795 Doctoral Seminar students, 2008 Mentor for two Part-time Instructors of the General Methods course, 2007-present

\section{Professional Level:}

Coordinator, SACS Accreditation for North Oldham High School, 2006

Coordinator, SACS Accreditation for North Oldham Middle School, 2004 


\section{Community Level:}

Board of Directors for the Crescent Hill Community Council, 1992 - 2004

Editor of community newsletter "Crescent Hill Newsletter", 1992 - 2004

Good Neighbor Award presented by the Frankfort Avenue Business Association, 2001

"Woman of Distinction" Awarded by Metro Councilwoman Tina Ward-Pugh, 2001

\section{PROFESSIONAL ASSOCIATION MEMBERSHIP}

Kappa Delta Pi, International Honor Society in Education

Association for Supervision and Curriculum

National Science Teacher Association

National Middle School Association

Member, Board of Directors of the Kentucky Science Teacher Association

Member, Regional Science Think Tank to improve science instruction and assessment sponsored by the University of Louisville 